\title{
Cellular Model Simulations of Solidification Structures in Ternary Alloys
}

by

\section{Ghazi H. Alsoruji}

\begin{abstract}
A thesis submitted to the Faculty of Graduate and Postdoctoral Affairs in partial fulfillment of the requirements for the degree of Master of Applied Science
\end{abstract}

In

Mechanical and Aerospace Engineering

Carleton University

Ottawa, Ontario

(C) 2013, Ghazi H. Alsoruji 
Library and Archives

Canada

Published Heritage

Branch

395 Wellington Street

Ottawa ON K1A ON4

Canada
Bibliothèque et

Archives Canada

Direction du

Patrimoine de l'édition

395 , rue Wellington

Ottawa ON K1A ON4

Canada
Your file Votre référence

ISBN: 978-0-494-94661-9

Our file Notre référence

ISBN: 978-0-494-94661-9
NOTICE:

The author has granted a nonexclusive license allowing Library and Archives Canada to reproduce, publish, archive, preserve, conserve, communicate to the public by telecommunication or on the Internet, loan, distrbute and sell theses worldwide, for commercial or noncommercial purposes, in microform, paper, electronic and/or any other formats.

The author retains copyright ownership and moral rights in this thesis. Neither the thesis nor substantial extracts from it may be printed or otherwise reproduced without the author's permission.
AVIS:

L'auteur a accordé une licence non exclusive permettant à la Bibliothèque et Archives Canada de reproduire, publier, archiver, sauvegarder, conserver, transmettre au public par télécommunication ou par l'Internet, prêter, distribuer et vendre des thèses partout dans le monde, à des fins commerciales ou autres, sur support microforme, papier, électronique et/ou autres formats.

L'auteur conserve la propriété du droit d'auteur et des droits moraux qui protege cette thèse. $\mathrm{Ni}$ la thèse ni des extraits substantiels de celle-ci ne doivent être imprimés ou autrement reproduits sans son autorisation.
In compliance with the Canadian Privacy Act some supporting forms may have been removed from this thesis.

While these forms may be included in the document page count, their removal does not represent any loss of content from the thesis.
Conformément à la loi canadienne sur la protection de la vie privée, quelques formulaires secondaires ont été enlevés de cette thèse.

Bien que ces formulaires aient inclus dans la pagination, il n'y aura aucun contenu manquant. 


\section{Abstract}

Solidification processes are an important part of many modern manufacturing processes. They can be found in different casting and welding processes. The solidification structure is very important for the quality of any product manufactured by such processes. This is so because the casting or weldment microstructure determines their mechanical properties. For welding processes, solidification theories can explain the evolution of the fusion zone microstructure and how this microstructure is influenced by the solidification parameters such as the temperature gradient and the solidification rate. In order to investigate the solidification parameters' effect on the microstructure, a numerical model based on Cellular Automaton combined with the finite difference method (CA-FD) is presented in this thesis. The simulation is conducted on a finite three dimensional control volume of the fusion zone. The model takes into account the solute-, curvature-, and kinetic undercooling. The temperatures are assumed to be distributed linearly within the control volume. The model predicts the morphology and density of the microstructure according to different values of the cooling rate and initial temperatures. It is demonstrated that the solidification structure has a columnar morphology at high temperature gradients and low cooling rates. The morphology changes to dendritic as the temperature gradient decreases and/or the cooling rate increases. It is also shown that an increase in the cooling rate results in the densification of the solidification structure. The results demonstrate that an increase in the initial substrate roughness can result in the increase in the density of the solidification structure. The simulation results show an agreement with the constitutional undercooling theory of solidification structures. 


\section{Acknowledgements}

I would like to thank Dr. Andrei Artemev for his support and help. I would like to thank Dr. Marcias Martinez who explains the original code which is used as starting point for this study. I am very grateful for the guidance that I have received from the facility of Engineering. At the same time I would like to thank Dr. John Goldak and his team for their advices. Finally, my great thanks go to my wife who supported and stood by me during my studies. 


\section{Preface}

The purpose of this thesis is to develop a numerical model that predicts the microstructure morphology and density of solidification during the directional growth of a solid phase. The model represents a further development of a previous model which was developed to simulate the casting process microstructure. In order to perform a parametric study, the temperature gradient, cooling rate and initial temperatures are used as input parameters. 


\section{Table of Contents}

$\begin{array}{lr}\text { Abstract } & \text { iii } \\ \text { Acknowledgments } & \text { iv } \\ \text { Preface } & \text { v } \\ \text { Table of Contents } & \text { vi } \\ \text { List of Figures } & \text { ix } \\ \text { Nomenclature } & \text { xii }\end{array}$

Chapter 1: Introduction 1

1.1 The Importance of Solidification Structures

1.2 Solidification in the Welding Processes

1.3 The Objective of this Study 3

1.4 The Outline 4

Chapter 2: Overview of Welding Process 5

2.1 Joining Processes

2.2 Welding Processes 7

2.3 Fusion Welding Processes 7

2.4 Arc Welding Processes 9

2.4.1 Parameters of Arc Welding Processes 11

2.5 Energy for Welding $\quad 12$

2.5.1 Heat Input and Energy Density 13 
2.5.2 Heat Flow in Welds

2.6 Welding Metallurgy

2.6.1 Heat-Affected Zone (HAZ)

2.6.2 Partially Melted Zone (PMZ)

2.6.3 Fusion Zone (FZ)

2.7 Welding Solidification

2.7.1 Nucleation Process

2.7.2 Undercooling

2.7.3 Constitutional Undercooling

2.7.4 Solidification Mode

2.7.5 The Effect of Cooling Rate on Microstructure

2.7.6 The Dendrite Growth Mechanism

2.7.7 Composition Variation- Segregation

2.7.8 Solute Redistribution

2.7.8.1 Complete Diffusion in Solid and Liquid

2.7.8.2 No Solid Diffusion and Complete Liquid Diffusion

2.7.8.3 No Solid Diffusion and Limited Liquid Diffusion

2.7.9 The Effect of Weld Pool Shape on Microstructure

2.7.9.1 Epitaxial and Competitive Growth of Crystals

2.7.9.2 The Effect of Welding Speed

2.7.10 Controlling Fusion Zone Microstructure.

2.7.11 Studying the Solidification Microstructure 
3.7 Solute Concentration Calculation

3.8 Calculation of the Solid/Liquid Interface Curvature 79

3.9 Boundary Condition Morphology

4.2 The Effect of Cooling Rate and Temperature Gradient on Microstructure Density Microstructure 


\section{List of Figures}

Figure2.1: Welding Processes Classification. 8

$\begin{array}{ll}\text { Figure2.2: } \quad \text { Typical welding circuit. } & 10\end{array}$

$\begin{array}{ll}\text { Figure 2.3: Weldment Metallurgy. } & 16\end{array}$

Figure 2.4: A hypothetical phase diagram and distinct weldment zones in a 17

Figure 2.5: Phase diagram and various zones of $0.15 \%(\mathrm{Fe}-\mathrm{C}) . \quad 18$

Figure 2.6: Instantaneous partially melted zone (PMZ) in a weldment. 20

Figure 2.7: Overall view of various weldment zones. 22

Figure 2.8: Variation in volume free energy with temperature. 24

Figure 2.9: The sequence of growth process. 25

Figure 2.10: Nucleation on the substrate. 26

Figure 2.11: Cooling curve for pure metal (a) without undercooling, (b) with undercooling.

Figure 2.12: Constitutional Undercooling; (a) composition gradient in front of S/L interface, (b) the zone of constitutional undercooling (c) 30 part of an equilibrium phase diagram.

Figure 2.13: Solidification mode; (a) planar, (b) cellular, (c) dendritic, (d) equiaxed.

Figure 2.14: The effect of constitutional undercooling on the Solidification mode.

Figure 2.15: The effect of constitutional undercooling on the Solidification mode.

Figure 2.16: A schematic diagram of a dendrite cell. 35

Figure 2.17: Concentration gradient within a solidified cell. 37

Figure 2.18: Two portions of hypothetically phase diagram. 38

Figure 2.19: The third case of solute redistribution; no Solid Diffusion and Limited Liquid Diffusion.

Figure 2.20: Segregation according to the type of liquid diffusion. 
Figure 2.21: Weld pool shape according to the weld speed; (a) $\mathrm{V}=$ $0.42 \mathrm{~mm} / \mathrm{s}$, (b) $\mathrm{V}=4.2 \mathrm{~mm} / \mathrm{s}$.

Figure 2.22: The microstructure around the weld pool. 45

Figure 2.23: Epitaxial growth. 46

$\begin{array}{lll}\text { Figure 2.24: } & \text { Competitive growth. } & 47\end{array}$

Figure 2.25: Welding speed effect at (a) high speed, (b) low speed. 48

Figure 2.26: Welding speed effect on axial grains at (a) high speed, (b) low speed.

Figure 2.27: The relationship between welding speed and growth rate.

Figure 2.28: The variation of (a) growth rate and (b) temperature gradient around the weld pool.

Figure 2.29: The variation of solidification mode within the weld pool. 51

Figure 2.30: Fusion zone microstructure refining mechanisms. 51

Figure 2.31: Dendrite with a parabolic tip shape. 62

Figure 3.1: The meshed control volume, showing all cells. 69

Figure 3.2: The initial phase field with a middle nucleus. 70

Figure 3.3: A sample of "phasein.txt" input file. 72

Figure 3.4: weight factors used to calculate the values of average phase field.

Figure 3.5: $\quad$ Periodical boundary conditions. 82

Figure 3.6: The temperature distribution within the control volume. 83

Figure 4.1: Dendritic microstructure (ISO surface presentation). $\quad 89$

Figure 4.2: Dendritic plus columnar grains (ISO surface presentation). $\quad 90$

Figure 4.3: Columnar grains (ISO surface presentation). 90

Figure 4.4: The effect of cooling rate and temperature gradient on the microstructure for simulation set one.

Figure 4.5: The effect of cooling rate and temperature gradient on the microstructure for simulation set two.

Figure 4.6: Microstructures of Sample $1(G=1.6 \mathrm{~K} / \mathrm{mm})$ for cooling rates: (a) $10 \mathrm{~K} / \mathrm{s}$, (b) $100 \mathrm{~K} / \mathrm{s}$, (c) $500 \mathrm{~K} / \mathrm{s}$, (d) $1000 \mathrm{~K} / \mathrm{s}$.

Figure 4.7: Microstructures of Sample_2 $(G=16 \mathrm{~K} / \mathrm{mm})$ for cooling rates:

(a) $10 \mathrm{~K} / \mathrm{s}$, (b) $100 \mathrm{~K} / \mathrm{s}$, (c) $500 \mathrm{~K} / \mathrm{s}$, (d) $1000 \mathrm{~K} / \mathrm{s}$. 
Figure 4.8: Microstructures of Sample_3 $(G=160 \mathrm{~K} / \mathrm{mm})$ for cooling rates: (a) $10 \mathrm{~K} / \mathrm{s}$, (b) $100 \mathrm{~K} / \mathrm{s}$, (c) $500 \mathrm{~K} / \mathrm{s}$, (d) $1000 \mathrm{~K} / \mathrm{s}$.

Figure 4.9: The effect of cooling rate on the microstructure for set number one.

Figure 4.10: Microstructures of set1_run test2 for cooling rates: (a) $1000 \mathrm{~K} / \mathrm{s}$ , (b) $3000 \mathrm{~K} / \mathrm{s}$, (c) $6000 \mathrm{~K} / \mathrm{s}$, (d) $12000 \mathrm{~K} / \mathrm{s}$.

Figure 4.11: The effect of cooling rate on the microstructure for simulation set number two.

Figure 4.12: The initial solid/liquid interface corresponding to the second solid phase surface.

Figure 4.13: The initial solid/liquid interface corresponding to the third solid phase surface.

Figure 4.14: Microstructure density versus cooling rate for the three initial solid surfaces.

Figure 4.15: The resultant microstructure of surface one, (number of grains =95), cooling rate $=1000 \mathrm{~K} / \mathrm{s}$.

Figure 4.16: The resultant microstructure of surface two, (number of grains $=249$ ), cooling rate $=1000 \mathrm{~K} / \mathrm{s}$.

Figure 4.17: The resultant microstructure of surface three, (number of grains $=274)$, cooling rate $=1000 \mathrm{~K} / \mathrm{s}$.

Figure 4.18: The resultant dendrite of using implicit solver. 


\section{Nomenclature}

$H A Z$ Heat-Affected Zone

FZ Fusion Zone

PMZ Partially-Melted Zone

CA Cellular Automation

$\mathrm{G}_{\mathrm{S}} \quad$ Free energy of solid phase

$\mathrm{G}_{\mathrm{L}} \quad$ Free energy of liquid phase

$T_{M} \quad$ Melting temperature

$\Delta \mathrm{T} \quad$ Total undercooling

$\Delta T_{\text {th }} \quad$ Thermal undercooling

$\Delta \mathrm{T}_{\mathrm{C}} \quad$ Constitutional undercooling

$\Delta T_{k} \quad$ Kinetic undercooling

$\Delta \mathrm{T}$ Curvature undercooling

$\Gamma \quad$ Gibbs-Thompson coefficient

G Temperature gradient

$\mathrm{G}_{\mathrm{FL}} \quad$ Temperature gradient at fusion line

$\mathrm{G}_{\mathrm{CL}} \quad$ Temperature gradient at center line

R Growth rate of solid phase

$\mathrm{R}_{\mathrm{FL}} \quad$ Growth rate of solid phase at fusion line

$\mathrm{R}_{\mathrm{CL}} \quad$ Growth rate of solid phase at center line

$D_{L} \quad$ Diffusion coefficient

$\mathbf{k}_{\mathbf{d}} \quad$ Segregation coefficient

$C_{L} \quad$ Solute concentration in liquid phase

$\mathrm{C}_{\mathrm{S}} \quad$ Solute concentration in solid phase 
$\mathrm{C}_{0} \quad$ Original alloy composition

$\mathbf{r}_{\mathbf{t}}$ Dendrite tip radius

$P_{c} \quad$ Peclet number

$\Omega \quad$ Dimensionless supersaturation

F Phase field value

$\Delta \mathrm{t} \quad$ Time step

K Curvature of solid/liquid interface

$T_{U} \quad$ The initial temperature of the upper surface of control volume

$T_{L} \quad$ The initial temperature of the lower surface of control volume 


\section{Chapter 1}

\section{Introduction}

\subsection{The Importance of Solidification Structures}

Many manufacturing processes depend on transforming a liquid metal into solid such as casting, welding, soldering, and brazing. Casting is considered a shaping process in which the liquid material can be formed into the final products or semi-final products that need additional forming processes. Fusion welding, soldering, and brazing are recognized as joining processes that are used to join several parts together. All of these processes are affected by the solidification process and the quality and properties of the final products depend on the solidification structure.

Welding is a manufacturing process, which has an important place in modern industrial sectors. The primary applications of the welding process include (1) piping, pressure vessels, boilers, and storage tanks; (2) automotive and railroad; (3) construction, such as buildings and bridges; (4) shipbuilding; and (5) aircraft and aerospace [1,2]. Nowadays, welding can be used under water and in space. Improving welding technology leads to improving the industrial sectors that depend on the welding processes. The production of vehicles, for instance, in the way that is customary today would not be possible at all without the application of welding technology [3]. The development of welding technology requires studying and investigating the effects of welding parameters on the weld microstructures. This is because welding parameters control the formation of weld 
microstructure and using incorrect welding parameters can form cracks and defects in the weldment. Therefore, studying weld microstructures is important to design safe structures and prevent catastrophic accidents. Furthermore, studying the microstructures has pronounced rewards in manufacturing economy and product reliability.

Because welding processes can be conducted by many energy sources including chemical, electrical or electrical resistance, lasers, and mechanical friction, they deal with complex disciplines such as mechanics, materials science, physics, chemistry, and electricity. Extensive trial and error experiments have been used to investigate and optimize welding processes. These experiments are costly and time consuming. Therefore, it is important to develop numerical methods to simulate welding processes by using computers.

\subsection{Solidification in the Welding Processes}

In fusion welding processes, the weldment's properties depend on the grains' size, the grains' shape, and the solute distribution in the grains. The grains sizes, shapes, and compositions are controlled by solidification process. Moreover, most weldment defects such as cracks are formed upon solidification. Therefore, understanding the solidification process is crucial to control the property and quality of the weldment $[4,5]$.

At the onset of the solidification process, the solid phase starts to form and then grows by advancing of a solid/liquid interface. The growth of the solid phase can have a simple or a complex pattern depending on the solidification parameters. The solidification parameters, which determine the morphology of the solid phase, are the temperature 
gradient, the growth velocity of solid/liquid interface, and the cooling rate $[4,6,7]$. However, the solidification parameters cannot be controlled directly. Because the welding parameters have a direct effect on the solidification parameters, the solidification process can be controlled by controlling the welding parameters. The principle welding parameters are welding speed and the power of the heat source. The welding speed is the dominant parameter that affects the weldment's microstructure [6].

\subsection{The Objective of this Study}

The objective of this study is to present a numerical model that simulates the formation of solidification microstructure. The model does not simulate the nucleation process, so it represents conditions similar to those of the welding process with autogenous solidification. The model is based on the thermodynamics of the solidification process and solved by finite difference method combined with cellular automaton (CA). In addition, the model considers the growth velocity of solid/liquid interface, the curvature of the solid/liquid interface, and the solute diffusion.

The model is developed to allow a parametric study, so the solidification parameters (temperature gradient and the cooling rate) can be changed easily by the user. The model assumes a constant cooling rate during the entire simulation and a linear temperature distribution, defined by two temperature values. The aim of this study is to introduce a qualitative investigation that deducts the relationship between solidification parameters and the resultant microstructure. 


\subsection{The Outline}

This thesis is divided into five chapters. Chapter 1 describes the importance of solidification process in modern manufacturing sectors, and why it is important to study the effects of solidification parameters on the weld microstructure. Chapter 2 gives an overview of welding process and its types. In addition, chapter 2 explains the flow of heat in welds. Furthermore, welding metallurgy and different weld zones are also described. Finally, the chapter describes in detail the solidification during welding process and the factors that control the microstructure of the weld zone. Chapter 3 explains the equations that describe the solidification process and how these equations are solved to simulate the formation microstructure. The results are presented in Chapter 4 to show the effect of solidification parameters on the resultant microstructures. Finally, Chapter 5 includes the conclusions, and it describes how to develop the model to simulate a real welding process. 


\section{Chapter 2}

\section{Overview of Welding Process}

\subsection{Joining Processes}

Joining processes are considered manufacturing processes because they are essential for the development of manufactured products. Many engineering products such as airplanes, automobiles, ships, machines, and similar products are manufactured in parts, required to be assembled together. Adhesive bonding, soldering, brazing, and welding are the main joining processes used today. As a comment, the term "joining" is generally used for welding, brazing, soldering, and adhesive bonding because they form permanent joints. The word "assembly" is used in case of mechanical fastening such as riveting and bolting.

Adhesive bonding is a joining technique in which an adhesive material "glue" is placed between the two parts being jointed. This process can be used for metallic and nonmetallic materials. It is typically employed in bookbinding, labelling, packaging, plywood, and joining composite materials in aircraft structures and other applications. In soldering and brazing process, filler metal is placed between the faying surfaces to be jointed. After that, a heat source is applied to the joint with a temperature high enough to melt the filler metal only-the base material remains solid. Therefore, the melted filler metal is distributed by capillary action between the faying surfaces. Both processes, soldering and brazing, have the same fundamentals, and they can be distinguished by the 
temperature of the process. Soldering is conducted with a temperature equal to or less than $450{ }^{\circ} \mathrm{C}$ while brazing is conducted above this value. Although soldering is extensively used by electronics industries, brazing is widely used in a variety of industries such as automotive, aerospace, cutting tools, plumbing, repairing, and jewellery making.

The last joining process is welding in which two parts are coalesced by the application of heat or pressure or both at their contacting surfaces. Most welding processes use high energy for either heating or applying pressure. Welding is the most common joining process because of its advantages. First, the weld joint can be as strong as the parent parts. Second, welding is an economical way to integrate parts for costing. Third, welding is a portable and versatile process that can be performed outdoor. Finally, it can be operated manually or automatically for a large production rate.

Knowing the joining method is important during the design phase. Therefore, manufacturing engineers work with design engineers from the conceptual design to final product. If the designers leave the problem of joining the parts to the manufacturing engineers, this could increase the cost of the product and decrease its reliability. The challenge is to determine which process gives the intended requirements with the lowest cost. Many factors influence the choosing of the joining process including part geometry, production rate, material, design complexity, service conditions, and availability of equipment. The joining process can be much easier, cheaper, and reliable if manufacturing — and design engineers work together effectively [8]. 


\subsection{Welding Processes}

American Welding Society (AWS) defines welding as "a localized coalescence of metals or non-metals produced either by heating the materials to the required welding temperatures, with or without the application of pressure, or by application the pressure alone, and with or without the use of filler materials" [2]. The definition declares that the welding processes use a combination of heat energy, pressure, and filler materials. A welding operation in which no filler metal is added is called an autogenous weld. Welding processes can be divided into two principle groups: (1) fusion welding and (2) solid-state welding. Solid-state welding processes do not experience any solidification process, thus beyond this study.

\subsection{Fusion Welding Processes}

To establish the continuous bonding between two pieces of material, it is necessary to use a combination of heat or pressure or both. The role of temperature and pressure in fusion welding processes, their classification, and their types is described next.

If the process temperature is sufficient to cause melting or fusion for the base metal, the process is called fusion welding. In this case, the melting metal provides mobile atoms moving between welding interfaces so the atoms will bond during solidification. In addition, the elevated temperature accelerates the diffusion process of the atoms. As a result, continuity of the base metal is achieved. Although fusion welding processes need high heat energy, they need a low pressure force that is only enough to hold the joint elements together during welding. By way of comment, non-fusion welding processes, 
such as solid-state welding, require low heat energy and high pressure force compared with fusion welding processes.

Proper classification of welding processes helps clarify the differences in these processes. In addition, it helps in the selection of suitable or necessary choices. Furthermore, welding classification could identify welding technology gaps so a new process, or material, can be invented or developed to fill these gaps. A basic classification is based on the heat source employed to provide the process energy. The three fundamental sources of energy are (1) chemical, the heat is generated from the combustion of fuel-gas; (2) electrical, the heat is generated by electrical arc or resistance; and (3) mechanical, the heat is generated by either plastic deformation or friction. These various types are illustrated in Figure 2.1. Moreover, there are sub-classifications to further distinguish between welding processes. For example, the processes could use filler materials, homogeneous, or not (autogenous). In addition, arc welding processes can use consumable- or non-consumable electrodes.

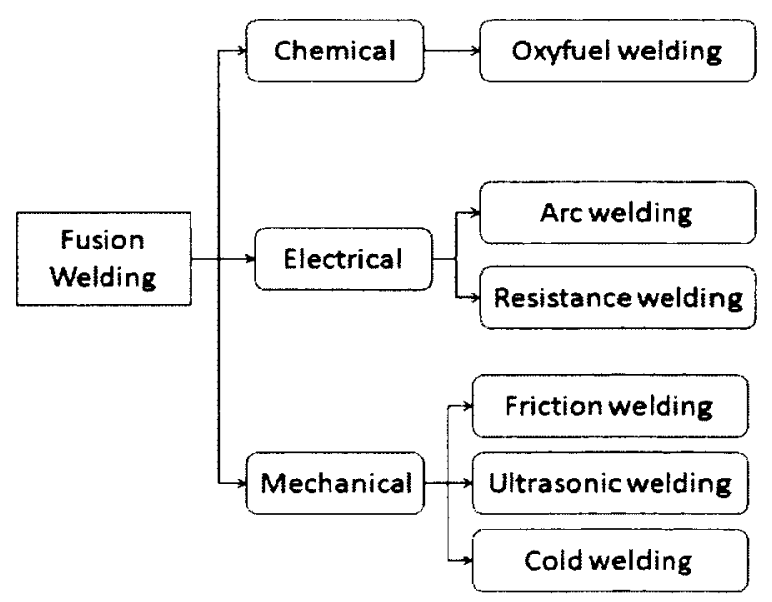

Figure2.1: Welding Processes Classification. 
As stated, the fusion welding processes differ according to the required energy. The main types of fusion welding include oxyfuel-gas welding, arc welding, resistance welding, and more recently electron beam and LASER welding. In oxyfuel-gas welding (OFW), the source of heat is fuel-gas combined with oxygen to produce a flame used to melt the metal at the joint. The most common fuel-gas is acetylene. Another type of fusion welding is resistance welding (RW). The heat required for resistance welding is produced by an electrical resistance across the two components to be joined. Spot-, seam-, projection-, flash-, and stud-welding are common resistance welding processes. The oldest fusion welding process is arc welding (AW). The source energy of arc welding is electrical energy. AC or DC passes from the electrode to the workpiece to create an electrical arc. There are many arc welding processes alternatives. These alternatives can be distinguished by many factors such as whether to use consumable electrodes, shield gases or fluxes, continuous or discrete filler metals. The most common arc welding processes are shielded metal arc welding (SMAW), gas metal arc welding (GMAW), flux-cored arc welding (FCAW), submerged arc welding (SAW), and gas tungsten arc welding (GTAW).

\subsection{Arc Welding Processes}

Arc welding processes are fusion welding that use electric arcs for heating. The arc is created between an electrode and a workpiece, in which each has different polarity. The power source of arc welding is usually an electrical transformer that uses a normal $\mathrm{AC}$ electric current to produce a current with controllable voltage and amperage. A typical arc welding circuit is shown in Figure 2.2 - the electrode is connected to either positive 
or negative transformer polarity, and the weldment is connected to the another transformer polarity. Thus, when the electrode is negative, the welding is termed directcurrent electrode negative (DCEN). By way of contrast, when the electrode is positive, the welding is termed direct-current electrode positive (DCEP). Alternative current can be used in welding process, and it is useful for welding aluminum alloys because AC helps remove the oxidized layers because of the bombardment of the positive ions.

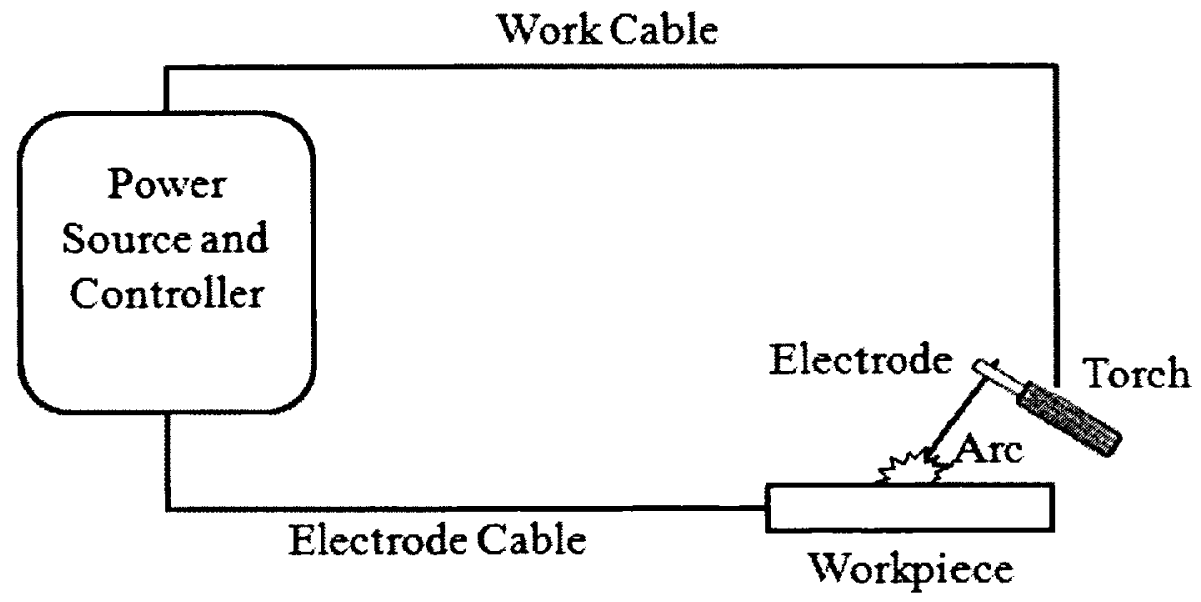

Figure2.2: Typical welding circuit.

The electrode in the welding circuit can be consumable, which generates the arc and acts as filler metal. On the other hand, the electrode can be non-consumable, usually composed of tungsten owing to its high melting temperature. Using a non-consumable electrode increases the productivity of welding process but the weldment must be protected from oxidation by using an inert shielding gas.

The electric power can be supplied to welding in tree types: 1) constant voltage (CV), the voltage remains constant during the welding; 2) rising arc voltage (RAV), the arc 
amperage increase with amperage increasing; and 3) constant current (CC), the voltage decreases as the amperage increases to maintain constant electric power.

The arc itself consists of positive ions and electrons that are emitted from both electrode and weldment. Thus, the potential field of voltage accelerates these electrons and ions to increase their kinetic energy. The accelerated electrons and ions produce heat when they convert their kinetic energy by collision with the opposite charged element. The positive ions have more kinetic energy than electrons because they gain more acceleration from voltage field.

\subsubsection{Parameters of Arc Welding Processes}

The quality of welds is determined by the welding process parameters: consumable electrode size and shape, welding current, arc length, electrode orientation and manipulation, and welding travel speed. The first parameter is electrode size or diameter. A small electrode needs less welding skill, has a low deposition rate, and takes more welding time. Although the large electrode increases deposition rate and welding time, it might overheat a thin workpiece because it delivers high heat input. Therefore, large electrode size is preferred in welding a thicker workpiece [2]. Welding current is the second parameter that affects welding quality. Basically, each electrode operates with a particular current depending on its size and material. Too low amperage results in poor fusion, poor arc stability, narrow bead and minimal penetration. Likewise, too high amperage results in wide bead, large penetration, and excessive splatter. Arc length, the distance of gap between electrode tip and workpiece, also influences the weld quality. Short arc length gives narrow bead and high weld build up; by contrast, long arc length 
gives minimum penetration, excessive splatter, low deposition, and could cause undercut. Electrode type, joint design, workpiece thickness, and amperage are factors that affect the arc weld setting. Arc length should be maintained constant during the welding process, especially if a consumable electrode is used, because it adversely affects the weld properties. Electrode angle is measured from the electrode surface to the workpiece surface, and it helps to blow the flux and molten metal away from the welding pass. At the same time, skilled welders move the electrode in a circular, square, and zigzag weave pattern. Electrode manipulation, or movement, affect weld bead penetration, build-up, width, overlap, and slag inclusions. Finally, the welding travel speed has a strong effect on weld quality and microstructure, and it is controlled by input heat. A slow welding speed causes excessive deposition and can reduce production time, whereas a high welding speed causes narrow bead, minimum penetration, low deposition rate.

\subsection{Energy for Welding}

Many energy sources are used to operate welding processes: mechanical, electrical, and chemical. Despite the energy sources, the energy source can be quantified by energy amount, energy density, and heat input. The particular function of the heat source is to melt the workpiece material by using a particular quantity of heat energy. The required heat is transferred from a heat source to a workpiece. All of these parameters, including welding process efficiency, will be described next. 


\subsubsection{Heat Input and Energy Density}

The energy source must be capable of supplying some energy amount and energy intensity. To clarify the difference between energy amount and intensity, consider, for instance, a large and small oxyacetylene torch. The large torch can supply more energy capacity to a workpiece than the small torch, but both torches have the same maximum temperature. Energy capacity per unit time (Watts) determines the value of transferred power. High transferred power means high heat is deposited in the workpiece for the same time, which has more effect on the workpiece.

Energy density is an important parameter in the welding process which is the concentration of heat over the area (Watts/area). Each type of welding process has definite range of energy density values. For example, the range of energy density of gasshielded arc welding is $5 \times 10^{6}$ to $5 \times 10^{8}\left(\mathrm{~W} / \mathrm{m}^{2}\right)$ and the range of energy density of electron beam and laser welding processes is $5 \times 10^{10}$ to $5 \times 10^{12}\left(\mathrm{~W} / \mathrm{m}^{2}\right)$ respectively [6]. The evolution of welding processes is a direct result of the ability to generate and apply a higher energy density. As the energy density increases, the ability to weld thicker workpieces with a minimum number of passes increases. In addition, high energy density welding processes can weld high melting point materials with minimum effect on the workpiece. Because the oxyacetylene welding process has a low energy density, it has been replaced by higher energy density processes such as arc welding. At the same time, for high melting point alloys and thick workpieces, greater energy density welding processes are needed such as plasma, electron beam, or laser welding. Energy density is expressed with a range of values rather than a precise number because it is complex to determine the exact contact area between heat and workpiece. Even more, the heat is 
neither equally distributed within the heat source (flame, arc) nor over the contact area. Generally, the energy density is highest at the workpiece center and drops off with the distance from the center, so it can be presented by Gaussian distribution [6].

Another important parameter in welding is heat input. It is the ratio of input power (in Watts) over welding traveling speed (in millimetre per second). In other words, heat input is the amount of energy introduced per unit length of weld from a traveling heat source (energy/unit of length). That means heat input is increasing as the speed of heat source is decreasing and vice versa. Increasing heat input strongly alters the weldment microstructures and must be determined for each welding practice.

The heat transfer to the workpiece can be produced in two modes: conduction mode and keyhole mode [6]. When the heat source is subjected on a workpiece surface, the heat is transferred to the workpiece and consequently conducted through the workpiece volume. If the energy density of the heat source is high enough, the deposited heat will exceed the conducted heat and eventually causes melting, known as conduction mode welding. The keyhole mode occurs if the energy density is high enough to raise the temperature above the boiling point; thus the workpiece material will be vaporized locally. Which welding mode is going to occur depends on energy density, workpiece thermal conductivity, and volume of the workpiece.

\subsubsection{Heat Flow in Welds}

Once the heat reaches a weldment surface, it flows and distributes on the surface and through the weldment volume. Part of this heat is conducted away from the fusion zone and raises the temperature of surrounding zone. Therefore, the metallurgies and 
characteristics of the surrounding zone material will be changed. This surrounding region is called the heat-affected zone (HAZ). Energy density, heat input, heat flow, and all welding parameters control the extent of fusion zone, the rate of melting, the rate of cooling and solidification in the fusion zone, and the extent HAZ. The weldment might contain discontinuities or microstructure defects if these welding factors are not determined correctly. The primary purpose of welding process simulation is to provide a mathematical tool to predict the correct welding procedures. An overview of weldment metallurgy and microstructure will be presented next.

\subsection{Welding Metallurgy}

A common characteristic of fusion welding processes is having a localized heat concentration. This localized heating is applied by either moving or stationary heating sources. As a result, welding operations alter the weldment metallurgical structures and properties locally. In addition, in worse cases, welding can cause defects such as cracks, porosities or local embrittlement. Consequently, it is important to understand the weldment metallurgical structure and the factors that cause metallurgical changes.

When the workpiece is heated, the heat flows through the workpiece and causes a thermal cycle. The maximum temperature is where the heat source is applied. Rapidly, the heat is conducted to the adjacent zones until it has no effect on the workpiece at a particular distance. The thermal cycle within the weldment creates three distinguished zones, as shown in Figure 2.3, which are the heat-affected zone HAZ, the partially-melted zone $P M Z$, and the fusion zone $F Z$. The remaining metal volume does not experience any temperature changes, so its name is the unaffected base metal zone. The structures and 
properties of these zones are influenced by the base metal alloy, thermal conductivity, thermal cycle, peak temperature, cooling and solidification rates, and welding velocity.

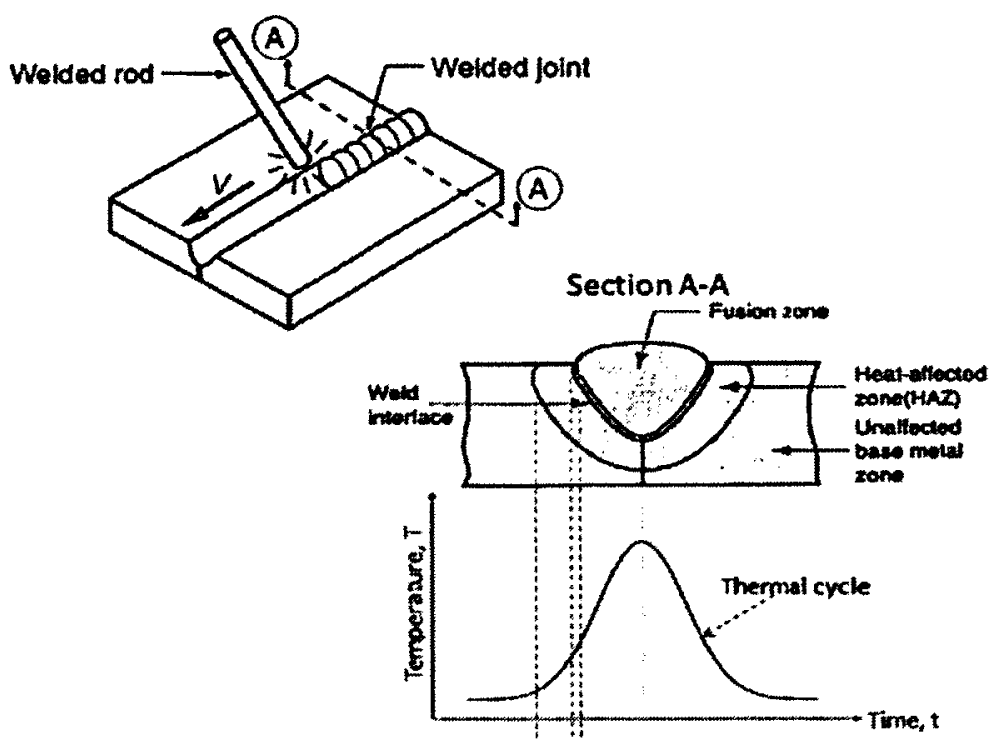

Figure 2.3: Weldment Metallurgy. Adapted from [1]

The structure and properties of HAZ and PMZ are discussed briefly in this section, and a detailed discussion of $\mathrm{FZ}$ is discussed in the next section because it is more related to the work of this thesis.

\subsubsection{Heat-Affected Zone (HAZ)}

Heat-affected zone is within the weldment next to the unaffected base metal zone. The HAZ has the same chemical composition of the base metal, but it has a different microstructure. Although $\mathrm{HAZ}$ does not melt because it is subjected to heat below the melting temperature, the temperature is high enough to cause metallurgical changes. In other words, the region of $\mathrm{HAZ}$ is heat treated due to high temperature and its properties are changed. The amount of metallurgical changes in grains' size or in phase composition 
of the HAZ or both depends on factors such as peak temperature, welding velocity, cooling rate, metal's alloy, and metal's thermal properties (namely, thermal conductivity, latent heat).

The distinct microstructural zones that appear in the weldment depend on whether the metal is a pure element or alloy. For example, a partially melted zone does not appear in the weldment of pure metal, yet it is appeared in the alloy weldment. That is because the pure metal has a constant melting point, whereas the alloy has a melting range defined by the liquids temperature and the solidus temperature of the alloy. Each weldment zone is correlated with a particular transformation zone in the alloy's phase diagram. Figure 2.4 shows that a phase diagram is related to the various weldment zones in a pure metal and an alloy.

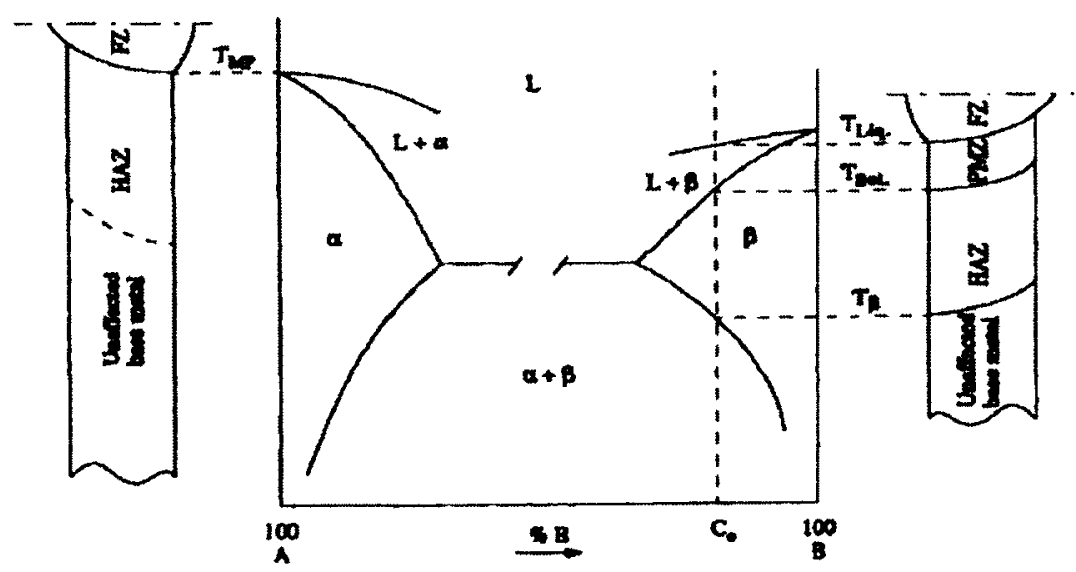

Figure 2.4: A hypothetical phase diagram and distinct weldment zones in a pure metal (left) and an alloy (right). [6]

In some alloys whose phase diagrams are complex, the HAZ zone can be divided into many zones because each has its own properties. Consider an example of $0.15 \% \mathrm{C}$ steel with behavior described by the Fe-C phase diagram as shown in Figure 2.5. 


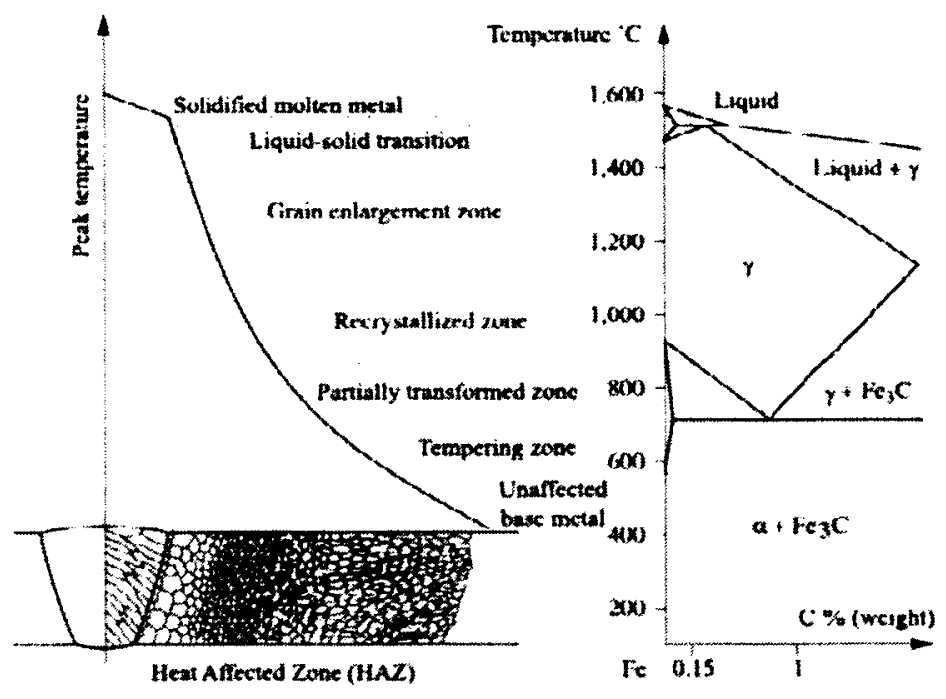

Figure 2.5: Phase diagram and various zones of $0.15 \%(\mathrm{Fe}-\mathrm{C})$. [9]

In Figure2.5 HAZ can be divided into three zones with different properties for each. The grains close to the fusion zone, grains enlargement zone, are subjected to a high temperature for long time; therefore, the grains will grow and become softer and have low strength. Moreover, grains of the zone away from the fusion zone, recrystallized zone, have been recrystallized into fine gains. Finally, the tempering zone, furthest away from the fusion zone, has experienced a temperature equal to steel's tempering temperature; therefore it is heat treated.

Recall that a phase diagram is a map that shows all the existing phases as a function of temperature, pressure, and material composition in the equilibrium conditions. Unfortunately, the real welding process occurs under non-equilibrium conditions because heating and cooling significantly deviate from equilibrium. Therefore, an equilibrium phase diagram is limited in predicting the actual structure changes and properties of HAZ 
and the entire weldment. In short, a phase diagram can be a guide on what to expect from the structure of HAZ but not realize the real structure.

The produced microstructure of $\mathrm{HAZ}$ determines its mechanical properties such as mechanical strength, ductility, toughness, and hardness. Thus, a good understanding of HAZ microstructure formation gives the utility to control the strength of the welded structure. For example, steels gain their mechanical properties from an optimized combination of hardening related to the nature of the microstructure. Furthermore, studying HAZ microstructure is important to prevent the negative mechanical properties which could cause failure in the welded joints. The strength and hardness of HAZ depend on the original strengthen mechanism of the workpiece such as cold working-, solid solution-, precipitation hardening.

The unaffected base metal zone is the portion of the weldment far enough from the heat source; therefore, it does not endure any metallurgical changes, and it has the same structure as the workpiece. Nevertheless, it is likely to be in a state of high residual stresses because of the fusion zone shrinkage and excessive workpiece constrain.

In short, the microstructure of HAZ is altered during welding process and the new structure is crucial to the weldment strength. The most significant factors that determine the HAZ metallurgical structure are peak temperature, cooling speed, welding velocity, and welding thermal cycle. 


\subsubsection{Partially Melted Zone (PMZ)}

The partially melted zone is the region that surrounds the perimeter of weld pool. This zone appears because its temperature is lower than the temperature that causes complete melting, but it affects the microstructure of the zone. Therefore, this zone does not exist in pure metals because melting occur at a constant temperature. A partially melted zone forms because of a welding thermal cycle that heats the alloy to a temperature between its liquids and solidus. Consequently, the grains endure localized melting along their interphase boundaries. Another cause that could help PMZ appear is Constitutional liquation $[6,7]$. Constitutional liquation states that liquation or melting can be caused by constitution or composition profile, where localized melting is possible at a temperature significantly below the freezing temperature of the workpiece material.

To weld a workpiece, the heat source has to move from the leading edge to the trailing edge of the workpiece. Upon that the PMZ will appear ahead of the weld pool instantaneously. As the heat source advances to the trailing edge, the formed instantaneous partially melted zone is completely melted leaving no trace in the fusion zone. Therefore, the partially melted zone persists all around and along both sides of the fusion zone as shown in Figure 2.6.

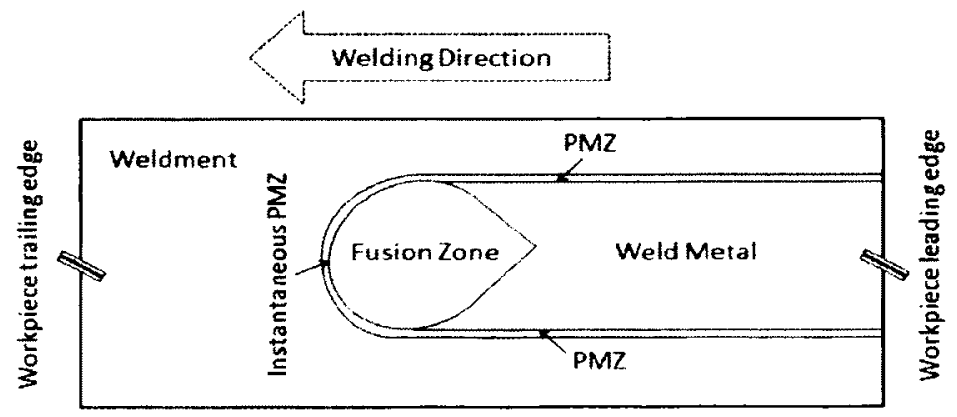

Figure 2.6: Instantaneous partially melted zone (PMZ) in a weldment. 
The main factors that affect the width of PMZ include: (1) the range between solidus and liquids temperature, a wide melting range produces a wider PMZ; (2) the thermal conductivity, a high thermal conductivity produces a wider PMZ; (3) the heat capacity and energy density of welding process, a high energy density produces narrower PMZ; (4) the heat input; and (5) welding practises such as preheating, electrode oscillation [6, 7].

Several defects can be produced in PMZ such as hot cracking, liquation cracking, hydrogen cracking, loss of ductility, and grains boundaries embrittlement. Several remedies could cure these defects include minimizing restraint, correct selection of filler metal that solidifies before the weld metal, and minimizing the heat input by using multipass welding and/or employing transverse arc oscillation.

\subsubsection{Fusion Zone (FZ)}

The fusion zone is the region that contains the melted metal. Pure metals melt when they are heated by the welding thermal cycle above their melting temperature, and alloys melt when they are heated above their liquidus temperature. Fusion zone is also designated as weld metal WM. When a workpiece is heated to its melting temperature, the material within the welding pool lose the rigidity and consequently melt forming a fusion zone. The atoms in the liquid state possess mobility and have no arrangement - this state is termed amorphous. As the heat source is moved ahead, the temperature of the melted zone is reduced. Then, the melted zone starts to solidify as its temperature reaches the material's solidus temperature. Therefore, the atoms order themselves and form a crystalline state. 
The composition of the fusion zone differs from the base metal because some components of an alloy might be evaporated because of high temperature. Obviously, the fusion zone composition differs from the base metal if a different metal is added. In addition, fusion zone structure is radically different from the base material because it undergoes melting and solidification. Because the fusion zone is formed by the solidification process, it has a long columnar grains' structure, or dendritic, as in the casting process. Figure 2.7 shows different zones in a weldment.

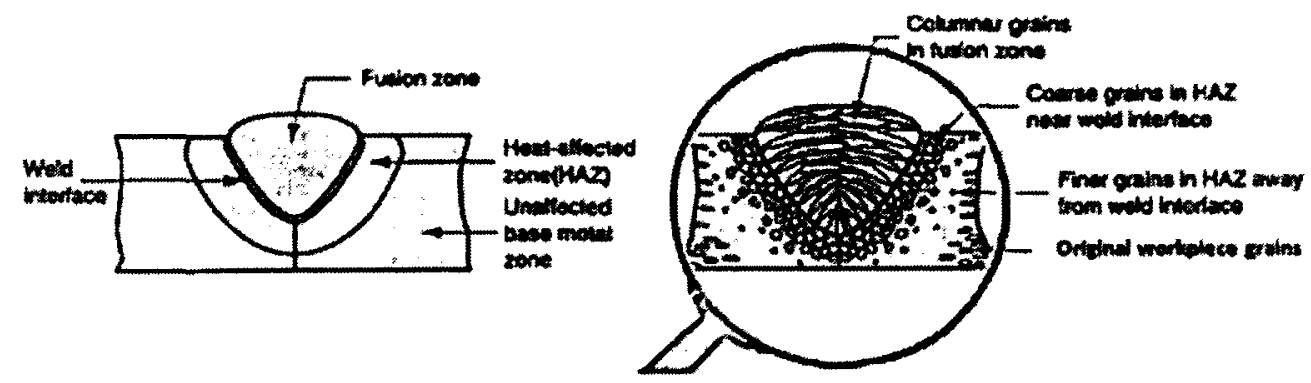

Figure 2.7: Overall view of various weldment zones. Adapted from [1]

The structure of the fusion zone depends on the base metal alloy, filler metal (if any), thermal cycle, welding process variables, and welding speed $[1,2,10]$. The quality and structure of fusion zone affects the total strength of weld joints; thus, it is an important aspect to study and investigate the formation of this fusion zone structure.

In short, welding thermal heat affects the workpiece and changes its microstructure. Two distinguishable zones appear in pure metals weldment, namely, the fusion- and heataffected zones. The partially melted zone is another zone that appears if the weldment is alloy. Each zone has its own properties and structure and formed in different mechanism. 
The quality and strength of the weld joints arise from their microstructures. Therefore, a robust understanding of welding metallurgy is crucial to design safe structures.

\subsection{Welding Solidification}

During fusion welding the thermal cycle, produced by the moving heat source, melts the base metal. Then, the melted metal will solidify again owning a different structure and composition. If a filler metal is used, it will extremely alter the compositions and properties. The resulting structure and composition give the weld its strength. Thus, studying the fusion zone solidification process is necessary to satisfy the design requirements. The solidification process starts with creating many nuclei that can grow under some conditions. Each nucleus grows and produces a tree-like structural shape, termed "dendrite". Dendrites grow in several modes according to various welding parameters. In addition, each dendrite has its own alloying composition. Finally the weld pool shape indicates the dendrite structures and growths.

\subsubsection{Nucleation Process}

Nucleation is the starting step of the solidification process. The driving force of solidification process is the volume free energy. Figure 2.8 shows the variation in volume free energy for the solid and liquid as a function of temperature, where $G_{S}$ and $G_{L}$ represent the free energy of solid- and liquid phases respectively. For a pure element, at temperature below the melting point $\left(\mathrm{T}_{\mathrm{m}}\right)$ the free energy of the solid phase is lower than the free energy of the liquid phase; as a result, the solid is the stable phase and will exist at equilibrium. By contrast, at temperature above $T_{m}$, the situation is reversed and the 
liquid phase is the equilibrium state of the system. As shown in Figure 2.8 at a temperature equal to $T_{m}$, the change in free energy equal to zero and thus there is no driving force for solidification. Therefore, undercooling is generally required to drive the nucleation process.

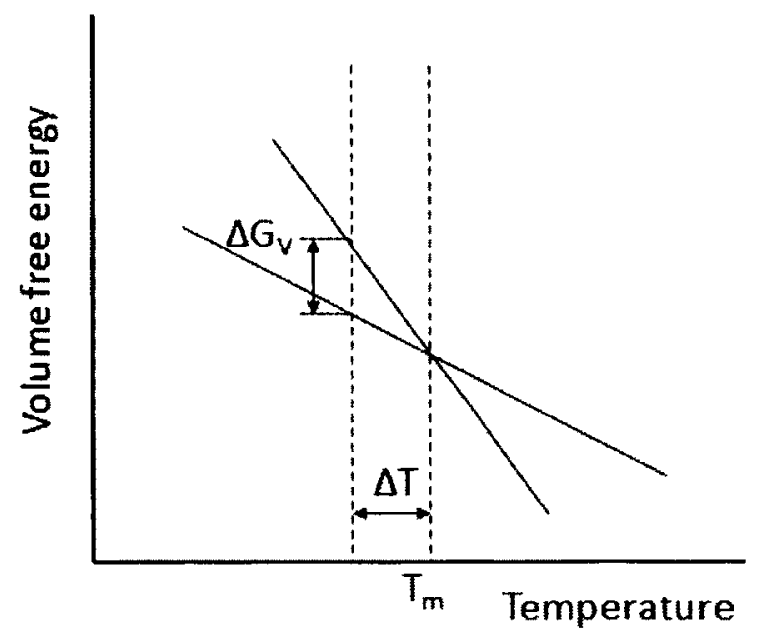

Figure 2.8: Variation in volume free energy with temperature.

In a thermodynamic perspective, the solidification process requires heat to flow from melt to the surrounding. Thus, the heat flow causes thermal fluctuations which are the driving forces of phase transformation. Thermal fluctuations provide additional heat energy to the system which might create minute nuclei, or embryos, even at temperature above the melting temperature. If at any instant a nucleus reaches the critical size by gathering atoms, it becomes stable and tends to form a complete grain. Finally, growth of all stable nuclei forms the final gain structure. A sequence of growth process, from nucleus to final grains, is shown in Figure 2.9. 

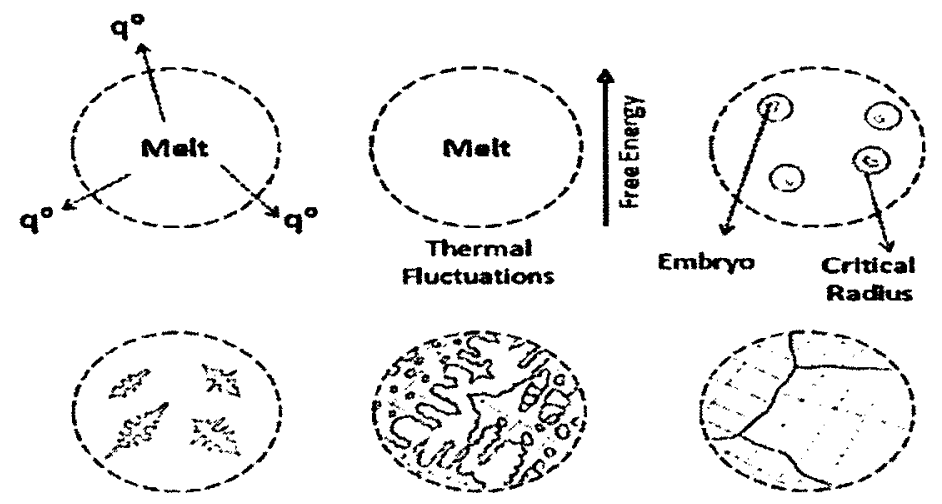

Figure 2.9: The sequence of growth process. Adapted from [11]

The presence of any solid surfaces can reduce the required number of atoms for stable nuclei; this will facilitate the nucleation process. In case of welding processes, the workpiece substrate acts as the nucleation site and is always present.

The classical nucleation theory (CNT) states that there are two nucleation processes namely, homogeneous and heterogeneous. Homogeneous nucleation occurs within a melt without a pre-existing solid surface. In this case, a particular degree of undercooling is needed to overcome the high energy barrier. A grain that has been grown from a homogenous nucleus is free to grow in all directions. These grains are usually formed in the middle of the mould, in the casting, far away from the walls. Homogeneous nucleus can be formed with large undercooling and relatively few atoms, or with small undercooling and a large number of atoms. The former case is more probable because a large undercooling value reduces the energy barrier to form a stable nucleus.

The other nucleation process is heterogeneous nucleation which occurs on a pre-existing solid surface; so it is likely to occur more often than homogeneous nucleation. The preexisting solid surface facilitates the nucleation process by reducing the number of atoms 
in a critical nucleus; in addition, lowering the energy barrier. Normally, a melt is in contact with the container walls which provide a preferred nucleation sites. In fusion welding, the boundary of the substrate is a nucleation site. Therefore, the prevailing nucleation process in fusion welding is heterogeneous nucleation because of the preexisting solid surface of the substrate.

Normally, the melt wets the solid surface when they are in contact, so that, a wetting angle can be defined as the angle between the solid surface and the tangent line that touches the surface of melt droplet, see Figure 2.10. The wetting angle, or contact angle, influences the nucleation process because it reduces the energy barrier and encourages particles to nucleate. A small wetting angle promotes the nucleation more than a bigger angle. Efficient wetting depends on the similarity of bonding and crystallographic match between the solid surface and the crystallized solid. Therefore, the wetting is efficient in case of autogenous fusion welding process.

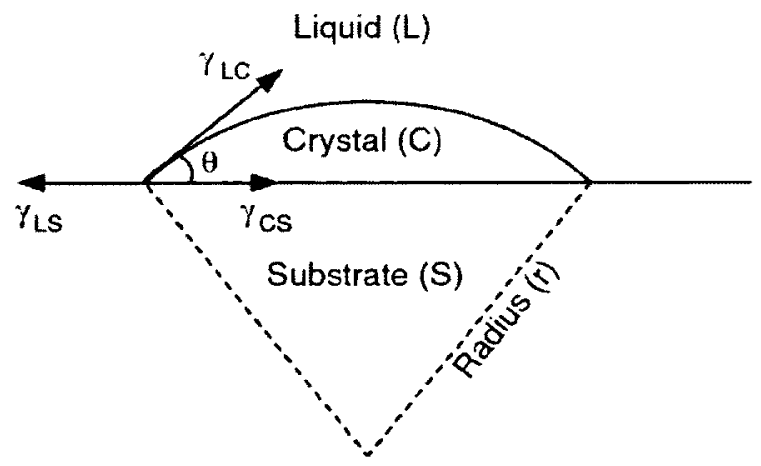

Figure 2.10: Nucleation on the substrate. $\gamma_{L S}, \gamma_{C S}$, and $\gamma_{L C}$ are the surface energies of liquid-substrate interface, and crystal-substrate interface, and liquid-crystal interface respectively. [7] 


\subsubsection{Undercooling}

The atoms of metal in a liquid phase possess mobility because their bonds do not have enough strength. If the temperature of molten metal decreases, the atoms start to bond and form crystalline structures. For a pure metal, the melt solidifies at its freezing temperature. When the pure metal starts to solidify, the growing solid phase releases the latent heat which increases the system temperature. Under equilibrium solidification conditions, the heat extraction from the melt by the cooling process will be equal to the released latent heat. As a result, the system temperature is kept constant as shown in Figure $2.11 \mathrm{a}$. At the end of the solidification process, the rate of latent heat released is decreased because most of the melt is already solidified. Therefore, the total system's temperature starts to decrease until the remaining liquid is solidified. For most industrial conditions, the pure metals are rarely used and some impurities can be found in the metal. In this case, the solidification will not start at the equilibrium freezing temperature, but it will start at temperature below the equilibrium freezing temperature (see Figure $2.11 \mathrm{~b}$ ). The difference between the melting temperature and the temperature at which the melt starts to solidify is called undercooling. For alloys, undercooling is the difference between the equilibrium liquidus temperature and the real solidification temperature. 

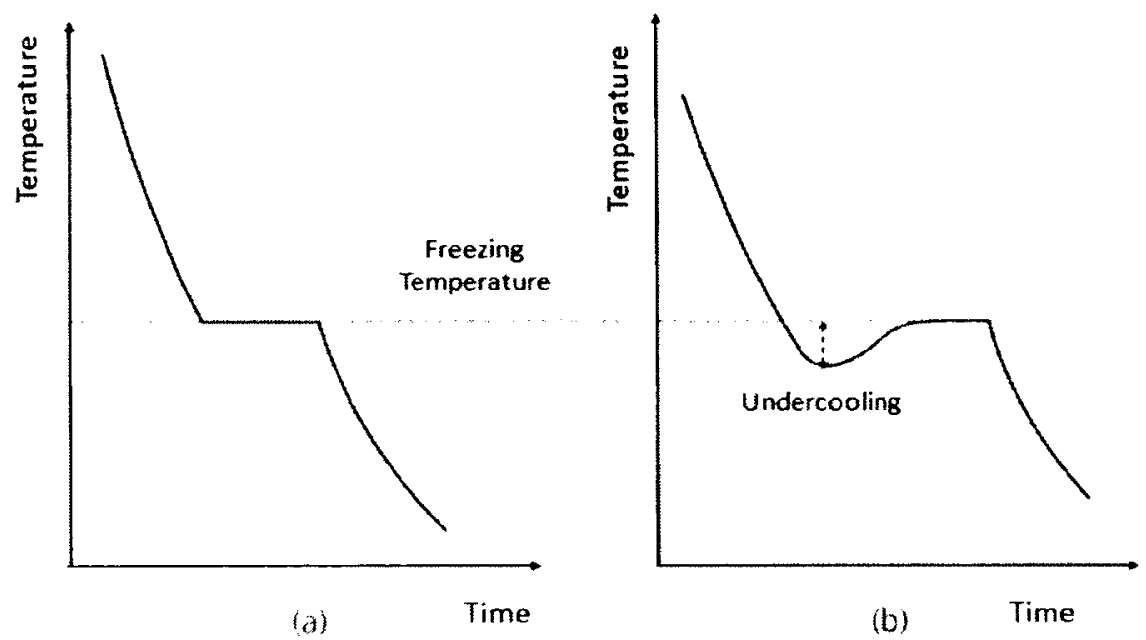

Figure 2.11: Cooling curve for pure metal (a) without undercooling, (b) with undercooling. [11]

Increasing the undercooling leads to increase the velocity of solidification process. The degree of undercooling comprises four different values: thermal-, constitutional-, curvature- (or capillary), and kinetic undercooling as expressed in the next equation.

$$
\Delta T=\Delta T_{t h}+\Delta T_{c}+\Delta T_{k}+\Delta T_{R}
$$

The first term of undercooling is called thermal undercooling $\left(\Delta T_{t h}\right)$. The second term is constitutional undercooling $\left(\Delta \mathrm{T}_{\mathrm{c}}\right)$, produced because of the local change in the compositions ahead of the newly formed solid. Kinetic undercooling $\left(\Delta T_{k}\right)$ is equal to the advancing velocity of solid phase divided by the alloy's kinetic coefficient as presented in Equation 2.2. The last term $\left(\Delta T_{R}\right)$ expresses the curvature undercooling.

$$
\Delta T_{k}=\frac{v}{\mu}
$$


Where (v) is the growth velocity of solid phase. Equation 2.2 shows that increasing the kinetic undercooling leads to an increase the growth velocity. In welding solidification, the kinetic undercooling is small, and it becomes important if the growth rate is in the meters per second.

Curvature undercooling is also known as capillary undercooling because of the common behaviour between curvature undercooling and capillary effect. The curvature of the solid surface depresses the melting point because of the Gibbs-Thomson effect. If the curvature of a solid surface increases, then its surface-to-volume ratio will increase; therefore, the solid's thermal properties will be altered. In addition, changing the curvature changes the bulk free energy of the solid. The effect of the curvature undercooling can be calculated according to the next equation.

$$
\Delta T_{R}=C \cdot \Gamma
$$

where,

$\mathrm{C}$ is the curvature of the solid surface.

$\Gamma$ is the alloy's Gibbs-Thompson coefficient.

\subsubsection{Constitutional Undercooling}

Solidification occurs by the accumulation of atoms, which happens in the diffusion process. During solidification, the formed solid rejects solute atoms into the liquid; thus, a solute-enriched transient layer, $\mathrm{C}(\mathrm{x})$, is being formed ahead of the solid/liquid interface (see Figure 2.12a). The composition profile in front of the solid/liquid interface reduces the liquidus temperature; so the liquidus temperature can be expressed as TL(x) with the 
help of the composition profile and phase diagram. If the actual temperature of the liquid ahead of the solid/liquid interface, $\mathrm{T}_{\text {actual }}(\mathrm{x})$, is lower than the equilibrium liquidus temperature $\mathrm{TL}(\mathrm{x})$, then the area between the two curves is constitutionally undercooled, as shown in Figure $2.12 \mathrm{~b}$. The value of constitutional undercooling at any distance in front of the solid/liquid interface is equal to the difference between the actual temperature and the equilibrium liquidus temperature as stated in the next equation.

$$
\Delta T_{\text {undercooling }}(x)=T_{L}(x)-T_{\text {actual }}(x)
$$

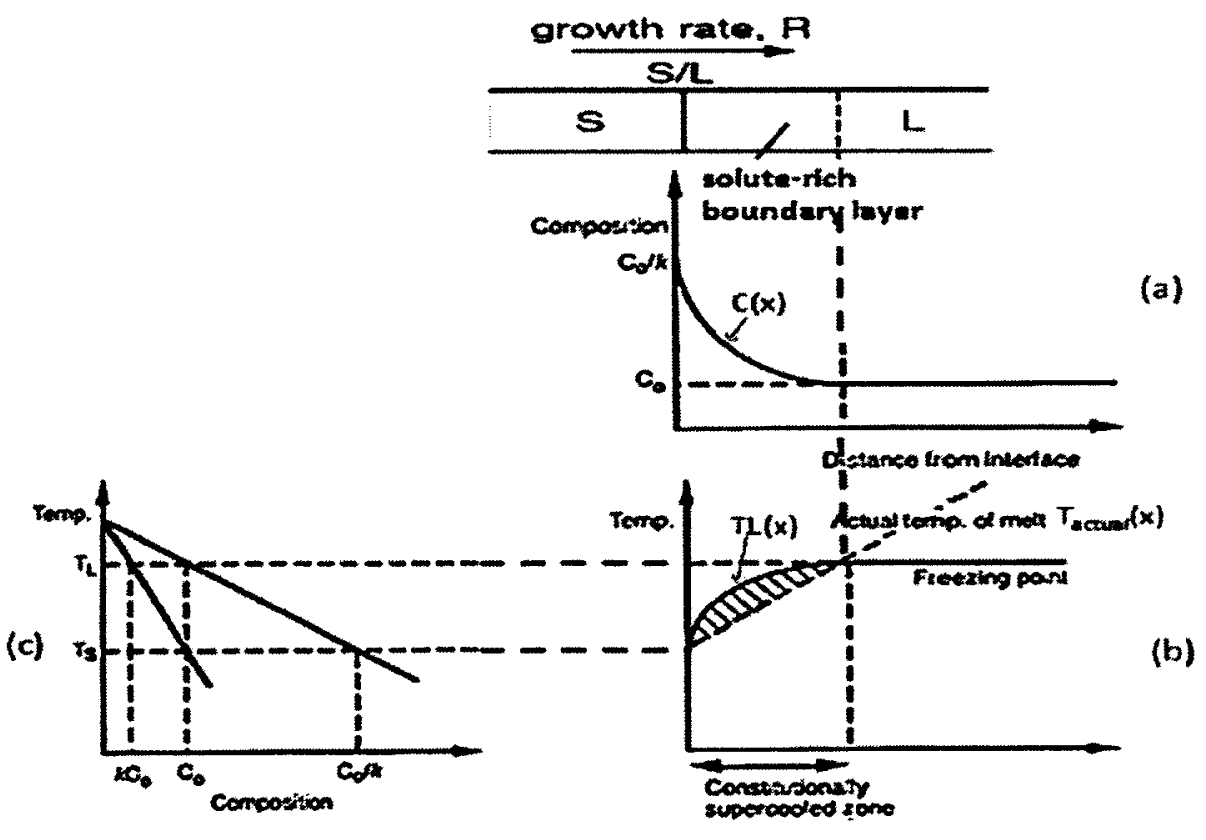

Figure 2.12: Constitutional Undercooling; (a) composition gradient in front of $\mathrm{S} / \mathrm{L}$ interface, (b) the zone of constitutional undercooling (c) part of an equilibrium phase diagram. [6]

\subsubsection{Solidification Modes}

The four basic modes of solidification process producing a different morphology of the solid phase are planar, cellular, columnar dendritic, and equiaxed dendritic (as shown in 
Figure 2.13). Which mode will take place depends on the alloying system and solidification conditions.

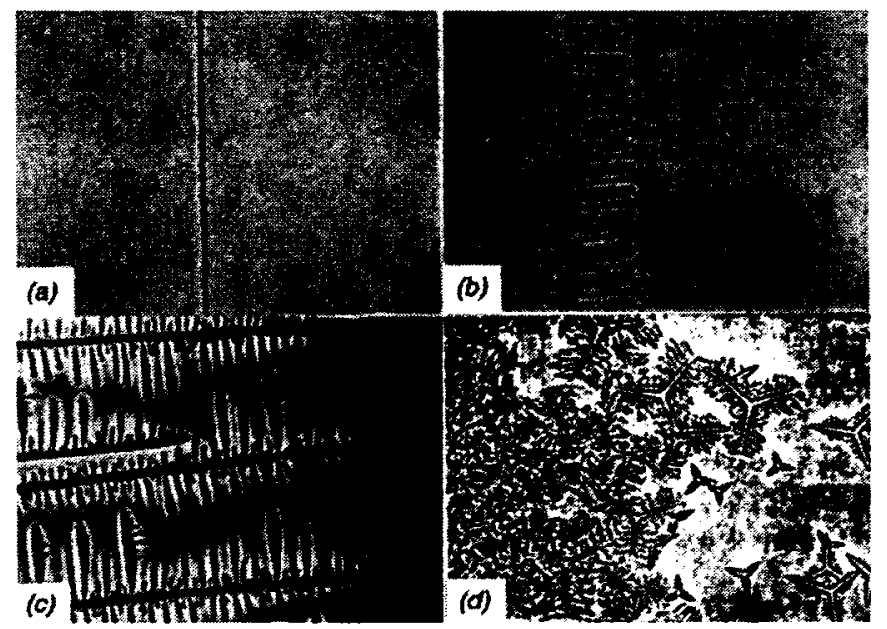

Figure 2.13: Solidification mode; (a) planar, (b) cellular, (c) dendritic, (d) equiaxed. [7]

Constitutional undercooling theory developed by Chalmer [12] proposed a quantitative description for the solidification mode. Constitutional undercooling theory based on the thermodynamics of alloy solidification states that to form a stable planar solid/liquid interface, the following condition must met.

$$
\frac{G}{R} \geq \frac{\Delta T}{\mathrm{D}_{\mathrm{L}}}
$$

where,

$\Delta T$ is equal to $T_{L}-T_{S}$, is the equilibrium freezing range, the temperature difference across the boundary layer.

$\mathrm{G}$ is the temperature gradient ${ }^{\circ} \mathrm{C} / \mathrm{cm}$.

$R$ is the growth rate $\mathrm{cm} / \mathrm{sec}$.

$D_{L}$ is the diffusion coefficient $\mathrm{cm}^{2} / \mathrm{sec}$. 
Constitutional undercooling theory proposes that for an alloy to be stable and grow in planar morphology, the ratio $G / R$ must be greater than or equal to $\Delta T / D_{L}$. The value of constitutional undercooling determines the growth mode because if a protuberance is accidentally formed, it will form in liquid below the effective liquidus so it will tend to grow. As the degree of constitutional undercooling increases, the solidification mode changes to cellular and columnar dendritic. Moreover, at a high degree of constitutional undercooling, it is easy for homogeneous nuclei to be formed within the melt and hence the equiaxed dendrites. Figure 2.14 shows the relationship between the constitutional undercooling and solidification mode.

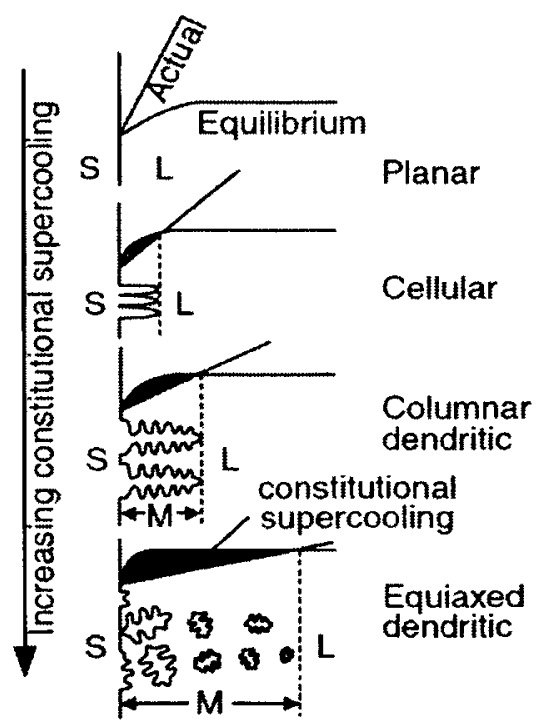

Figure 2.14: The effect of constitutional undercooling on the Solidification mode. [7]

The constitutional undercooling theory was verified experimentally. Although the constitutional undercooling theory gives a quantitative value at which the planar interface will form, it does not give such a value for other solidification modes. At the same time, 
there is no theory such as constitutional undercooling to predict the transitions between cellular, dendritic, or equiaxed modes.

\subsubsection{The Effect of Cooling Rate on Microstructure}

While the ratio of temperature gradient over growth rate $(G / R)$ governs the mode of solidification, the product of these two values $(G \times R)$ governs the microstructure scale. The unit of temperature gradient is ${ }^{\circ} \mathrm{C} / \mathrm{cm}$ and the unit of growth rate is $\mathrm{cm} / \mathrm{sec}$; so, the unit of their multiplication is ${ }^{\circ} \mathrm{C} / \mathrm{s}$ - which basically means cooling rate.

The value of the cooling rate affects the microstructure; high cooling rates shorten the solidification time and reduce grain size. By contrast, slow cooling rates increase the solidification time, resulting in increased grain size that is called coarsening effects. The distances between dendrite's arms specify the size of the dendrite. As the distances between arms increased, the overall size of the dendrite increased. Large dendrite arms grow at the expense of smaller ones, during solidification, because they have lower surface area per unit volume and thus energy. The schematic diagram in Figure 2.15 depicts the effect of temperature gradient ( $G)$ and solidification rate $(R)$ on the microstructure. 


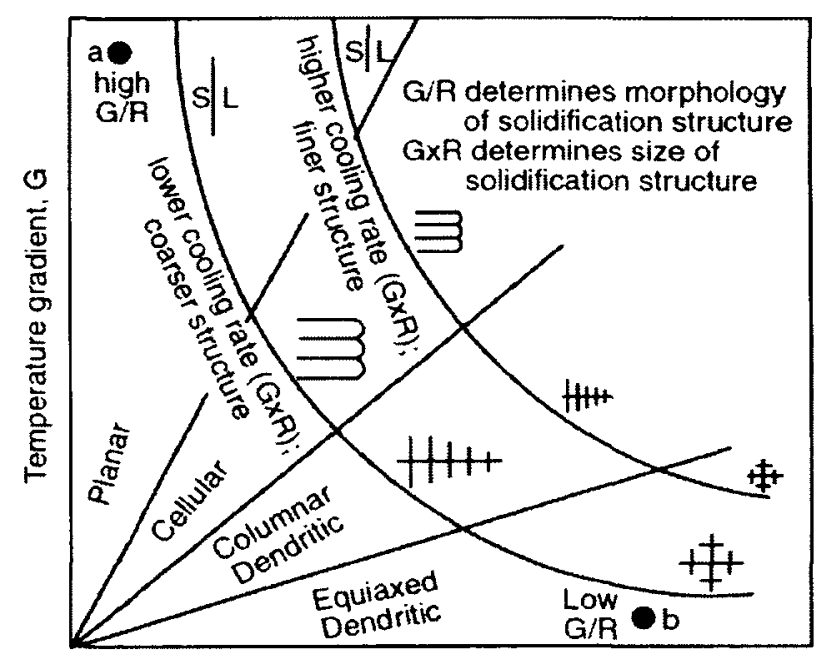

Growth rate, $R$

Figure 2.15: The effect of constitutional undercooling on the Solidification mode. [7]

Temperature gradient $(G)$ and solidification rate $(R)$ can be controlled by heat input and welding velocity. For example, high heat input and slow welding speed heats the surrounding material more. As a result, the temperature gradient will decrease and the microstructure becomes coarser. In addition, increasing welding velocity increases the cooling- and growth rate under the same heat input. It can be said that welding velocity, power, and power density distribution are the dominant parameters that controls the weld microstructure.

\subsubsection{The Dendrite Growth Mechanism}

Once nuclei are formed on a solid substrate surface, the atoms from the molten metal will join the atoms of nuclei. The accumulation of atoms will produce crystals. The crystals grow and extend away from the substrate in the direction opposite to the heat transfer direction. At a particular undercooling value, the crystals grow in the shape of spines or 
needles. As these spines enlarge, lateral branches form and sub-branches producing treelike shapes named dendrites. Figure 2.16 shows a schematic diagram of a dendrite cell.

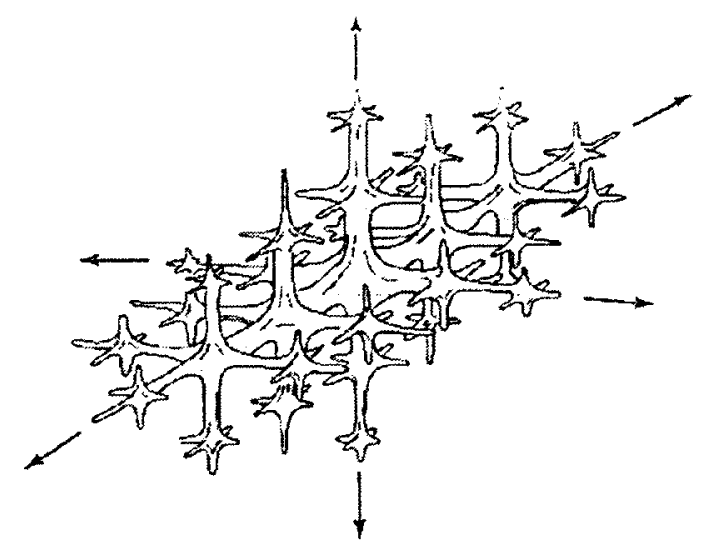

Figure 2.16: A schematic diagram of a dendrite cell. [11]

The dendrites are formed in the mushy zone, in which the temperature is between the liquidus and solidus temperature. In the mushy zone the solid, in form of dendrite, and liquid, in form of molten metal coexist. The mushy zone can be either wide or narrow depending on the solidification conditions, cooling rate, and the difference between liquidus and solidus temperature.

During solidification, many dendrites grow simultaneously and their branches become more complex and interfere with each other. As the growth continue, each dendrite grows until the spaces between the branches are filled up and finally forms a grain. When the branches of one dendrite meet the branches of another one, they collide and restrict the growth of each other and grains' boundaries are formed. Finally, the dendrites gradually grow during solidification, as additional metal is continually deposited on the dendrites until complete solidification has occurred. 


\subsubsection{Composition Variation-Segregation}

The composition of the solidified unit is not uniform even if the original alloy composition is uniform. This is so because the solute atoms are redistributed during solidification. The redistribution of solute atoms depends on the phase diagram, diffusion, undercooling, fluid flow, and cooling rate.

The redistribution of solute atoms during alloy solidification produces variation in the chemical composition, or segregation, in the fusion zone structure. The two types of segregation, that are, microscopic- and macroscopic segregation. Micro-segregation means that the variation of chemical components takes place across each individual grain. By contrast, macro-segregation takes place across the entire fusion zone structure. Macro-segregation is important in casting process, and it is named ingot segregation.

Upon cooling, cells or dendrites are formed and start to grow with higher concentration of component that increases the liquidus temperature of an alloy. Therefore, the growing dendrites will have more of one component than the others. As a result, an imbalance in composition will be created between the solidified metal and the remaining molten metal. As the solidification process proceeds gradually, the first solidified component is depleted; thus, the dendrites continue to grow by consuming the second component remaining in the molten metal. At the end of solidification process, the remaining molten metal is trapped among dendrites branches, and it has a high concentration of the second component. 
Finally, the trapped liquid will solidify causing more segregation. If the core of the cell has a higher solute concentration than the surface does, the concentration gradient in this case is called coring. In contrast, if the surface of cell has a higher solute concentration, then the concentration gradient is called inverse-coring, as shown in Figure 2.17.
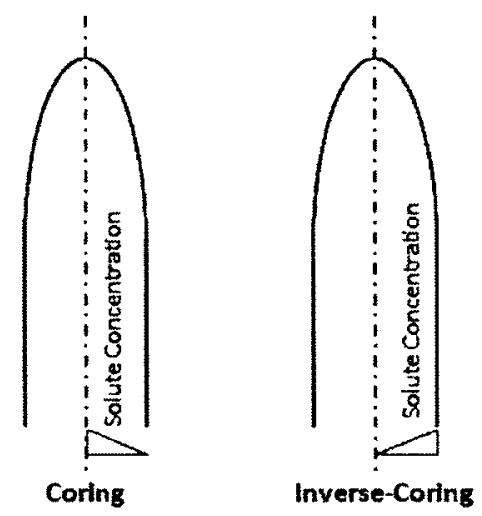

Figure 2.17: Concentration gradient within a solidified cell.

\subsubsection{Solute Redistribution}

Consider the phase diagram of a hypothetically binary alloy system as shown in Figure 2.18. In addition, consider an alloy whose initial melt composition is equal to $\left(\mathrm{C}_{0}\right)$. Assume that undercooling is negligible and there is equilibrium between the solid/liquid interfaces during solidification. The melting $\left(\mathrm{T}_{\mathrm{L}}\right)$ and solidifying $\left(\mathrm{T}_{\mathrm{S}}\right)$ temperature of the alloy can be determined by drawing a vertical line through $\mathrm{C}_{0}$. At the same time, the concentration of liquid $\left(\mathrm{C}_{\mathrm{L}}\right)$ and solid $\left(\mathrm{C}_{\mathrm{S}}\right)$ at any temperature $(\mathrm{T})$ can be determined by using the initial composition and the segregation coefficient $\left(k_{d}\right)$. The segregation coefficient is defined as the ratio of solid composition and liquid composition as stated in Equation 2.6. 


$$
k=\frac{C_{S}}{C_{L}}
$$

For simplicity, both solidus and liquidus line are assumed to be straight; thus, the segregation coefficient is also constant and has the same value at any temperature. When the temperature is equal to liquidus temperature $\left(T=T_{L}\right)$, the composition of liquid is equal to $C_{0}$ and the composition of solid is equal to $\left(k \cdot C_{0}\right)$.

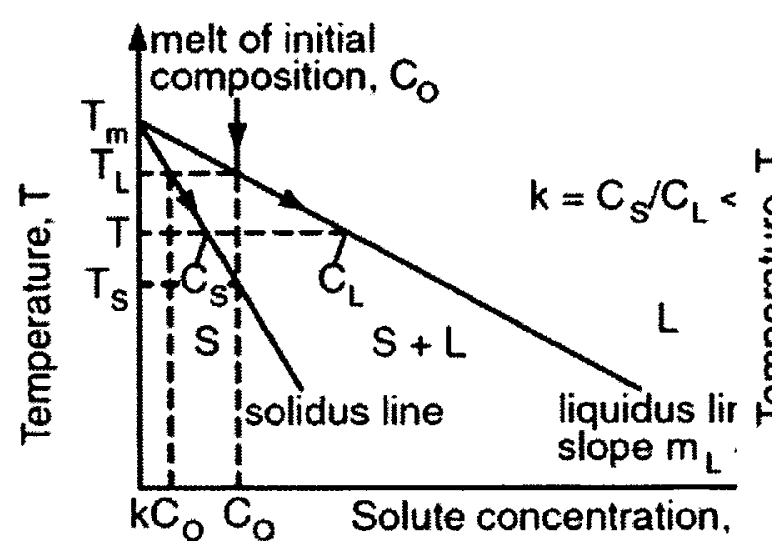

(a)

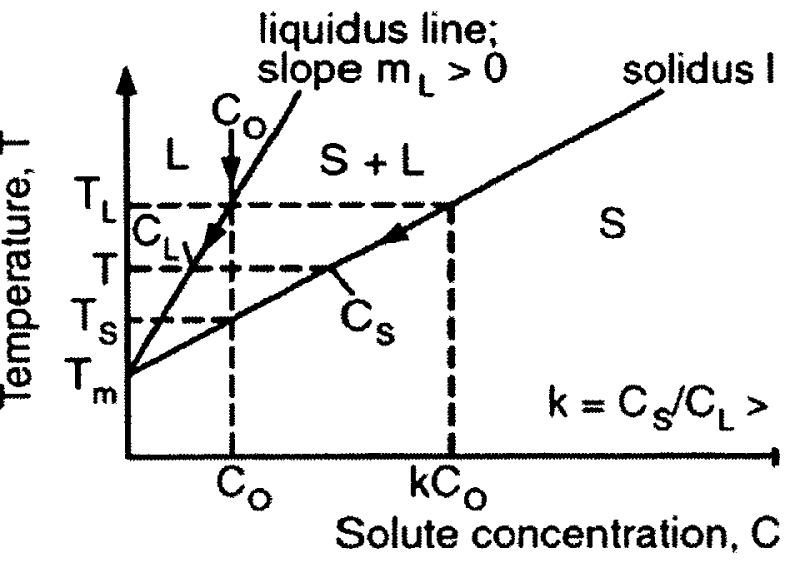

(b)

Figure 2.18: Two portions of hypothetically phase diagram. [7]

The solid will reject the solute into the liquid during solidification when the segregation coefficient is less than one (Figure 2.18a). Consequently, the concentration of solute in the liquid continues to increase during solidification and inverse-coring might take place. If the segregation coefficient is greater than one (Figure $2.18 \mathrm{~b}$ ), the solid will absorb the solute from the liquid during solidification. As a result, the concentration of solute in liquid continues to drop during solidification and coring might take place. The development of micro-segregation is controlled not only by the phase diagram but also by the kinetics of solidification and diffusion processes. 
Solute redistribution can be presented by three proposed cases. These cases include: complete diffusion in solid and liquid, no solid diffusion and complete liquid diffusion, and no solid diffusion and limited liquid diffusion.

\subsubsection{Complete Diffusion in Solid and Liquid}

In this case, equilibrium solidification occurs because equilibrium exists between the solid-liquid interface and the entire solid and liquid phases. The diffusion is assumed to be complete in both solid and liquid; thus, they are uniform in composition. To get a liquid with uniform composition, strong convection or complete diffusion in the liquid is required. This requirement can be achieved when the diffusion coefficient is very high and/or solidification is so slow that the solute has enough time to diffuse across the liquid. During equilibrium solidification the composition of the entire liquid follows the liquidus line, and the composition of the entire solid follows the solidus line. In results, the compositions of the solid and liquid are uniform at any time during solidification and the solidified solid has no segregation. Equilibrium solidification is virtually never encountered because it needs very slow solidification rate under ideal conditions.

\subsubsection{No Solid Diffusion and Complete Liquid Diffusion}

This case assumes there is no diffusion in the solid; so as a result, the solid composition is not uniform. At the same time, the diffusion in the liquid is complete, so the composition of liquid is uniform. The uniformity in the liquid composition can be achieved by either complete diffusion in the liquid or mixing by convection. In this case, equilibrium exists only at the interface between the solid and the liquid. Because the solute is rejected by the 
growing solid and cannot back diffuse into it, the solute concentration in liquid phase $\left(C_{L}\right)$ will be increased during solidification. Meanwhile, the solute concentration in solid phase $\left(\mathrm{C}_{\mathrm{S}}\right)$ will increase as the solid continue to grow. Consequently, the formed solid endures segregation in the composition, and it is mathematically expressed by Scheil model $[6,7,13]$.

From the solute conservation law, which states that the amount of solute in solid and liquid is conserved, the next relationship is deduced:

$$
\left(C_{L}-C_{S}\right) d f_{S}=\left(1-f_{S}\right) d C_{L}
$$

Where $\left(f_{s}\right)$ expresses the fraction of solid. By substituting $\left(\mathrm{C}_{\mathrm{S}}=\mathrm{kC}_{\mathrm{L}}\right)$ into Equation 2.7 and integrating from $C_{L}=C_{0}$ at $f_{S}=0$, yields to:

$$
C_{S}=k C_{0}\left(1-f_{S}\right)^{k-1} \text { or } C_{L}=C_{0} f_{L}^{k-1}
$$

From the non-equilibrium lever rule the fraction of solid can be stated as:

$$
f_{S}=\frac{C_{L}-C_{0}}{C_{L}-\overline{C_{S}}}
$$

Where the average composition of the solid $\left(\overline{C_{s}}\right)$ can be determined as:

$$
\bar{C}_{s}=\frac{C_{0}\left[1-\left(1-f_{s}\right)^{k}\right]}{f_{s}}
$$

Because the solidus and liquidus lines are both assumed straight and $\left(T_{L}-T_{m}\right) / C_{0}=m_{L}$, the Scheil model can expresses the fraction of solid as follows:

$$
f_{L}=1-f_{S}=\left(\frac{-m_{L} C_{0}}{T_{m}-T}\right)^{\frac{1}{1-k}}
$$




\subsubsection{No Solid Diffusion and Limited Liquid Diffusion}

In this case the diffusion of solute in solid is assumed to be zero and limited in liquid without convection. As a result, the composition of solid and liquid is not uniform during the solidification process. In addition, a concentration gradient of solute is produced ahead of the solid-liquid interface because the solute is rejected by the solid and cannot diffuse in the liquid completely. Therefore, a solute-rich boundary layer appears in front of the solid as shown in Figure 2.19a.

At the beginning of solidification, the solute concentrations in both solid and liquid, $\mathrm{C}_{\mathrm{S}}$ and $C_{L}$, increase rapidly until the concentration of solute in solid phase becomes equal to the original composition $\left(C_{S}=C_{0}\right)$. This period is called the initial transient. A steadystate period starts when $C_{S}$ and $C_{L}$ reach $C_{0}$ and $C_{0} / k$ respectively. During the steadystate period, the solute-rich layer is constant, and its width in linearized approximation is equal to the diffusion coefficient in liquid over the solid growth rate, as shown in Figure 2.19b. In addition, the composition of solid and liquid remains constant during the steady-state period. When the thickness of the remaining liquid layer becomes equal to the thickness of the steady-state layer, the concentration of solute raises sharply in both solid and liquid, known as a final transient period. 


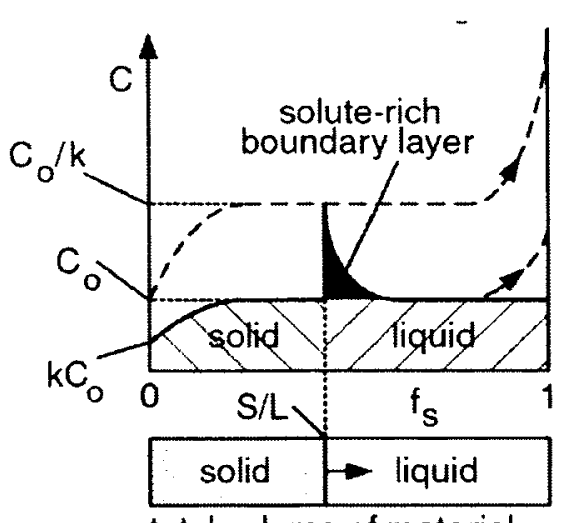

total volume of material

(a)

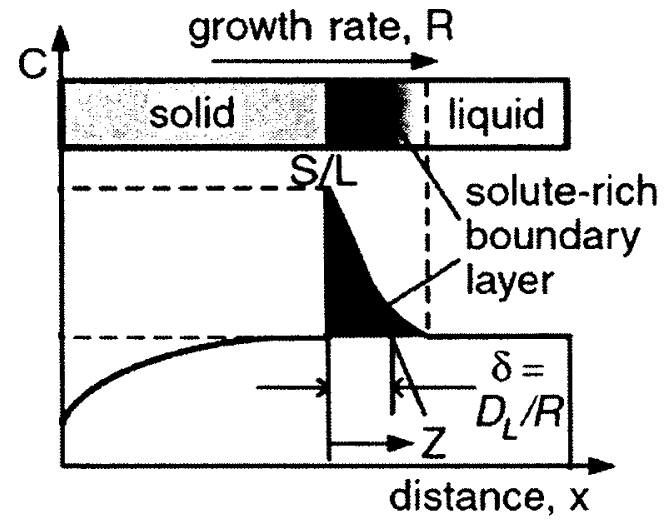

(b)

Figure 2.19: The third case of solute redistribution; no Solid Diffusion and Limited Liquid Diffusion. [7]

According to Fick's second law of diffusion, the net flux of solute atoms out of a small element of transient layer can be expressed as [6]:

$$
J_{D}=D_{L} \frac{d^{2} C}{d x^{2}}
$$

The solid/liquid interface is moving with rate $\mathrm{R}(\mathrm{cm} / \mathrm{s})$. In the coordinate system moving at the same rate, the flux associated with the interface movement can be presented as [6]:

$$
J_{M}=R \frac{d C}{d x}
$$

During the steady-state period, the rate of solute atoms' flow into the solid caused by interface migration is equal to the rate of solute atoms out of the solid by diffusion, thus:

$$
R \frac{d C}{d x}+D_{L} \frac{d^{2} C}{d x^{2}}=0
$$

By solving Equation 2.14, the solute concentration in the liquid during the steady state period, for $\mathrm{k}<1$, is equal to: 


$$
C_{L}(Z)=C_{0}\left[1+\frac{1-k}{k} e^{\left(-\frac{R}{D} Z\right)}\right]
$$

The concentration of solute in the solid during initial-transit period can be mathematically expressed as follows:

$$
C_{S}(x)=C_{0}\left[(1-k)+\left[1-x \cdot e^{\left(-\frac{k \times R}{D}\right)}\right]+k\right]
$$

The three types of solute redistribution occur when the diffusion in the solid is negligible during solidification. The first type occurs when the diffusion and mixing in the liquid is complete. The second type occurs when the diffusion and mixing in the liquid is limited. The third type occurs when there is no convection and the diffusion in the liquid is limited. In the first type the solute segregation is the worst whereas the segregation in the third type is less severe as shown in Figure 2.20.

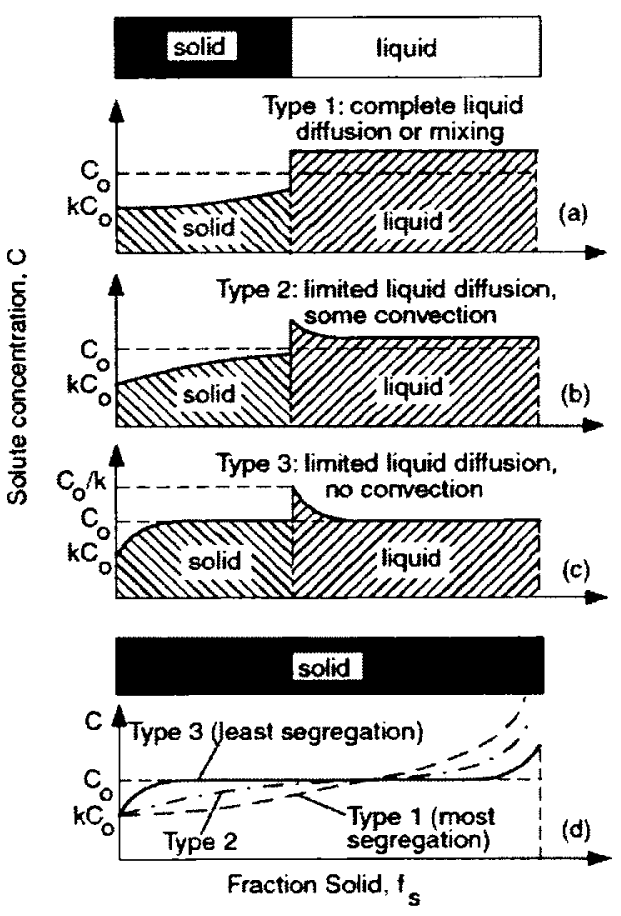

Figure 2.20: Segregation according to the type of liquid diffusion. [7] 


\subsubsection{The Effect of Weld Pool Shape on Microstructure}

The shape of the weld pool depends mainly on the heat input, power density distribution, and welding speed. At low heat input and welding speed, the weld pool has an elliptical shape. By contrast, if they increase, the weld pool elongates and has a teardrop shape; as shown in Figure 2.21. Further increasing of welding speed and heat input will increase the teardrop's length-to-width ratio.

(a)
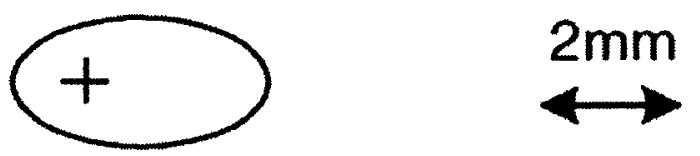

(b)

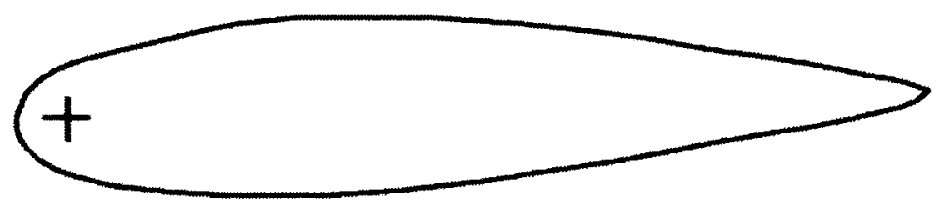

Figure 2.21: Weld pool shape according to the weld speed; (a) $V=0.42 \mathrm{~mm} / \mathrm{s}$, (b) $\mathrm{V}=$ $4.2 \mathrm{~mm} / \mathrm{s}$. The cross sign in each pool indicates the position of the electrode tip relative to the pool. [7]

It is better to discuss the microstructure around the weld pool first in order to understand the relationship between the weld pool shape and microstructure. Figure 2.22 illustrates the microstructure around the weld pool according to the imposed thermal cycle. In both sides of the weld pool and in front of it, partially melted grains appear. At the trailing edge of the weld pool, a mushy zone, which consists of solid dendrites and melted metal, is formed. The pool itself, or the fusion zone, contains liquid metal. 


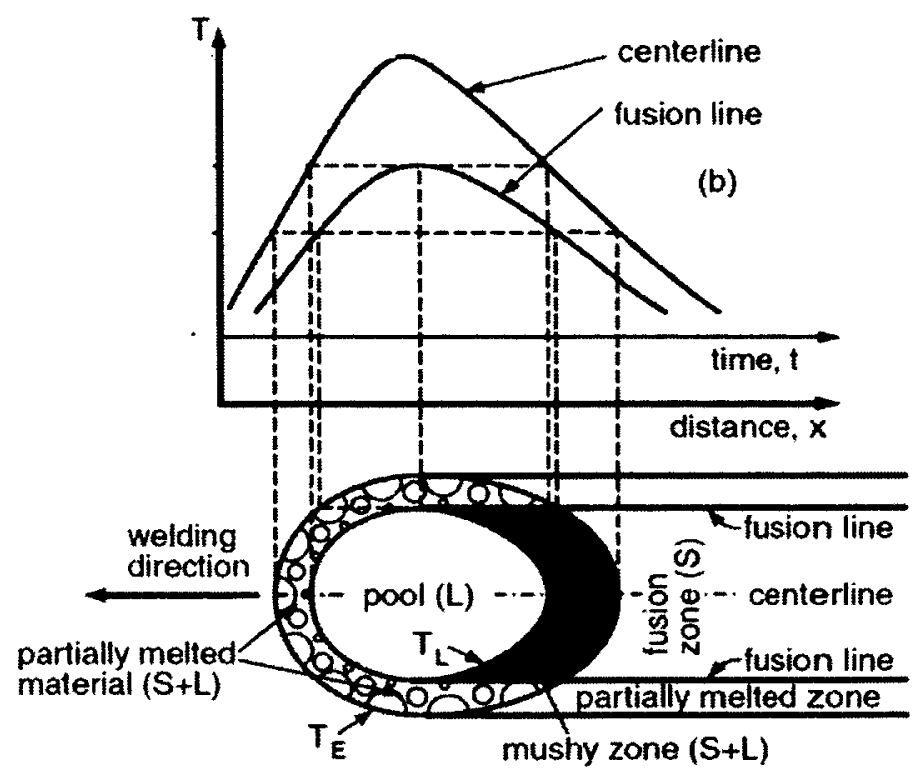

Figure 2.22: The microstructure around the weld pool. [7]

\subsubsection{Epitaxial and Competitive Growth of Crystals}

The liquid metal in the weld pool is in contact with the substrate grains with complete wetting. With autogenous welding, the solidification starts by arranging the melt's atoms on the substrate grains in such a way that the new formed grains have the same crystallographic orientations of the substrate grains. The name of this mechanism is epitaxial growth, and it is shown in Figure 2.23. This growth mechanism was studied using Laue x-ray back-reflection technique. In addition, Savage and Hrubec use a transparent organic material (camphene) as the working material to study the epitaxial growth [14]. 


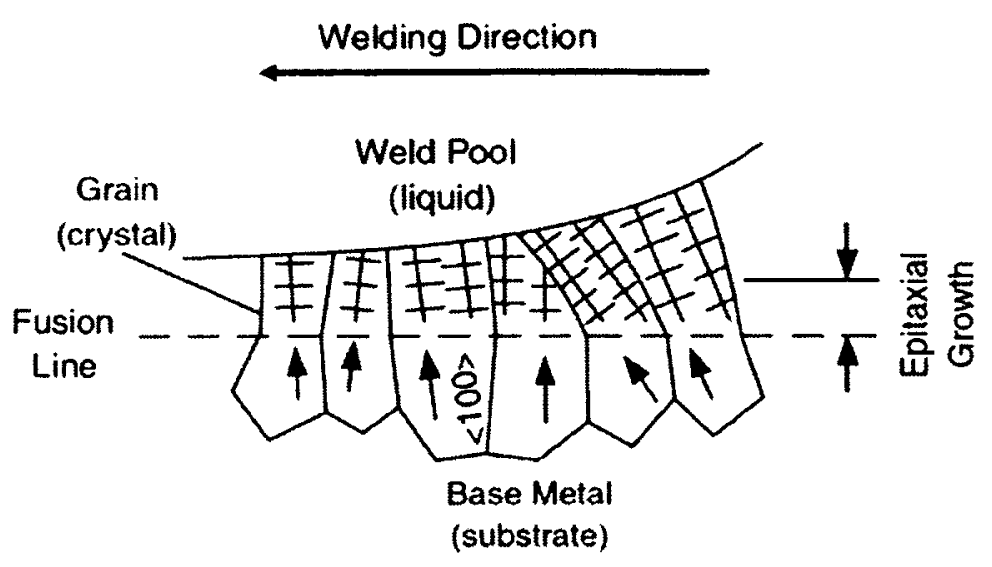

Figure 2.23: Epitaxial growth. [7]

When welding with a filler metal is used (or joining two different materials), the weld metal composition differs from the base metal composition, and the weld metal crystal structure can differ from the base metal crystal structure. When this occurs, epitaxial growth is no longer possible and new grains will have to nucleate at the fusion boundary.

When welding different materials together, or using a filler metal with different material, the resultant weld metal composition differs from the base metal composition, and the weld metal crystal structure can differ from the base metal crystal structure. Thus, epitaxial growth is no longer possible and new grains will have to nucleate at the fusion boundary. As a result, there are random misorientations between the grains of base metal and the grains of weld metal.

The growth of grains continues by competitive growth that occurs away from the fusion line. In competitive growth, the grains tend to grow in direction perpendicular to the pool boundary because this is the direction of maximum heat extraction. In addition, dendrite cells tend to grow in the easy-growth directions which depend on the material's crystal structure. For example, the easy-growth direction for $f c c$ and $b c c$ materials is $<100>$. 
Therefore, the solidified grains that are perpendicular to the pool boundary and have their easy-growth direction will crowd out other grains, as shown in Figure 2.24. While epitaxial growth dominates the grains' structure near the fusion line of a weld, competitive growth mechanism dominates the grains structure for the rest of the weld metal.

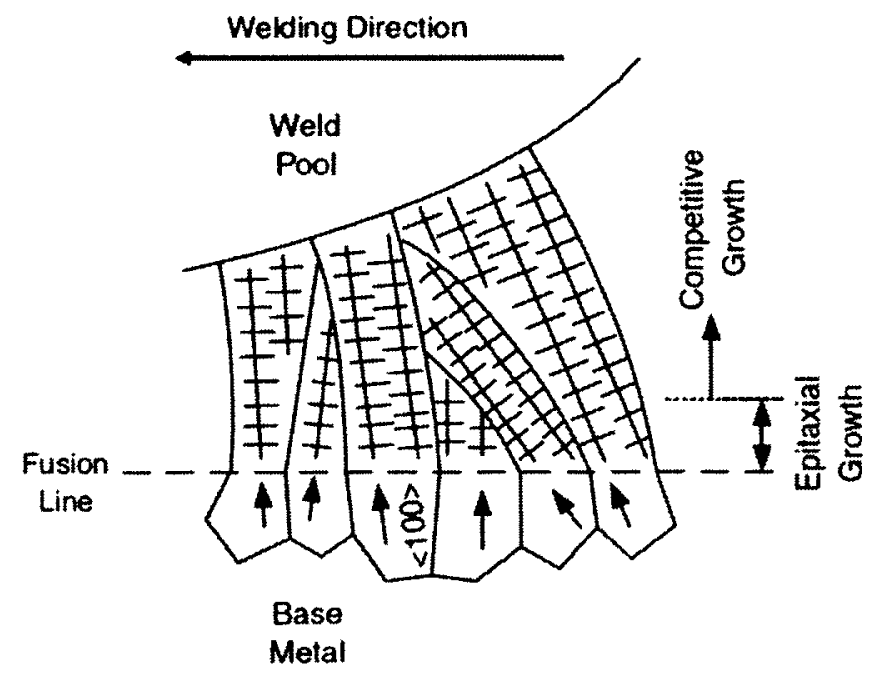

Figure 2.24: Competitive growth. [7]

\subsubsection{The Effect of Welding Speed}

At high welding speed, the weld pool has a teardrop shape with straight trailing pool boundary. In this case, the columnar grains tend to grow in straight line perpendicular to the weld pool boundary (Figure 2.25a). In contrast, at low welding speed, the weld pool has an elliptical shape; therefore, the columnar grains tend to grow in curved paths perpendicular to the weld pool boundary as shown in Figure $2.25 \mathrm{~b}$. 


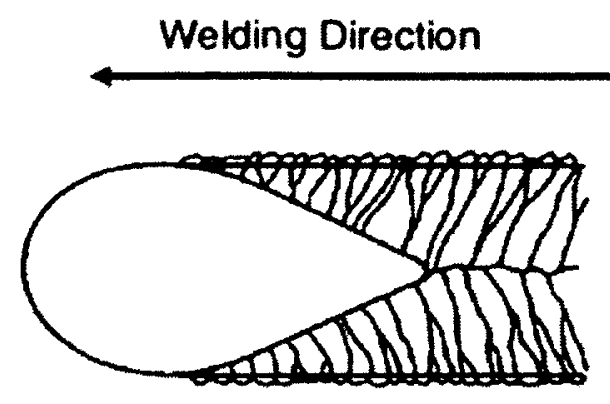

(a)

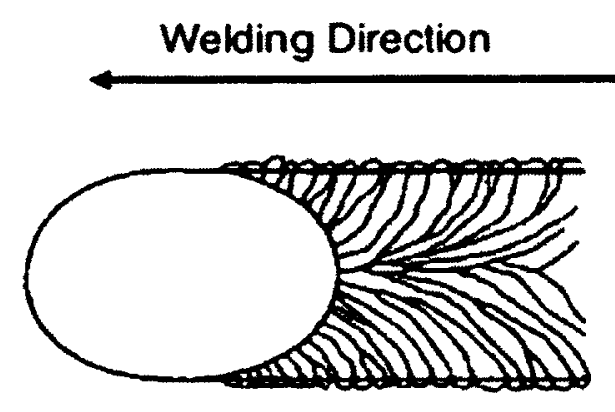

(b)

Figure 2.25: Welding speed effect at (a) high speed, (b) low speed. [7]

At the same time, axial grains can be initiated at the starting point of the weld in the middle of the fusion zone. They continue to grow along the length of the weld line blocking the growth of columnar grains inward to the weld center. These axial grains also tend to grow perpendicular to the weld pool boundary. Therefore, if the weld pool has a teardrop shape, the axial grains have only a narrow region within which to grow. In contrast, if the weld pool has an elliptical shape, the axial grains have a wider region for growing. Both cases are shown in Figure 2.26.

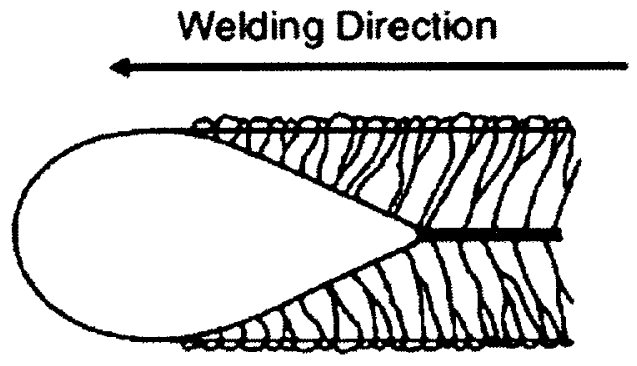

(a)

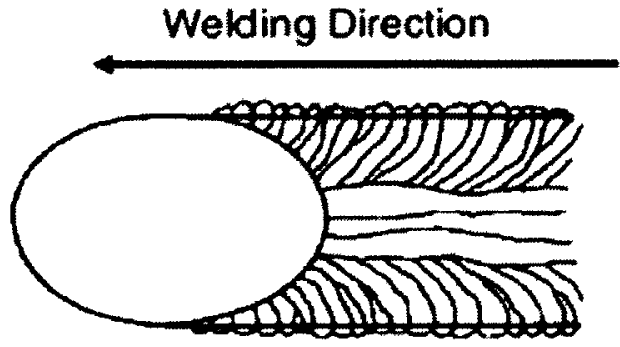

(b)

Figure 2.26: Welding speed effect on axial grains at (a) high speed, (b) low speed. [7] 


\subsubsection{Solidification Mode within the Weld Pool}

The mode of solidification varies from weld to weld according to the used welding parameters (e.g. welding speed and heat input) which specify the value of constitutional undercooling. As the degree of constitutional supercooling increases, the solidification mode changes from planar to columnar, columnar to dendritic, and dendritic to equiaxed dendritic.

The solidification mode can also vary within the weld itself from the centerline to the fusion line. The relationship between crystal's growth rate $(\mathrm{R})$ and the welding speed (see Figure 2.27$)$ is expressed by Nakagawa et al as follows $[6,7,13]$ :

$$
R=\frac{V \cos \alpha}{\cos (\alpha-\beta)}
$$

For small difference between the two angles $(\alpha-\beta)$ is small as an approximation, Equation 2.17 becomes:

$$
R=V \cos \alpha
$$

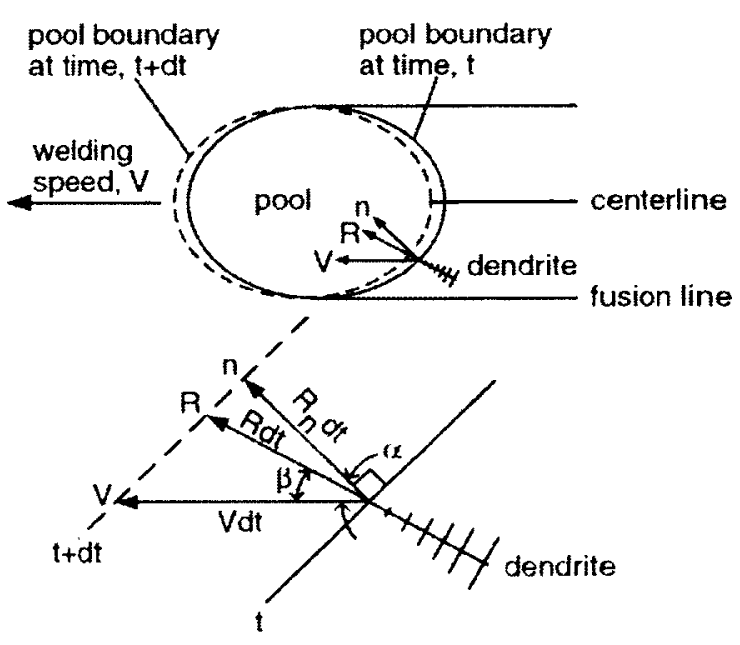

Figure 2.27: The relationship between welding speed and growth rate. [7] 
At the fusion center line $\alpha=0^{\circ}$, so the growth rate is maximum which is equal to the weld speed $\left(R_{C L}=V\right)$. By contrast, at the fusion line $\alpha=90^{\circ}$, so the growth rate is minimum and equal to zero $\left(\mathrm{R}_{\mathrm{FL}}=0\right)$, as shown in Figure 2.28a. Inversely, the temperature gradient at the weld pool center $\left(\mathrm{G}_{\mathrm{CL}}\right)$ line is smaller than the weld pool fusion line $\left(\mathrm{G}_{\mathrm{FL}}\right)$. This is because the weld pool is elongated, so the distance between the maximum temperature point and the pool boundary is longer at the center line as shown in Figure $2.28 \mathrm{~b}$. Consequently, the next relationship can be deduced.

$$
\left(\frac{G}{R}\right)_{C L} \ll\left(\frac{G}{R}\right)_{F L}
$$

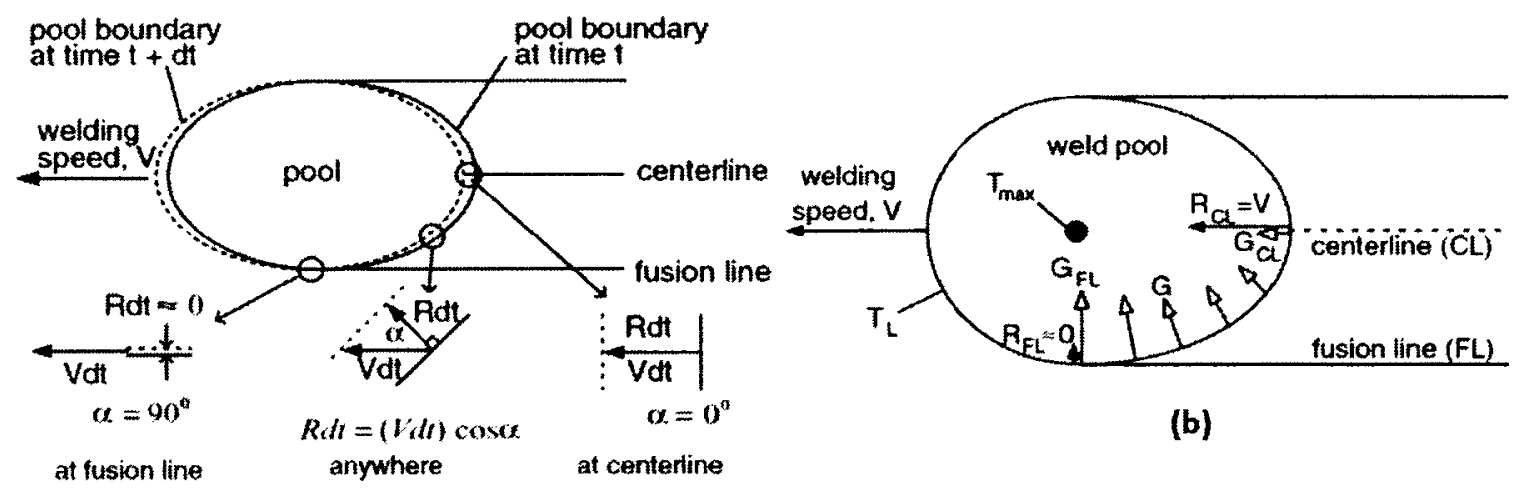

(a)

Figure 2.28: The variation of (a) growth rate and (b) temperature gradient around the weld pool. [7]

Equation 2.19 shows that the ratio $G / R$ is maximum at the fusion line and continues to decrease until reaching its minimum value at the centerline. Therefore, the solidification mode might change across the fusion zone as seen in Figure 2.29. 


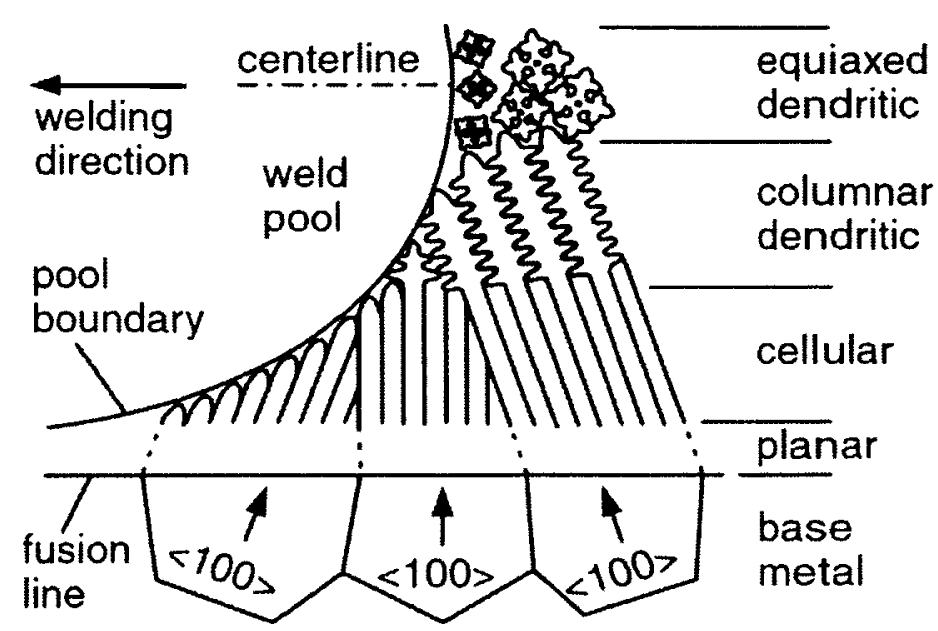

Figure 2.29: The variation of solidification mode within the weld pool. [7]

\subsubsection{Controlling Fusion Zone Microstructure.}

Four mechanisms, imported from casting technology, can be used to refine the size of grains in a fusion zone. These mechanisms are dendrites fragmentation, grains detachment, heterogeneous nucleation, and surface nucleation [6,7], and they are shown in Figure 2.30.
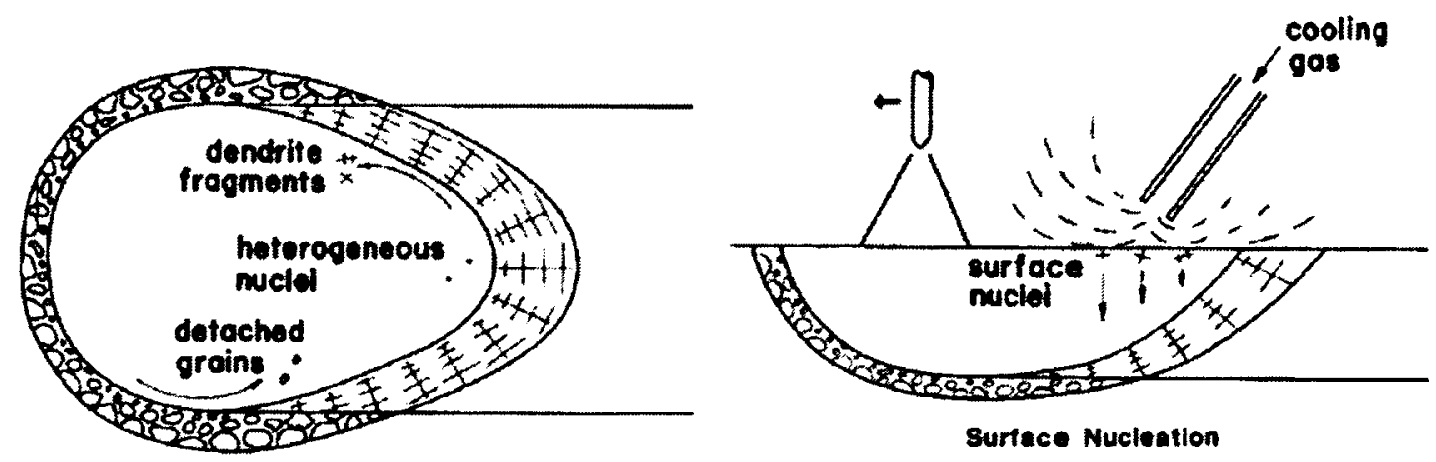

Figure 2.30: Fusion zone microstructure refining mechanisms. [7] 
Dendrite fragmentation happens when the tips of dendrite are broken into pieces within the weld pool. Then, if any fragment survives the weld pool temperature, it will act as a heterogeneous nucleus and form new grain. The possible cause of the fragmentation processes is weld pool convection which could cause remelting, friction forces of fluid flow, impact with any particles in the convective flow, as well as weld pool stirring. Incidentally, this mechanism is assumed to be refining mechanism for weld metals without proof.

The second refining mechanism is grains detachment. In this case, grains can be detached from a partially melted zone and transported, by weld pool convection, to a fusion zone. By the same way as dendrite fragmentation, if the detached grains survives the weld pool temperature, it can act as nuclei for new grains. The third mechanism, heterogeneous nucleation, is similar to the grain detachment mechanism, but the presence of solid particles comes from other sources such as tungsten rod, flux, dust, or nucleation agents "inoculation".

The last refining mechanism is surface nucleation. If the weld pool is exposed to a cooling stream (e.g. inert gas), then the surface of the weld pool can be undercooled thermally; thus, new nuclei can form on that surface. Consequently, if nucleation conditions are available, the nuclei will grow and form new grains.

In short, dendrites fragmentation, grains detachment, heterogeneous nucleation, and surface nucleation are four mechanisms that influence the nucleation process. In addition, they can be used to refine the welds microstructure to improve mechanical properties. The mentioned refining techniques can be gained by adding nucleation agents, arc 
oscillation, arc pulsation, mechanical stirring of the liquid pool, and ultrasonic vibration of the liquid metal.

\subsubsection{Studying the Solidification Microstructure}

In order to achieve the optimum microstructures of materials during solidification, we have to study and control their evolutions under given processing conditions such as temperature, cooling rate, and composition. Because the details of dendrite morphology (for example primary dendrite arm spacing, secondary arm spacing, and microsegregation patterns) are affected by the process conditions and have a strong link with the mechanical properties of the final products; therefore, many experimental and theoretical works have been carried out to characterize dendritic growth behavior.

A simple technique was demonstrated by Kou [15] to reveal the microstructural development, microsegregation, and nucleation mechanisms during welding. This technique was performed by quenching the weld pool and its surrounding area with liquid tin or water. A more recent technique, namely in-situ X-ray diffraction, provides an advanced tool for studying phase transformations during welding. The quenching can be used for studying microsegregation and nucleation mechanisms as well as phase transformations. Theoretical modeling for dendrites growth is explained in section 2.7.12.

Increasing the computational power has led to extensive development of numerical methods. Therefore, numerical simulation becomes a powerful tool for studying microstructure formation during the solidification process. Various models for simulating

dendrite formation such as the Front Tracking model, Monte Carlo method, Phase Field model (section 2.7.14), and the Cellular Automaton model have been used $[16,17,18]$. 
Von Neumann introduced the concept of cellular automata in the late 1940's. "Cellular automata are synchronous algorithms that describe the discrete spatial and temporal evolution of complex systems by applying local (or sometimes mid-range) deterministic or probabilistic transformation rules to lattice cells with local connectivity" [16]. Early applications of cellular automaton were in fluid dynamics, biological processes, and reaction-diffusion systems. In addition, cellular automata took place in the field of microstructure simulation. The typical applications of cellular automata for materials simulation include recrystallization, grain growth, dendritic growth, and phase transformation phenomena [16].

The first CA model to simulate the dendrite growth was developed by Packard [19]. It took into account the effects of local solid/liquid interface curvature. Later, the model was modified to simulate qualitatively both columnar and equiaxed 2D dendritic growth, coupled growth phenomena, and the relationship between dendrite tip growth velocity and liquid supercooling.

Some earlier researches had been done to investigate the influence of undercooling on the dendrites growth rate. After that some other researches attempted to predict the influences of temperature gradient, radius of curvature, and alloy composition on the growth rate [20]. In the last decade several papers have been published on the use of $2 \mathrm{D}$ and 3D cellular automata for simulating solidification.

In 1993, Rappaz and Gandin proposed a CA model to simulate grain growth by assuming a uniform temperature field. The following year (1994), Gandin and Rappaz simulated grain structures by coupling the CA method with a finite element (FE) solver for the heat 
flow (CA-FE) [21]. That was the first fully coupled finite element-cellular automaton (CA-FE) model. They presented a new algorithm based on a $2 \mathrm{D}$ cellular automaton for the simulation of dendritic grain formation during solidification. The temperature calculation was based on finite element method. The model took into account heterogeneous nucleation and growth kinetics. The model was applied to simulate the columnar-to-equiaxed transition according to the solidification process. The results were verified with solidification experiments of an organic alloy.

Work by Spittle et al. investigated the relationship between the tip growth velocity and the melt undercooling [22]. They used the $2 \mathrm{D}$ cellular automaton non-isothermal model for their study. The model was simple where it involved only the thermal diffusion and the interface capillarity. A regular $2 \mathrm{D}$ square lattice used to simulate the space. The model assumed nine solidified cells as a nucleus. They fitted their results into $\mathrm{V} \propto \Delta \mathrm{T}^{\mathrm{b}}$ form where the exponent $b$ is associated with the interfacial energy. Finally, they proposed that cellular automata modeling gives a reasonable simulation of the factors governing the evolution of a dendrite under conditions of steady-state free growth. Spittle and Brown, in 1995, simulated microstructure formation by coupling the CA method with a finite difference (FD) solver for solute transfer (CA-FD). They considered the solute redistribution during the solidification of melt, as a result the dendrite morphology was first predicted.

Another attempt to simulate the dendrite structure by using cellular automaton was introduced by Artemev and Goldak [23]. They used a 2D square lattice model to present the space. Three possible cases are assumed for each cell: completely solid, completely 
liquid, and partially solidified. The transition rule, when a cell starts to solidify, stated that crystallization can occur in a cell that has a fraction of solid or it has at least one completely solidified neighbor cell. The model is based on the kinetic equation involving the alloying composition and interface curvature. The model solved the solute diffusion equation by using explicit finite difference method to predict the solute concentration in the liquid phase. The simulation was carried out on $\mathrm{Al} \mathrm{Si}$ alloy with various initial compositions. They obtained typical dendrite morphology with a stable dendrite tip shape. In addition, they obtained the liquid solute concentration around the solid phase. The predicted growth velocity, dendrite tip radius, and tip velocity showed good values compared with the analytical model. Finally, they concluded that the cellular model is an effective tool for dendrite growth simulation for both alloys and pure metals.

Another study was conducted to simulate the growth of 2D free dendrites [24]. The study presented a computer simulation model that can visualize the growth of thermal dendrites in two dimensions by using cellular automaton. The model provided a capability of remelting in order to investigate the process of side-branch development and coarsening during dendrite growth. The study used an indicator "specific surface area" defined as a perimeter/unit area of the side branches to evaluate the side branch evolution process with time. They found that the maximum specific surface area achieved is higher for higher undercoolings.

A 2D model based on cellular automaton method is developed to simulate dendrite growth at the edge of weld molten pool [25]. The growing morphology of the columnar dendritic grains is simulated with various cooling rates and various numbers of seeds. In 
addition, the growth of secondary and tertiary dendrite arms and their competitive growth are also simulated. The results showed that as the cooling rate increases, the growing speed increases obviously. Moreover, the tendency of competitive growth in low cooling rate conditions is stronger than the one in high cooling rate conditions. It is concluded that the cellular automaton method can be used to simulate the grain growth in weld a molten weld pool.

As computational power has been increased, the attempts to simulate the growth of dendrites by using 3D cellular automaton have been performed. A study was proposed to investigate the relationship between the undercooling and the dendrites growth morphology [20]. The study was performed to simulate the growth of free dendrites in a $3 \mathrm{D}$ domain by and various values of undercooling. The results of the model showed a good agreement with earlier experimental results. The authors conclude that it is possible to simulate the growth of highly complex 3-D dendritic morphologies that exhibit many of the features observed in real dendrites by using CA.

The $2 \mathrm{D}$ model mentioned in [23] was extended by M. Martinez and A. Artemev to simulate 3D dendrite growth [26]. The 3D model developed to simulate the casting process of tertiary alloys under isothermal condition. The effects of curvature undercooling, kinetic undercooling, solute undercooling, and anisotropy were considered. The author presented a relationship between the mesh size and dendrite's tip radius. In addition, the model was verified with the analytical solution of tip radius and growth velocity and showed a good agreement. 
A 3D cellular automaton model was coupled in [27] to finite element method (CA-FE) to predict the grain structures of a cast. The model is fully coupled with FE to compute the heat flow. In addition, the ability to track the development of dendritic and eutectic grains structure was introduced. The CA-FE model was tested on an Al-7 wt\% Si cylindrical ingot and compared with experiment results. Finally, the model was used to predict the columnar-to-equiaxed transition in an $\mathrm{Al}-7 \mathrm{wt} \% \mathrm{Si}$ ingot.

Simulation of dendrites growth for multi-component alloys is developed by using a 3D cellular automaton model [28]. The velocity of the solid/liquid (S/L) interface is calculated using the solute conservation relationship at the $\mathrm{S} / \mathrm{L}$ interface. The model is first validated by comparison with the theoretical predictions for binary and ternary alloys. Then, the calculated results of secondary dendrite arm spacing were in good agreement with the experimental results.

A modified 3D cellular automaton model was developed for simulating the dendrite morphology of cubic system alloys [29]. The model was applied to simulate the competitive growth of columnar dendrites with different preferred growth orientations under constant temperature gradient. The results of simulation were compared with the results of a transparent alloy solidification. It was found that the primary dendrite arms spacing were affected by initial seed numbers. In addition, it was also found that the crystal orientation parallel to heat flow direction can overgrow the misaligned one. The study proposed that the cellular automaton model is reliable for simulating the 3-D dendrite growth. 
In a recent research [30], a model based on cellular automaton method was developed to study the morphology and micro segregation of free and constrainted dendrite for multicomponents alloys. The model was used to investigate the influence of cooling rate on the secondary dendrite arm spacing and micro segregation.

A recent research presented a coupled two-dimensional CA-FD model to quantitatively predict the dendritic growth in an undercooled melt by using cellular automaton [31]. The model used to simulate the growth of free "equiaxed" and constrained "columnar" dendrites. The results showed that the predicted steady state tip velocity is in reasonable agreement with the analytical value of Lipton-Glicksman-Kurz analytical model. The model was able to simulate the single dendritic growth, the multi-dendritic growth, and the competitive dendritic growth. In addition, the dendritic growth features, such as crystallographic orientation, dendrite arm growing and coarsening, side branching, and arms fusion were graphically revealed.

A study was done to investigate the effect of fluid convection on the growth of free dendrite [32]. The authors coupled a $2 \mathrm{D}$ cellular automaton model with the momentum and mass conservation equations in liquid, solid and solid/liquid interface. They concluded that melt convection produces asymmetrical dendrite and accelerates the overall average solidification velocity because it promotes solute transport in the melt. The results were verified with experimental observations and phase-field simulation.

The simulation of grain morphologies in the weld pool of $\mathrm{Ni}-\mathrm{Cr}$ alloy are simulated using cellular automaton model based on finite difference method (CA-FD) [33]. The model was used to simulate the competitive growth process between columnar grain and 
equiaxed grain in a two-dimension zone of the weld pool. It is indicated that the grain boundary segregations in the weld become more severe when there is competitive growth between columnar grains and equiaxed grains. In addition, the more complicated the thermal field, the more complex grain morphologies of the weld pool. The study concluded that CA-FD model is effective to simulate grain morphologies evolution in the weld pool of $\mathrm{Ni}-\mathrm{Cr}$ alloy.

Pavlyk and Dilthey used CA-FD model to simulate the microstructure of weld pool [34]. The calculations of solidification conditions during fusion welding such as temperature gradient, local solidification rate, and weld pool shape are carried out with a numerical finite element modeling. The simulation results were compared with the experimental results.

\subsubsection{Analytical Model of Diffusion Limited Dendrite Growth}

The simplest approximation of dendrite growth uses a needle-like approximation of dendrite tip region with a cylindrical dendrite body and a hemispherical tip [35]. The model assumes that there is no diffusion flux into solid phase and a steady state growth takes place. The growth occurs by increasing the dendrite length while the cross-section remains constant. While the surface area of the hemispherical cap determines the amount of radial solute diffusion, the dendrite body is responsible for the rejection of solute. Therefore, the diffusion equation of a flux due to solute rejection and one due to diffusion in the liquid ahead of the tip yields to: 


$$
\frac{R \cdot r_{t}}{2 \cdot D_{l}}=\frac{\left(c_{l}^{*}-c_{0}\right)}{c_{l}^{*} \cdot\left(1-k_{d}\right)}
$$

where,

$R$ is the velocity of growth.

$r_{t}$ is the tip radius.

$D_{1}$ is the diffusivity coefficient in liquid.

$\mathrm{c}_{0}$ is the original solute composition.

$c_{1}^{*}$ is the solute composition at the concerning temperature.

$\mathrm{k}_{\mathrm{d}}$ is the segregation coefficient.

The left-hand side of Equation 2.20 demonstrates the characteristics of growth combined into the dimensionless Peclet number $\left(\mathrm{P}_{\mathrm{c}}\right)$. At the same time, the right-side of the equation demonstrates the solidification conditions, and it represents a so-called dimensionless supersaturation $(\Omega)$. Equation 2.20 gives to us the relationship between the velocity of growth (R), dendrite tip radius $\left(r_{t}\right)$ and dimensionless supersaturation of a liquid phase $(\Omega)$. So, if any two of these parameters are known, the third can be calculated. This analytical model has two problems. The first problem is that the shape of the dendrite tip cannot be constant during the growth in radial direction which contrasts with the steady state assumption. The second problem is that even if the Peclet number is known, still it is impossible to determine how much the growth rate and tip radius contributes to it. 


\subsubsection{The Parabolic Model}

A much better and more realistic model of the dendrite tip was introduced by the works of Papapetrou and Ivantsov [35]. They suggested a parabolic shape for the tip of the dendrite because the parabolic shape is consistent with a constant curvature under normal growth conditions. Figure 2.31 shows a dendrite with parabolic tip shape.

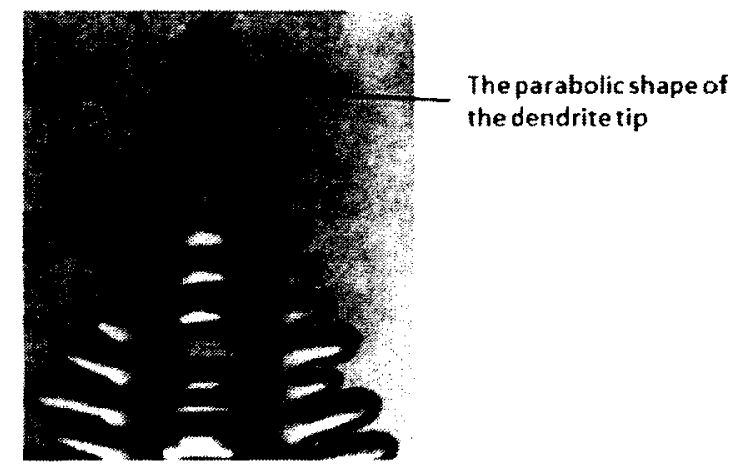

Figure 2.31: Dendrite with a parabolic tip shape. [36]

In this model, the steady state diffusion equation yields an approximate solution obtained by the method of residuals as:

$$
\Omega=\frac{2 \cdot P_{c}}{2 \cdot P_{c}+1}
$$

This equation gives us the relationship between the solute supersaturation, crystallization velocity and dendrite tip radius. The exact solution for the paraboloid of revolution has the form:

$$
\Omega=I\left(P_{c}\right)=P_{c} \cdot e^{P_{c}} \int_{P_{c}}^{\infty} \frac{e^{-s}}{s} d s
$$


Where $I\left(P_{c}\right)$ is the Ivantsov function which can also be represented in the continued fraction form as follows:

$$
I\left(P_{c}\right)=\frac{P_{c}}{P_{c}+\frac{1}{1+\frac{1}{P_{c}+\frac{2}{1+\frac{2}{P_{c}+\ldots}}}}}
$$

If the continued fraction is limited to the zero order term, then the same approximation of the hemispherical shape model is obtained for $\Omega\left(P_{c}\right)$. In the same way, if the continued fraction is truncated at the second order terms, that gives the same approximation as a solution of the parabolic growth problem obtained by the method of residuals.

The obtained estimation of $\Omega\left(P_{c}\right)$ for a parabolic shape can give us only the coupled value of $\left(R \cdot r_{t}\right)$ as function of the dimensionless supersaturation. Therefore, it is necessary to obtain the value of one of them from some external data or using additional assumptions. Thus, it is considered there is a dependence between the growth velocity and the radius of dendrite tip for a fixed value of the dimensionless supersaturation. By using the criterion of marginal stability, which states that a unique tip radius is corresponding to definite supercooling conditions, and substituting it into the supercooling balance equation we can get the dependence of the growth rate on the supercooling (or supersaturation).

The supersaturation balance equation in solutal dimensionless units can be expressed as follows:

$$
\Omega_{0}=\Omega_{C}+\Omega_{T}+\Omega_{R}+\Omega_{K}
$$


where,

$\Omega_{\mathrm{C}}$ is the supersaturation that presents the compositional undercooling.

$\Omega_{\mathrm{T}}$ is the supersaturation that presents the thermal undercooling.

$\Omega_{R}$ is the supersaturation that presents the capillarity undercooling.

$\Omega_{\mathrm{K}}$ is the supersaturation that presents the kinetic undercooling.

By solving the previous equation for Peclet number the growth rate (v) can be obtained as follows:

$$
v=2 \cdot P_{C} \cdot \xi\left\{\left[\frac{\Theta}{|m| \cdot \Delta C_{0}}\right] \cdot\left(\frac{P_{C}}{\eta}\right)+2 \cdot P_{c} \cdot C_{0} \cdot p \cdot A\left(P_{C}\right)\right\}
$$

The tip's radius $\left(r_{t}\right)$ can be calculated by using Peclet number as follows:

$$
P_{C}=\frac{r_{t} \cdot v}{2}
$$

\subsubsection{Phase-Field Method}

The first step for a phase-field model is to postulate a function of space and time coordinates $x$ and $t, \emptyset(x, t)$. This function is called a phase-field which indicates by its value whether the material's phase is solid or liquid. Commonly, $\emptyset=-1$ is used to indicate solid, and $\emptyset=+1$ is used to indicate liquid. Because the function of a phase-field is continuous, the interfaces constitute a continuous transition in the value of $\emptyset(x, t)$ between -1 and +1 and so are attributed a finite thickness. A free-energy functional $(F)$ is constructed for the region, denoted by (V), to be considered. Specifically (F) has the next form: 


$$
F=\int_{V}\left[0.5 \cdot \epsilon^{2}|\nabla \emptyset|^{2}+f(\emptyset, T)\right] d V
$$

where $(\epsilon)$ is a function of interface orientation and $(T)$ is temperature. Two terms contribute to the value of free-energy as shown in the previous equation. The first term is the quantity of $f(\emptyset, T)$ that constitutes the free-energy density due to a state in which phi is everywhere constant. For example, $\mathrm{f}(+1, \mathrm{~T})$ represents that of the system everywhere in the liquid phase. The second term, gradient energy term, recognizes the increase in free-energy associated with the formation of an interface. An interface is represented by $\emptyset$ continuously taking intermediate values at which the free-energy density is increased compared with solid or liquid states. To obtain a partial differential equation for the evolution of $\emptyset$ we require that $(F)$ decreases in time and so specify:

$$
\frac{\partial \emptyset}{\partial t}=-M \frac{\delta F}{\delta \emptyset}
$$

Where $\mathrm{M}$ is a positive constant. Evaluating the variational derivative gives:

$$
\frac{\partial \emptyset}{\partial t}=M\left[\epsilon^{2} \nabla^{2} \emptyset-f_{\emptyset}(\emptyset, T)\right]
$$

Langer and Caginalp developed a corresponding equation for the temperature by employing a modified heat equation as follows:

$$
\lambda \nabla^{2} T=c \cdot p \frac{\partial T}{\partial t}+\frac{L}{2} \frac{\partial \emptyset}{\partial t}
$$


Where:

$\lambda$ is the thermal conductivity.

c is the heat capacity.

$\mathbf{p}$ is the density.

$\mathbf{L}$ is the latent heat per unit volume.

Equation 2.28 and Equation 2.29 comprise the phase-field equations. Various choices are proposed for $f(\emptyset, T)$, Langer and Caginalp proposed [37]:

$$
f(\emptyset, T)=\frac{\left(\emptyset^{2}-1\right)^{2}}{16 a}+\alpha\left(T-T_{M}\right) \emptyset
$$

Other choices for the free energy density $f(\emptyset, T)$ have been suggested by other investigators. The phase-field method has been successfully applied to solidification, solid-state phase transformations, coarsening and growth, and many others applications. This method is computationally intensive especially for 3D modeling, which limits its implementations. 


\section{Chapter 3}

\section{The Simulation of Dendrites Growth}

This chapter describes how the model simulates the dendrites growth during solidification by using cellular automaton. The model is developed to simulate the growth of 3D dendrites for a multi components material. First, the chapter explains how a small control volume of a fusion zone is geometrically presented. Then the chapter presents the analytical equations that can describe the evolution of phase field. It also describes how the finite difference method is used for the solution of the mass transport equation and analysis of solute redistribution effects. Moreover, the chapter explains how to calculate the curvature of the solid/liquid interface to determine the velocity of the advancing solid interface at each cell. Because the welding process is a transient process, the temperature varies with time. Thus, how the temperature values vary with time is described. Finally, the algorithm of the developed programme to simulate dendrites growth by $\mathrm{CA}$ is explained.

\subsection{Cellular Automata Method}

In general, the CA method consists of four basic steps. The first step is to divide a space into cubic cells in the 3-dimensional cases. In the second step, state variables are assigned for each cell. The state variable can be a single Boolean value, 0 and 1 , or in more complex cases it can be any numerical value. The third step is to define the neighbor cells 
for each cell in the space. Two common types of neighbor cells definition can be used: von Neumann and Moore environment. In von Neumann environment cell's neighbors are the six-nearest cells, but in Moore's environment the next-nearest cells are also involved. The final step in $\mathrm{CA}$ is to define a transition rule(s), which computes the new state of a cell by considering its current state and the state of its neighbor cells. The CA simulation proceeds by breaking the simulation time into small time steps, and the calculations will be done at each time step for all cells. Although CA steps are straight forward and simple, linking CA to a physical problem is the challenge.

\subsection{The Geometrical Modeling of Fusion Zone}

Nowadays, simulating the dendrite growth for the entire fusion zone by $\mathrm{CA}$ is impossible because of the limitation of available computational power. Therefore, a finite control volume of the fusion zone just above the substrate surface is considered. The control volume has a rectangular shape. As mentioned earlier, the space in CA is divided into small cubic cells; thus, the control volume is divided into small cells. In our model, all cells have the same size where the cell's length along $x$-axis, $y$-axis, and z-axis is equal to $\Delta x, \Delta y$, and $\Delta z$ respectively. Figure 3.1 shows how the fusion zone is modeled. The overall size of the control volume used in the simulation was 80 cells along $\mathrm{x}$-axis, 80 cells along the $y$-axis, and 120 cells along the $z$-axis. Although increasing the number of cells gives more accurate results, that needs more computational power. Because of that, studying microstructure evolution is restricted by the available computational power. 


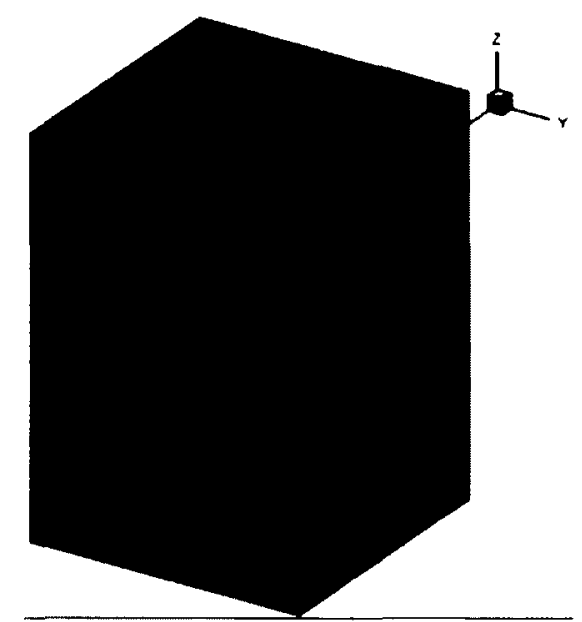

Figure 3.1: The meshed control volume, showing all cells.

In this study, two computer programmes are developed using $\mathrm{C}++$ to simulate the dendrites growth. The first programme is named Initial-phase producer. The aim of this programme is to produce the initial fields values that represent the control volume. Four state variables are assigned for each cell in the control volume. The first state variable presents the volume fraction of the liquid phase inside each cell, namely phase-field. The concentrations of the first and second alloy are the second and third state variable. Finally, the last field value is the temperatures of the cells. In the initial field values, produced by Initial-phase producer programme, all cells in the first layer of the control volume are assumed to be completely solid, which means their phase-field values equal to one. In addition, a small nucleus is created just above the first layer. The volumetric size of the initial nucleus is equal to 35 cells, distributed within three layers of control volume in a pyramid shape, see Figure 3.2. The value of initial solutes concentration is determined by the user and assigned by the programme to each cell in the control volume. The second programme is Phase-evolution which simulates the dendrite growth. The 
algorithm and description of Phase-evolution programme is explained at the end of this chapter.

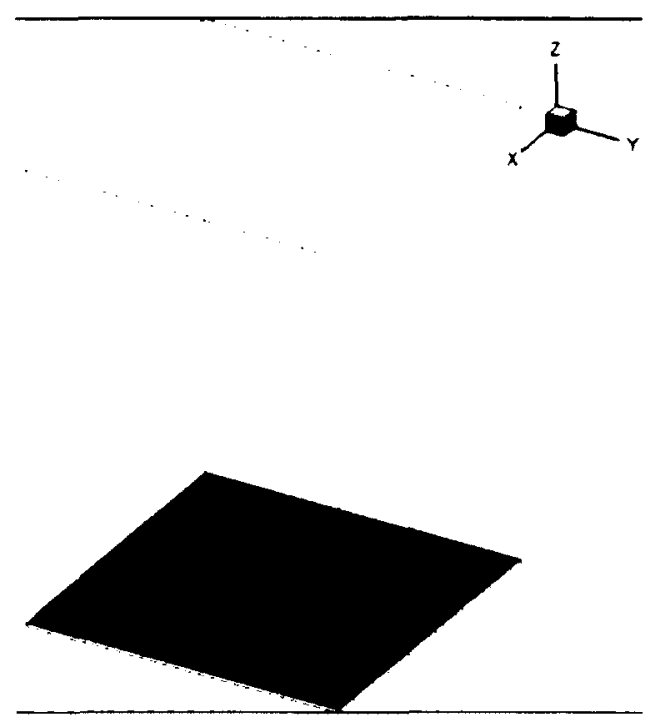

Figure 3.2: The initial phase field with a middle nucleus.

\subsection{Material Modeling}

Our model is designed to simulate a three component alloy. Aluminum-silicon-copper (Al-Si-Cu) alloy is used in this study. The initial concentration of the first and second alloying components $(\mathrm{Si}, \mathrm{Cu})$ are input parameters. The concentration of the third element, Aluminum in our case, is obtained from the fact that in each cell the sum of all element concentration is equal to $100 \%$. The required material properties for simulation are listed in the next table. 


\begin{tabular}{|l|c|}
\hline \multicolumn{1}{|c|}{ Parameters } & Unit \\
\hline Kinetic coefficient & $0.1\left(\frac{m}{s \cdot K}\right)$ \\
\hline Diffusion constant liquid host & $3 e^{-9}\left(\frac{m^{2}}{s}\right)$ \\
\hline Diffusion constant liquid element I & $3 e^{-9}\left(\frac{m^{2}}{s}\right)$ \\
\hline Diffusion constant liquid element 2 & $3 e^{-9}\left(\frac{m^{2}}{s}\right)$ \\
\hline Gibbs Thomson coefficient & $2 e^{-7}(m \cdot k)$ \\
\hline Liquid slope of element I (K/\%wt use negative sign convention) & $-6 \frac{K}{\% w t}$ \\
\hline Liquid slope of element 2 (K/\%wt use negative sign convention) & $-3 \frac{K}{\% w t}$ \\
\hline Solidus slope of element 1 (K/\%wt use negative sign convention) & $-50 \frac{K}{\% w t}$ \\
\hline Solidus slope of element 2 (K/\%wt use negative sign convention) & $-20 \frac{K}{\% w t}$ \\
\hline Segregation coefficient & 0.13 \\
\hline
\end{tabular}

All input parameters of simulation (e.g. material properties, temperature profile, solute initial concentration, and simulation options) are input parameters to Initial-phase producer programme. The output is a text file "phasein.txt" that contains all simulation parameters and the values of the initial phase field as shown in Figure 3.3. 


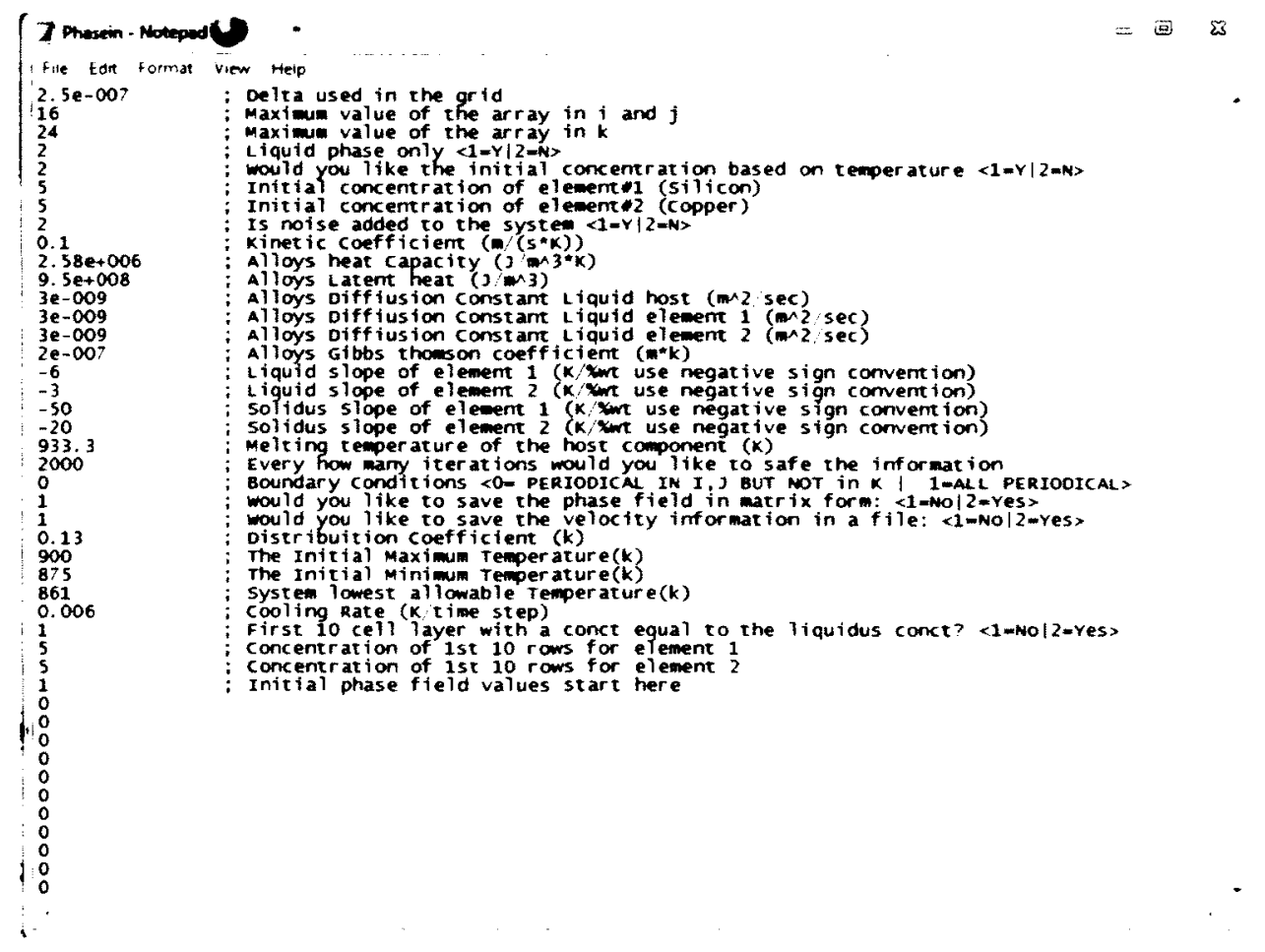

Figure 3.3: A sample of "phasein.txt" input file.

\subsection{Phase Field Calculation}

The phase field $(f)$ in each cell is considered a state variable as required by CA method. In liquid cells the value of the phase field is equal to zero, and the value of the phase field in solid cells is equal to one. The value of the phase field in any cell will be between zero and one if the cell is solidifying $(0<f<1)$. As a transition rule, the solidification can take place in cells with $0<f<1$ or in cells with $f=0$ having at least one neighbor cell with $f$ equal to one [26]. The movement of the solid/liquid interface within a cell is considered planer because the size of cells is smaller than the curvature of the interface and the length of diffusion layer [23]. Therefore, the change of the phase field parameter in a cell can be calculated by the next equation: 


$$
\Delta f_{i j k}^{l}=f_{i j k}^{l+1}-f_{i j k}^{l}=\frac{\Delta t \cdot v_{i j k} \cdot S}{\Delta x \cdot \Delta y \cdot \Delta z}
$$

where,

$S$ is the cross section area of a cell.

$\Delta x, \Delta y$, and $\Delta z$ are the dimensions of a cell in $x, y$, and $z$ axes respectively.

$\Delta t$ is the time step obtained by Fourier number. Equation 3.4

$v_{i j k}$ is the velocity of the movement solid/liquid interface within a cell, which can be calculated by using the next equation.

$$
v_{i j k}=\mu_{k} \cdot\left(T_{m}+C_{i j k_{-} 1}^{l} \cdot m_{1}^{l}+C_{i j k_{-} 2}^{l} \cdot m_{2}^{l}-\Gamma \cdot k_{i j k}-T_{i j k}\right)
$$

where,

$\mathrm{C}_{\mathrm{ijk} \mathrm{k}_{1}}^{\mathrm{l}} \& \mathrm{C}_{\mathrm{ijk} \mathrm{k}_{-}}^{\mathrm{l}}$ are the concentrations of alloying components of a cell whose index is $\mathrm{i}, \mathrm{j}, \mathrm{k}$. $k_{i j k}$ is the curvature of the solid interface of a cell whose index is $i, j, k$. $T_{i j k}$ is the temperature of a cell whose index is $i, j, k$.

The growth of a dendrite from its nucleus is due to mass transport effects at the solid/liquid interface. This mass transport causes the movement of the solid/liquid interface. The factors that affect the phase field value in a cell are the time step, the velocity of solid/liquid interface, and the cell size. 


\subsection{Time Step Calculation According to Stability Criterion}

Because the dendrite growth is a time-dependent problem, a transient numerical analysis is required for simulation. In this model the explicit scheme is used to solve the diffusion equations, so Fourier number is used because it defines the stability criterion. Fourier number is mathematically described as:

$$
F_{o}=\frac{\propto \cdot \tau}{S^{2}}
$$

where,

$S$ is the characteristic dimension of the body.

$\propto$ is the mass diffuisivity.

$\tau$ is the time step.

The Fourier number can relate the time step to the grid size within a numerical mesh if the cells have regular shapes such as sphere, cylinder or cube. For our numerical transient problem, the relationship between the time step and grid size can be determined by the inverse of Fourier number as follows.

$$
M=\frac{\Delta x^{2}}{\alpha \cdot \Delta t}
$$

where,

$M$ is a number equal to or greater than 2 for $1 D$, to 4 for $2 D$ and 8 for $3 D$.

$\propto$ is the mass diffusivity.

$\Delta t$ is the time step. 
The simulation time step is automatically calculated once the grid size and mass diffusivity are determined by the user. The grid size should be equal to or less than the analytical tip radius as calculated by [26]. It can be noted that the calculated time step can impose sever constraints on the modeling process with low undercooling.

\subsection{Velocity of the Solid/Liquid Interface}

The velocity of the solid/liquid is influenced by parameters such as concentration, temperature, and the curvature of the solid/liquid interface. The growth velocity, $v$, can be estimated from the kinetic equation:

$$
v=\mu_{k} \cdot \Delta T_{k}=\mu_{k} \cdot\left(T_{L}^{e}-T^{m}\right)
$$

where,

$\mu_{\mathrm{k}}$ is the kinetic coefficient.

$\Delta T_{k}$ is the kinetic undercooling.

$\mathrm{T}^{\mathrm{m}}$ is the melt temperature.

$\mathrm{T}_{\mathrm{L}}^{e}$ is the equilibrium temperature corresponding to a given cell of the liquid/solid interface.

The equilibrium temperature can be determined as the liquidus at a curved interface by using the next equation:

$$
T_{L}^{e}=T_{m}+C_{1}^{l} \cdot m_{1}^{l}+C_{2}^{l} \cdot m_{2}^{l}-\Gamma \cdot k
$$


where,

$T_{m}$ is the melting temperature of the host component.

$C_{1}^{l}$ is the concentration of the first alloy component.

$C_{2}^{l}$ is the concentration of the second alloy component.

$m_{1}^{l}$ is the liquidus slope of the first alloy component.

$m_{2}^{l}$ is the liquidus slope of the second alloy component.

$k$ is the curvature of solid/liquid interface.

$\Gamma$ is Gibbs-Thomson coefficient.

By substituting Equation 3.6 into the kinetic equation, the velocity of solid interface of any cell in the control volume can be presented by Equation 3.2. The effect of capillary undercooling appears in Equation 3.2 by $\left(\Gamma . \mathrm{k}_{\mathrm{ijk}}\right)$ term. Thus it is required to calculate the curvature of solid/liquid interface at each cell as discussed in section 3.8 . The solute concentration is governed by the transfer of solute mass as explained in the next section.

\subsection{Solute Concentration Calculation}

The solute transfers from regions of high concentration to regions of low concentration within the control volume, which drives the growth of the dendrite from its nucleus. The solute mass transports according to Fick's second law of diffusion is:

$$
\frac{\partial C}{\partial t}=D \cdot \Delta \cdot C
$$

where,

$D$ is the diffusivity of solute.

$\Delta$ is the Laplacian. 
$C$ is the solute concentration.

$t$ is the time.

Every cell in the control volume has a value of liquid $\left(\mathrm{C}^{\prime}\right)$ and solid $\left(\mathrm{C}^{s}\right)$ solute concentration. In this model the diffusion of solute into solid is neglected, for simplicity, since it has a small value. The solution of Fick's second law can be approximated by finite difference scheme to calculate the solute concentration for each cell per time step. The solution can be mathematically expressed as:

$$
\begin{aligned}
\frac{C_{i j k}^{t+1}-C_{i j k}^{t}}{\Delta t}=D & \cdot\left[\left(\frac{C_{i+1, j, k}^{t}+C_{i-1, j, k}^{t}-2 \cdot C_{i, j, k}^{t}}{\Delta x^{2}}\right)+\left(\frac{C_{i, j+1, k}^{t}+C_{i, j-1, k}^{t}-2 \cdot C_{i, j, k}^{t}}{\Delta y^{2}}\right)\right. \\
& \left.+\left(\frac{C_{i, j, k+1}^{t}+C_{i, j, k-1}^{t}-2 \cdot C_{i, j, k}^{t}}{\Delta z^{2}}\right)\right]
\end{aligned}
$$

Equation 3.8 does not include the solute concentration built up in front of the interface because of solute rejection from the solid phase during the movement of solid/liquid interface. Therefore, a new term, excess solute released, is introduced to present the amount of solute rejection. The excess solute rejection can be calculated as follows:

$$
\text { Excess_Solute }=\Delta f_{i j k} \cdot\left(C_{i j k}^{l} \cdot\left(1-k_{d}\right)\right)
$$

The value of the new concentration at any cell depends on the cell's liquid fraction. If the liquid fraction is greater than or equal to zero, the solute concentration in liquid taking into account the concentration due to solute rejection can be calculated as follows: 


$$
\begin{aligned}
& C_{i j k}^{l+1}=C_{i j k}^{l}+\frac{D_{l} \cdot \Delta t}{1-f_{i j k}^{l}} \\
& {\left[\begin{array}{l}
\frac{\left(C_{i+1, j, k}^{l}-C_{i j k}^{l}\right) \cdot \theta\left(1-f_{i+1, j, k}^{l}\right)}{\Delta x^{2}}-\frac{\left(C_{i, j, k}^{l}-C_{i-1, j, k}^{l}\right) \cdot \theta\left(1-f_{i-1, j, k}^{l}\right)}{\Delta x^{2}}+ \\
\frac{\left(C_{i, j+1, k}^{l}-C_{i, k}^{l}\right) \cdot \theta\left(1-f_{i, j+1, k}^{l}\right)}{\Delta y^{2}}-\frac{\left(C_{i, j, k}^{l}-C_{i, j-1, k}^{l}\right) \cdot \theta\left(1-f_{i, j-1, k}^{l}\right)}{\Delta y^{2}}+ \\
\frac{\left(C_{i, j, k+1}^{l}-C_{i j k}^{l}\right) \cdot \theta\left(1-f_{i, j, k+1}^{l}\right)}{\Delta z^{2}}-\frac{\left(C_{i, j, k}^{l}-C_{i, j, k-1}^{l}\right) \cdot \theta\left(1-f_{i, j, k-1}^{l}\right)}{\Delta z^{2}}
\end{array}\right]} \\
& +\frac{\Delta f_{i j k} \cdot\left(c_{i j k}^{l} \cdot\left(1-k_{d}\right)\right)}{1-f_{i j k}^{l}}
\end{aligned}
$$

Where $k_{d}$ is the segregation coefficient where the liquidus and solidus are considered straight lines. The step function $\theta(x)$ is defined as follows:

$$
\theta(x)= \begin{cases}0 & \text { if } x \leq 0 \\ 1 & \text { if } x>0\end{cases}
$$

Step function is imposed in Equation 3.10 to stop the diffusion of solute from liquid into the solid phase. In addition, the solute concentration evolution in the solid phase can also be calculated by Equation 3.10 if the diffusivity coefficient in the liquid $D_{1}$ is replaced by the diffusivity coefficient in the solid $D_{s}$.

In our model, if the fraction of liquid in any cell is greater than or equal to 0.5 , the solute will transfer within the cell itself. When a cell is almost completely solidified (liquid fraction $<0.5)$, the liquid fraction of the cell becomes close to zero which produces arbitrary changes in the concentration. Therefore, in this case, the transfer of solute occurs proportionally to the liquid in the neighboring cells. The neighboring cells are 
chosen according to Von-Neumann's environment where the immediate neighbors that have at least one face in common with the cell are selected.

If the liquid fraction of a cell[i][j][k] is less than 0.5 , the concentration of the cell approaches infinity at the last stage of its solidification. This will cause a large concentration fluctuation. If the change of the phase field in the cell is positive, the excess solute is calculated according to Equation 3.9, then redistributed to the neighboring cells. Each neighboring cell, receives a percentage of the total excess solute calculated for the cell[i][j][k] based on the fraction of liquid remaining in each neighboring cells. In the other case, if the change of the phase field in the cell is negative, this indicates that the cell is melting, impossible in the simulation of welding process.

\subsection{Calculation of the Solid/Liquid Interface Curvature}

The curvature of the solid/liquid interface contributes in the calculation of the Solid/liquid interface velocity as shown in Equation 3.2. The curvature at any cell can be calculated by using its phase field value. However, using the actual values of the phase field produces abrupt changes in the curvature values of all cells, and in hence the calculated curvatures will not present the real curvatures of the solid/liquid interface. In order to resolve this problem, M. Martinez and A. Artemev [26] suggest the use of an average phase field values $\left(\mathrm{G}_{\mathrm{ijk}}\right)$ to calculate the curvatures instead of using the real values, and their method showed a good curvature perspective. 
The average phase field value in each cell is calculated by using weighted-neighbor cells. For a cell whose coordinates are $\mathrm{i}, \mathrm{j}, \mathrm{k}$ there are 26 neighbor cells where each neighbor has a weight factor (Wf) as shown in Figure 3.4. The average phase field of the cell in the middle, according to Figure 3.4 , is equal to:

$$
G_{i j k}=\sum_{\substack{a=i-1, i, i+1 \\ b=j-1, j, j+1 \\ c=k-1, k, k+1}}^{27} W f_{a b c} \cdot f_{a b c} / \sum_{\substack{a=i=1, i, i+1 \\ b=j-1, j, j+1 \\ c=k-1, k, k+1}}^{27} W f_{a b c}
$$

Where $\sum \mathrm{Wf}_{\mathrm{abc}}$ is the summation of all weight factors that equal to 3.9 .

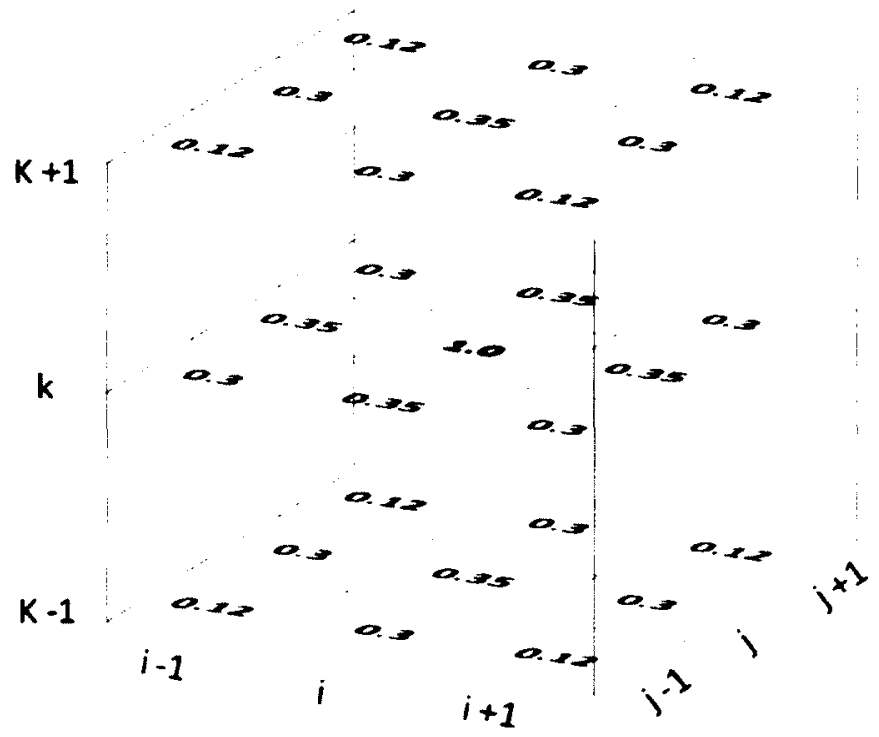

Figure 3.4: Weight factors used to calculate the values of average phase field.

After obtaining the average phase field values, the curvature values can be calculated by using the next mathematical expression:

$$
k_{i j k}=\nabla \cdot\left(\frac{\nabla \cdot G_{i j k}}{\left|\nabla \cdot G_{i j k}\right|}\right)
$$


In the $3 \mathrm{D}$ domain Equation 3.13 can be expanded to the next form:

$$
\left.\begin{array}{l}
k_{i j k} \\
=\frac{G x_{i j k}^{2}\left(G y y_{i j k}+G z z_{i j k}\right)+G y_{i j k}^{2}\left(G x x_{i j k}+G z z_{i j k}\right)+G z_{i j k}^{2}\left(G x x_{i j k}+G y y_{i j k}\right)-}{2\left(G x_{i j k} G y_{i j k} G x y_{i j k}+G x_{i j k} G z_{i j k} G x z_{i j k}+G y_{i j k} G z_{i j k} G y z_{i j k}\right)} \\
\left(G x_{i j k}^{2}+G y_{i j k}^{2}+G z_{i j k}^{2}\right)^{3 / 2}
\end{array}\right)
$$

where,

$[i, j, k]$ is the cell index.

$k_{i j k}$ is the curvature of the cell.

$G x$ is the partial derivative of the average phase field " $G$ " as regards $x$.

$G y$ is the partial derivative of the average phase field " $G$ " as regards $y$.

$G z$ is the partial derivative of the average phase field " $G$ " as regards $z$.

$G x x$ is the second partial derivative of the average phase field " $G$ " as regards $x$.

Gyy is the second partial derivative of the average phase field " $G$ " as regards $y$.

$G z z$ is the second partial derivative of the average phase field " $G$ " as regards $z$.

$G x y$ is the second partial derivative of the average phase field " $G$ " as regards $x$ and $y$.

$G x z$ is the second partial derivative of the average phase field " $G$ " as regards $x$ and $z$.

$G y z$ is the second partial derivative of the average phase field " $G$ " as regards $y$ and $z$.

Curvature is calculated only for cells not completely solid and not completely liquid $(0<$ $f<1$ ). The obtained curvature results will be quite accurate if the simulation is carried out with small cells size; for example, 10 time smaller than the theoretical tip radius estimated by Fisher and Kurz model [35]. 


\subsection{Boundary Condition}

For any cell we need to calculate the values of the phase field, curvature, and concentration. The model uses a finite control volume and solves the equations by using finite difference method. In some cases, if a cell $\left(\right.$ Cell $\left._{i, j, k}\right)$ is located on the end of the control volume "the wall", we need to know the values of a cell that is outside the control volume $\left(\right.$ Cell $\left._{i+1, j, k}\right)$. Therefore, the model uses a periodical boundary condition which means all values of the outside cell are equal to the values of a cell that is located on the opposite side of the control volume $\left(\right.$ Cell $\left._{1, j, k}\right)$, see Figure 3.5 . When computing the values for a cell at the ceiling of the control volume, periodical boundary condition uses the values of two cell layers below the ceiling. Periodical boundary condition physically means that the resultant dendrites structure is repeating itself periodically.

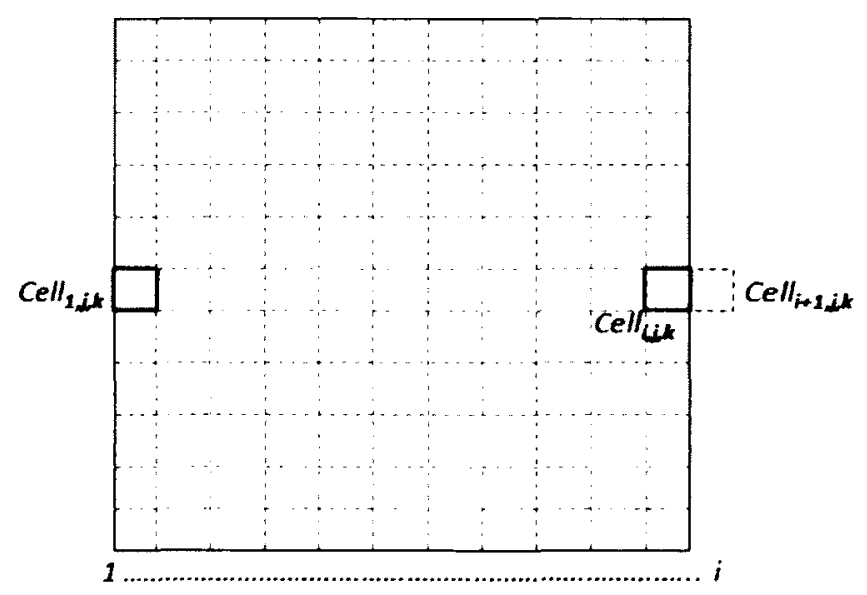

Figure 3.5: Periodical boundary conditions. 


\subsection{Temperature Modeling}

In the welding process, the heat source (e.g. from the torch or electrode) is applied to a workpiece's surface; thus, the heat will transfer by conduction through the workpiece volume. In the control volumes used in simulations the temperature was set to maximum value at the top surface as shown in Figure 3.6 and minimum value at the bottom surface.

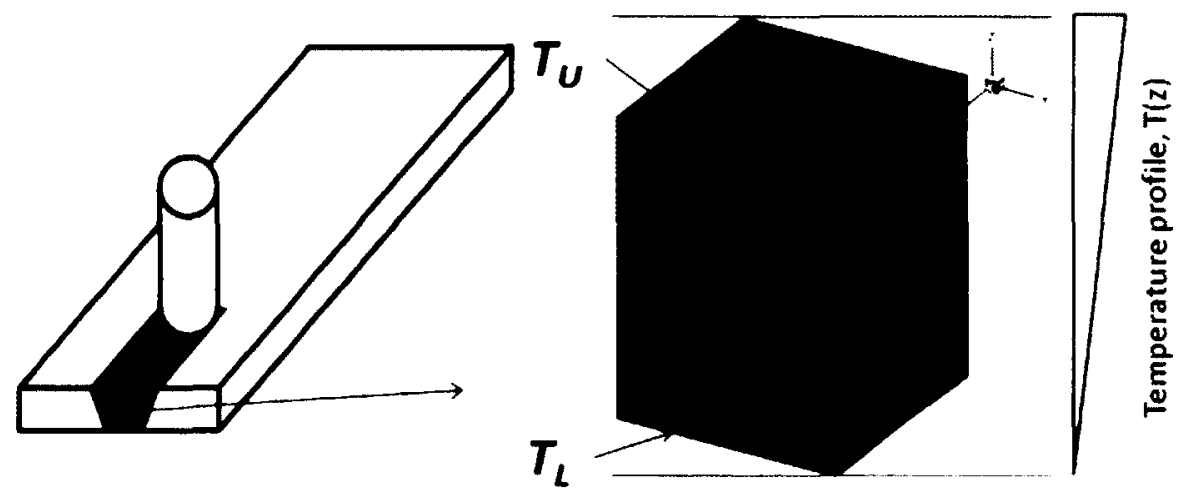

Figure 3.6: The temperature distribution within the control volume.

Our model assumes the temperature is linearly distributed through the control volume. Therefore, by knowing the temperature of the upper surface $\left(T_{U}\right)$ and the lower surface $\left(T_{L}\right)$, the temperature of the entire control volume can be calculated according to a linear equation. Both values $\left(T_{U}, T_{L}\right)$ are user input parameters, so the temperature gradient $(G)$ can be changed according to these two values. The temperature values of control volume are calculated according to the following linear relationship:

$$
T(z)=T_{L}+\frac{T_{U}-T_{L}}{\max \_k} \times z
$$


where:

$T_{U}$ is the temperature of the upper surface of control volume.

$T_{L}$ is the temperature of the lower surface of control volume.

$\mathrm{z}$ is the layer number.

$T(z)$ is the temperature of layer number $z$.

$\max \_\mathrm{k}$ is the number of cells in $z$-direction.

To simulate the welding process, a transit temperature field is imposed. At each time step, the upper and lower temperature $\left(T_{U}, T_{L}\right)$ are decreased by a particular value $(d T)$ according to the next equations:

$$
T_{U}^{t+d t}=T_{U}^{t}-d T \quad \& \quad T_{L}^{t+d t}=T_{L}^{t}-d T
$$

The calculation of temperature distribution according to Equation 3.15 is produced for each time step by using the new values of $\left(T_{U}^{t+d t}, T_{L}^{t+d t}\right)$. If (dT) increases, that causes more drop in temperature values. In other words, increasing of (dT) means increasing of welding speed and vice versa. In our model, the parameter (dT) presents the cooling rate, and it is determined by the user in order to perform a parametric study. 


\subsection{The Algorithm of the Developed Model}

The model is developed to simulate non-isothermal condition. My first contribution was imposing a temperature field across the control volume. The temperature field is determined by two temperature values, defined by user, for the upper surface of the control volume $\left(T_{U}\right)$ and the lower surface $\left(T_{L}\right)$. Thus, the temperature values for each cell in the control volume will be calculated according to a linear distribution. At the same time and in order to add the effect of cooling rate, the value of $T_{U}$ and $T_{L}$ is decreased by a user defined value $(d T)$ at each time step. My second contribution was creation of Initial-phase producer code. The purpose of this code is to generate the initial phase field values and assign the user input parameters to the control volume. Initial-phase producer code is developed with capability of producing many nuclei with different sizes as specified by the user. The need of this modification is to generate different initial solid/liquid interface roughness in order to investigate the effect of the roughness on the evolved microstructures. In addition, Initial-phase producer code produces a complete text file "phasein.txt" which contains all simulation parameters. The "phasein.txt" file is designed in such way that it can be used directly by the main code "Phase_evolution" without any onscreen input. Finally, the code was built as executable file so that the programme can be run by any computer without installation, which eases the uses and increases the reliability of test run.

The calculations of the temperature profile, phase evolution, curvature, solute concentration, and solid/liquid interface velocity are done in separate functions. All parameters for phase field-, concentration-, curvature-, velocity-, and temperature values are stored in matrices. The main body of the programme contains a DO-loop that calls all 
function sequentially at each time step. At the end of every step, the programme will check whether the ending-condition is satisfied. The ending condition is satisfied if any cell in the ninth layer from the top is completely solidified. The algorithm of the developed code is explained next.

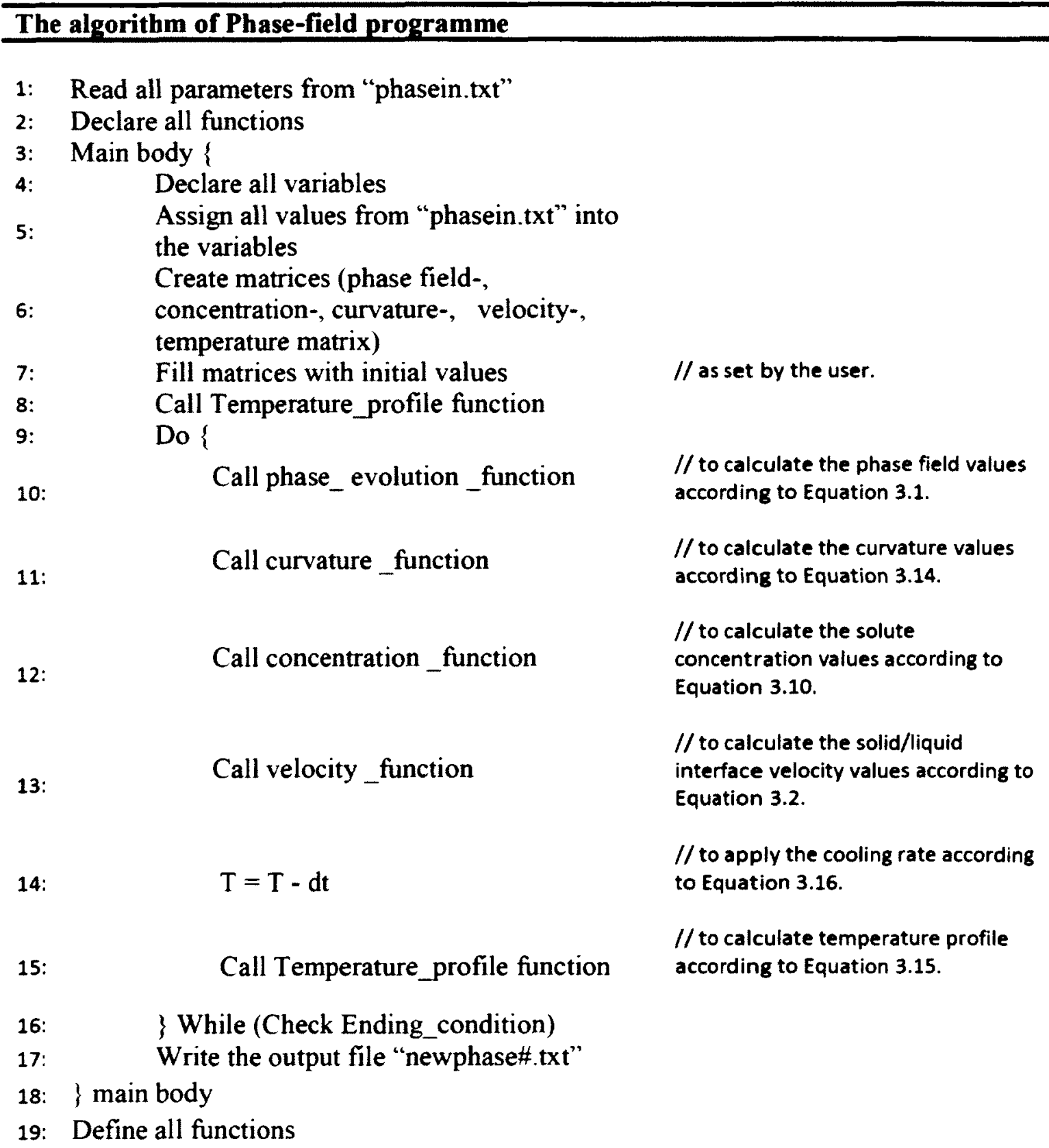




\section{Chapter 4}

\section{The Effect of Solidification Parameters on the Microstructure}

The solidification parameters control the microstructure evolution in the fusion zone. The solidification parameters cannot be controlled directly in fusion welding, but they are governed by the welding parameters: heat input and welding speed. In order to investigate the effects of solidification parameters on the microstructure, we simulate many test runs with various cooling rates and temperature gradient by using our model. The first study was to investigate the influence of solidification parameters on the shape of the microstructure. In the second study, the effect of cooling rate on the density of microstructure was investigated. Moreover, we studied the effect of the initial solid/liquid

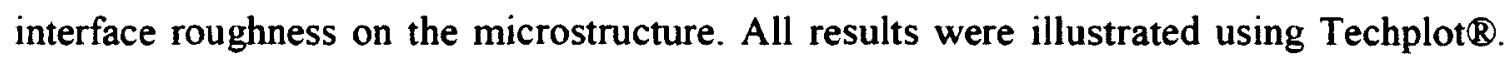
Finally, the adaptation of the developed model for the implicit algorithm based solver capable of modeling of a real welding process is briefly presented.

\subsection{The Effect of Cooling Rate and Temperature Gradient on Microstructure Morphology}

As shown in Figure 3.6 the temperatures within the control volume are specified by the temperature on the upper surface $\left(T_{U}\right)$ and the lower surface $\left(T_{L}\right)$. In this case, the temperature gradient $(\mathrm{G})$ can be calculated as follows: 


$$
G=\frac{d t}{d z}=\frac{T_{U}-T_{L}}{\text { gride hieght } \times \text { number of cells in } z \text { direction }}
$$

The cooling rate is measured in Kelvin per second $(\mathrm{K} / \mathrm{s})$. The first study was carried by using two simulation sets. The grid size was equal to $(\Delta x=\Delta y=\Delta z=0.25 \mu \mathrm{m})$. Each set has sixteen test runs; for the first simulation set the initial temperatures values, the temperature gradient, and the cooling rates are listed next:

- $\left(T_{U}=883 \mathrm{~K}, T_{L}=871 \mathrm{~K}, G=400 \mathrm{~K} / \mathrm{mm}\right)$ with four cooling rates: 1000,3000 , 6000 , and $12000 \mathrm{~K} / \mathrm{s}$.

- $\left(\mathrm{T}_{\mathrm{U}}=905 \mathrm{~K}, \mathrm{~T}_{\mathrm{L}}=881 \mathrm{~K}, \mathrm{G}=800 \mathrm{~K} / \mathrm{mm}\right)$ with four cooling rates: 1000,3000 , 6000 , and $12000 \mathrm{~K} / \mathrm{s}$.

- $\left(\mathrm{T}_{\mathrm{U}}=907 \mathrm{~K}, \mathrm{~T}_{\mathrm{L}}=871 \mathrm{~K}, \mathrm{G}=1200 \mathrm{~K} / \mathrm{mm}\right)$ with four cooling rates: 1000,3000 , 6000 , and $12000 \mathrm{~K} / \mathrm{s}$.

- $\left(\mathrm{T}_{\mathrm{U}}=919 \mathrm{~K}, \mathrm{~T}_{\mathrm{L}}=871 \mathrm{~K}, \mathrm{G}=1600 \mathrm{~K} / \mathrm{mm}\right)$ with four cooling rates: 1000,3000 , 6000 , and $12000 \mathrm{~K} / \mathrm{s}$.

High values of temperature gradients and cooling rates were used to decrease the simulation time. The simulation time of a single test run varies from 24 to 48 hours. The need to use conditions producing a high growth rate arises from the use of an explicit algorithm for the solution of mass transportation equations, which restrict the time step size. 
The resultant microstructures can be grouped into three categories. The first category is presented by dendritic grains as shown in Figure 4.1. The second category is a combination of dendritic and columnar grains as shown in Figure 4.2. The last category consists of only columnar grains (Figure 4.3). Both temperature gradient and cooling rate influence the solidification microstructure in such a way that as the temperature gradient increases, the microstructure changes from dendritic to columnar shape as illustrated in Figure 4.4. The same change in the morphology of solidification structure can be obtained if solidification rate decreases (Figure 4.4).

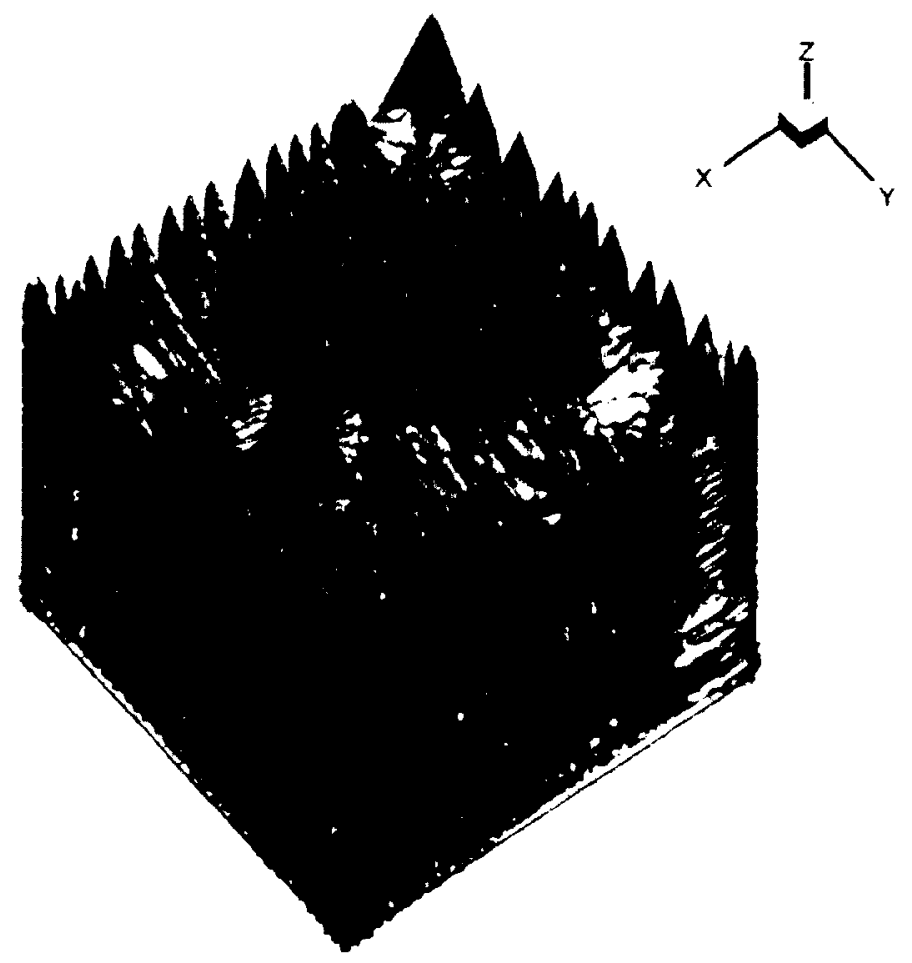

Figure 4.1: Dendritic microstructure (ISO surface presentation). 


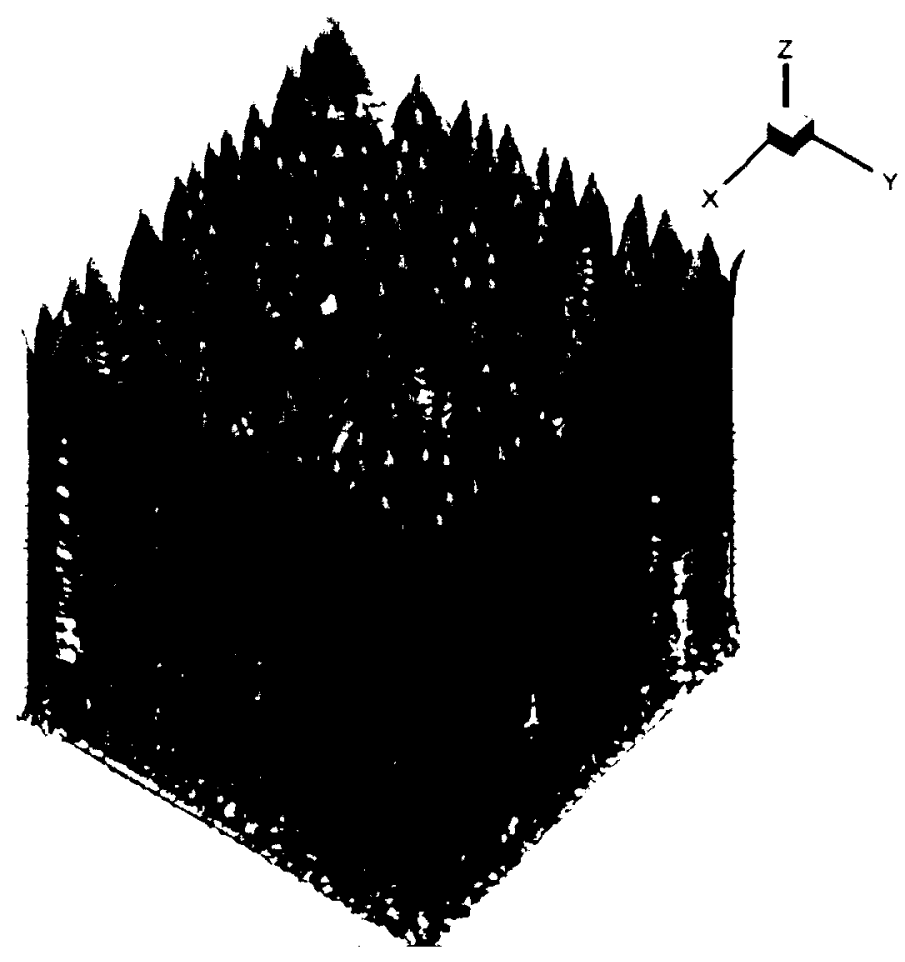

Figure 4.2: Dendritic plus columnar grains (ISO surface presentation).

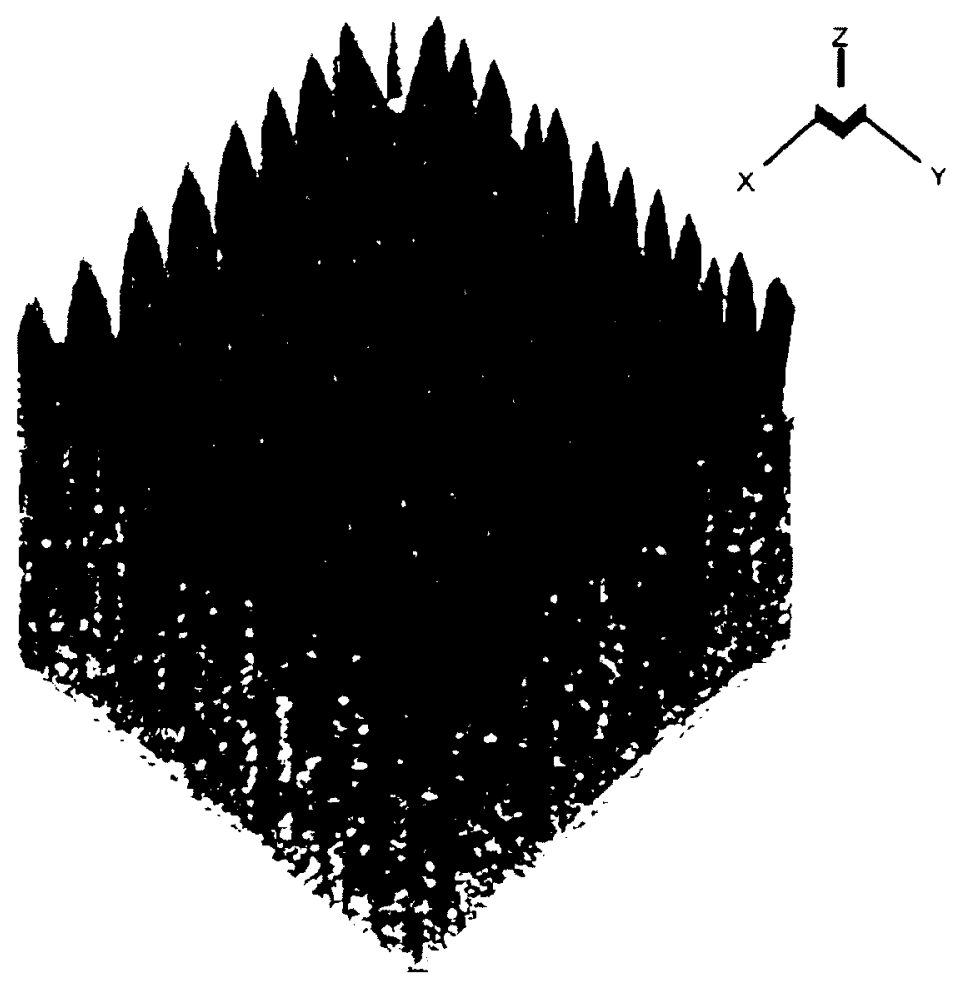

Figure 4.3: Columnar grains (ISO surface presentation). 


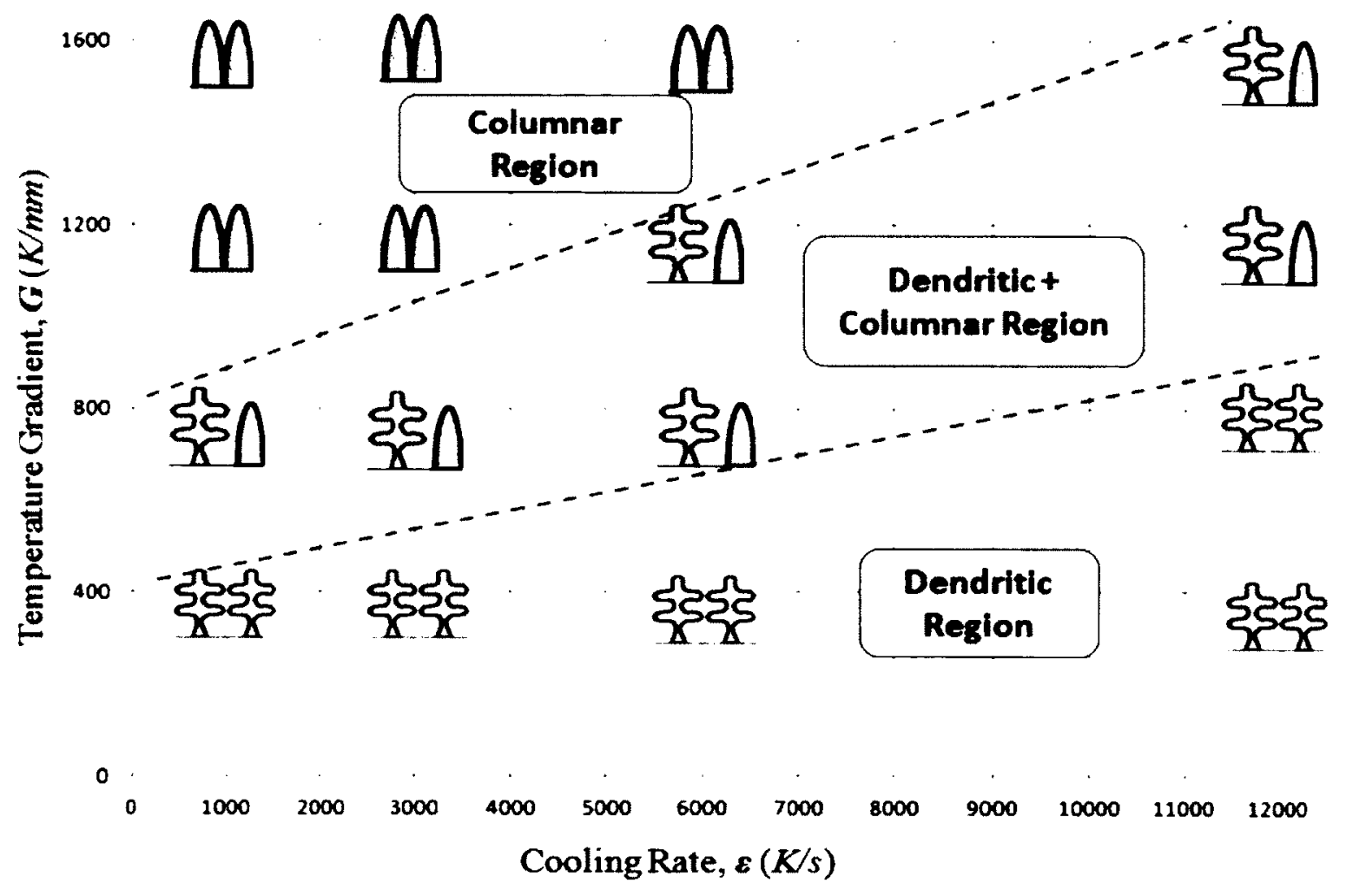

Figure 4.4: The effect of cooling rate and temperature gradient on the microstructure for simulation set one.

The second simulation set was investigated with the same temperature gradients and cooling rates as in simulation set one but with various initial temperatures values. The parameter values of the second set are listed next:

- $\left(\mathrm{T}_{\mathrm{U}}=893 \mathrm{~K}, \mathrm{~T}_{\mathrm{L}}=881 \mathrm{~K}, \mathrm{G}=400 \mathrm{~K} / \mathrm{mm}\right)$ with four cooling rates: 1000,3000 , 6000 , and $12000 \mathrm{~K} / \mathrm{s}$.

- $\left(\mathrm{T}_{\mathrm{U}}=915 \mathrm{~K}, \mathrm{~T}_{\mathrm{L}}=891 \mathrm{~K}, \mathrm{G}=800 \mathrm{~K} / \mathrm{mm}\right)$ with four cooling rates: 1000,3000 , 6000 , and $12000 \mathrm{~K} / \mathrm{s}$.

- $\left(\mathrm{T}_{\mathrm{U}}=917 \mathrm{~K}, \mathrm{~T}_{\mathrm{L}}=881 \mathrm{~K}, \mathrm{G}=1200 \mathrm{~K} / \mathrm{mm}\right)$ with four cooling rates: 1000,3000 , 6000 , and $12000 \mathrm{~K} / \mathrm{s}$. 
- $\left(T_{U}=929 \mathrm{~K}, T_{L}=881 \mathrm{~K}, G=1600 \mathrm{~K} / \mathrm{mm}\right)$ with four cooling rates: 1000,3000 , 6000 , and $12000 \mathrm{~K} / \mathrm{s}$.

The effect of cooling rate and temperature gradient on the microstructure of simulation set two shows the same behavior as set one where the dendritic grains change to columnar grains as the temperature gradient and cooling rate increases, see Figure 4.5.

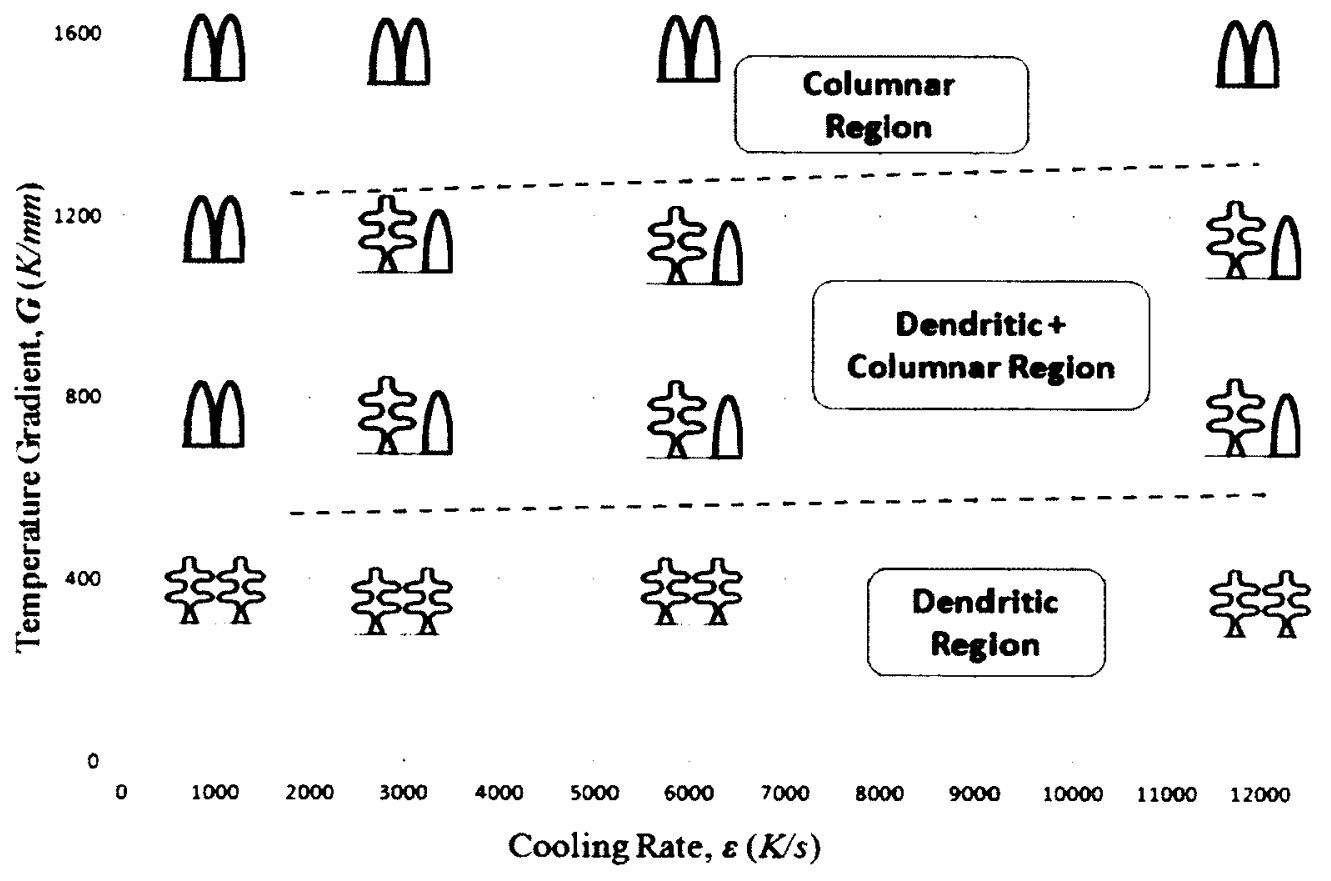

Figure 4.5: The effect of cooling rate and temperature gradient on the microstructure for simulation set two.

Three more simulation sets with low cooling rates and temperature gradients values were produced in this study. The grid size was equal to $(\Delta x=\Delta y=\Delta z=0.0625 \mu \mathrm{m})$ with the next parameters: 
1. Set_l has $\left(T_{U}=870 \mathrm{~K}, T_{L}=869.88 \mathrm{~K}, \mathrm{G}=1.6 \mathrm{~K} / \mathrm{mm}\right)$ with cooling rates: 10 , $100,500,1000 \mathrm{~K} / \mathrm{s}$.

2. Set_2 has $\left(T_{U}=870 K, T_{L}=868.8 K, G=16 K / m m\right)$ with cooling rates: 10,100 , $500,1000 \mathrm{~K} / \mathrm{s}$.

3. Set_3 has $\left(T_{U}=875 \mathrm{~K}, T_{L}=863 \mathrm{~K}, \mathrm{G}=160 \mathrm{~K} / \mathrm{mm}\right)$ with cooling rates: 10,100 , $500,1000 \mathrm{~K} / \mathrm{s}$.

The resultant microstructures obtained in simulation sets 1,2 and 3 are shown in Figure 4.6, Figure 4.7, and Figure 4.8 respectively. The results in Figure 4.6 and Figure 4.7 show that there is one dendrite grain in the middle of the control volume. The dendrite has long branches and sub-branches. These results arise from using small cooling rate and temperature gradient which cause excessive growth of the dendrite. When the temperature gradient increases, many grains appear and the microstructures become denser as shown in Figure 4.8. 


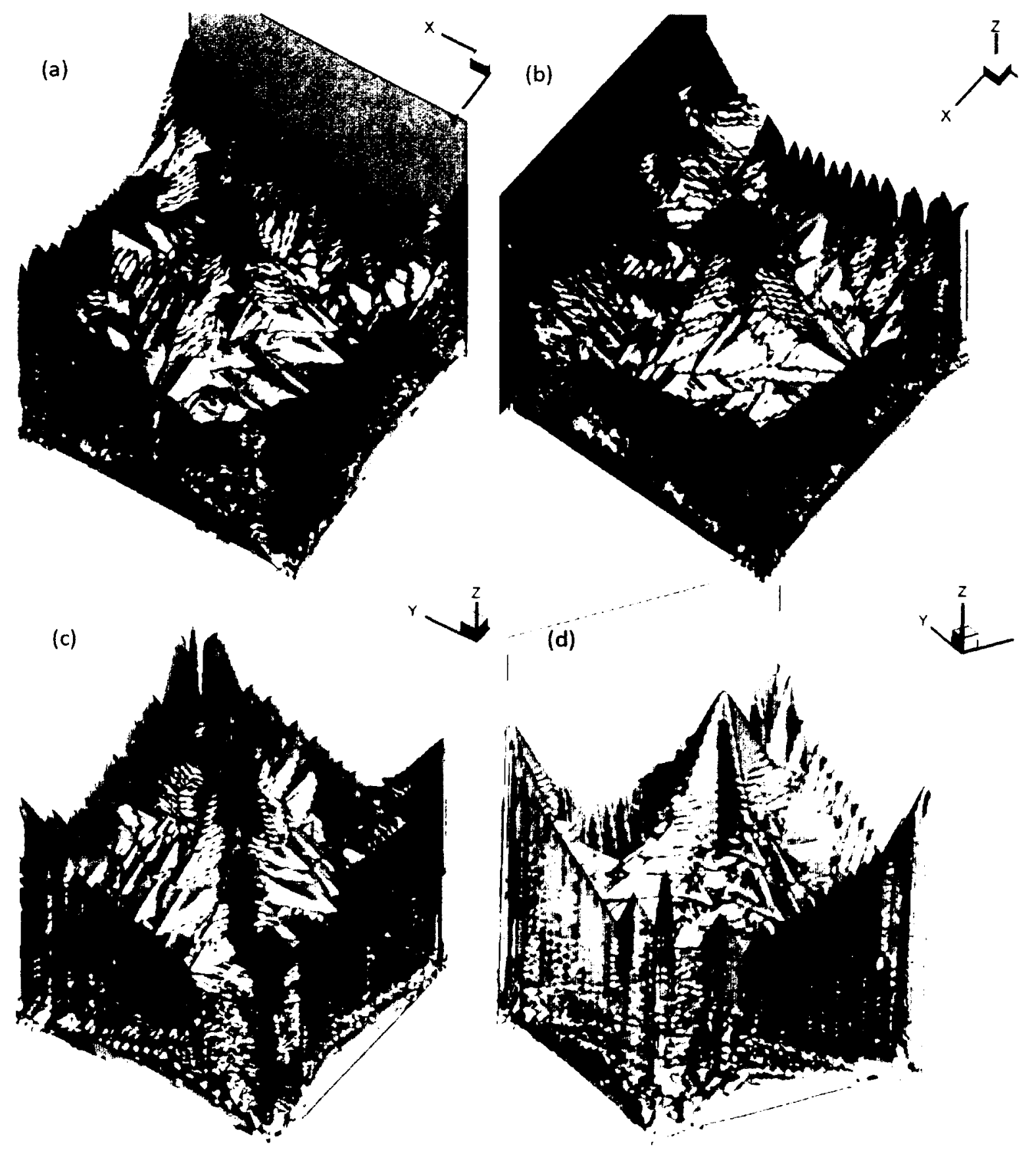

Figure 4.6: Microstructures of Sample_l $(G=1.6 \mathrm{~K} / \mathrm{mm})$ for cooling rates: (a) $10 \mathrm{~K} / \mathrm{s}$, (b) $100 \mathrm{~K} / \mathrm{s}$, (c) $500 \mathrm{~K} / \mathrm{s}$, (d) $1000 \mathrm{~K} / \mathrm{s}$. 


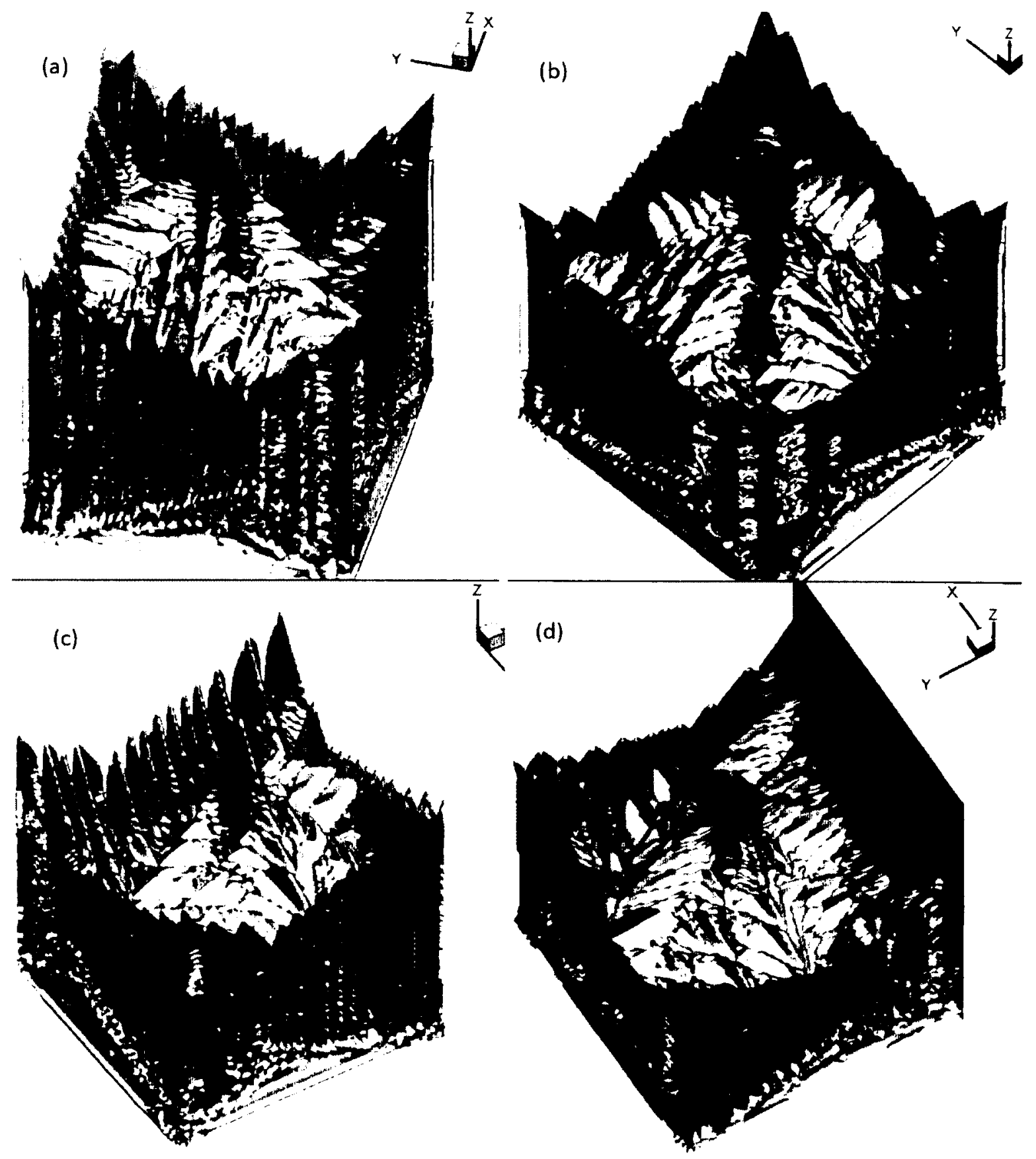

Figure 4.7: Microstructures of Sample_2 $(G=16 \mathrm{~K} / \mathrm{mm})$ for cooling rates: (a) $10 \mathrm{~K} / \mathrm{s}$, (b) $100 \mathrm{~K} / \mathrm{s}$, (c) $500 \mathrm{~K} / \mathrm{s}$, (d) $1000 \mathrm{~K} / \mathrm{s}$. 


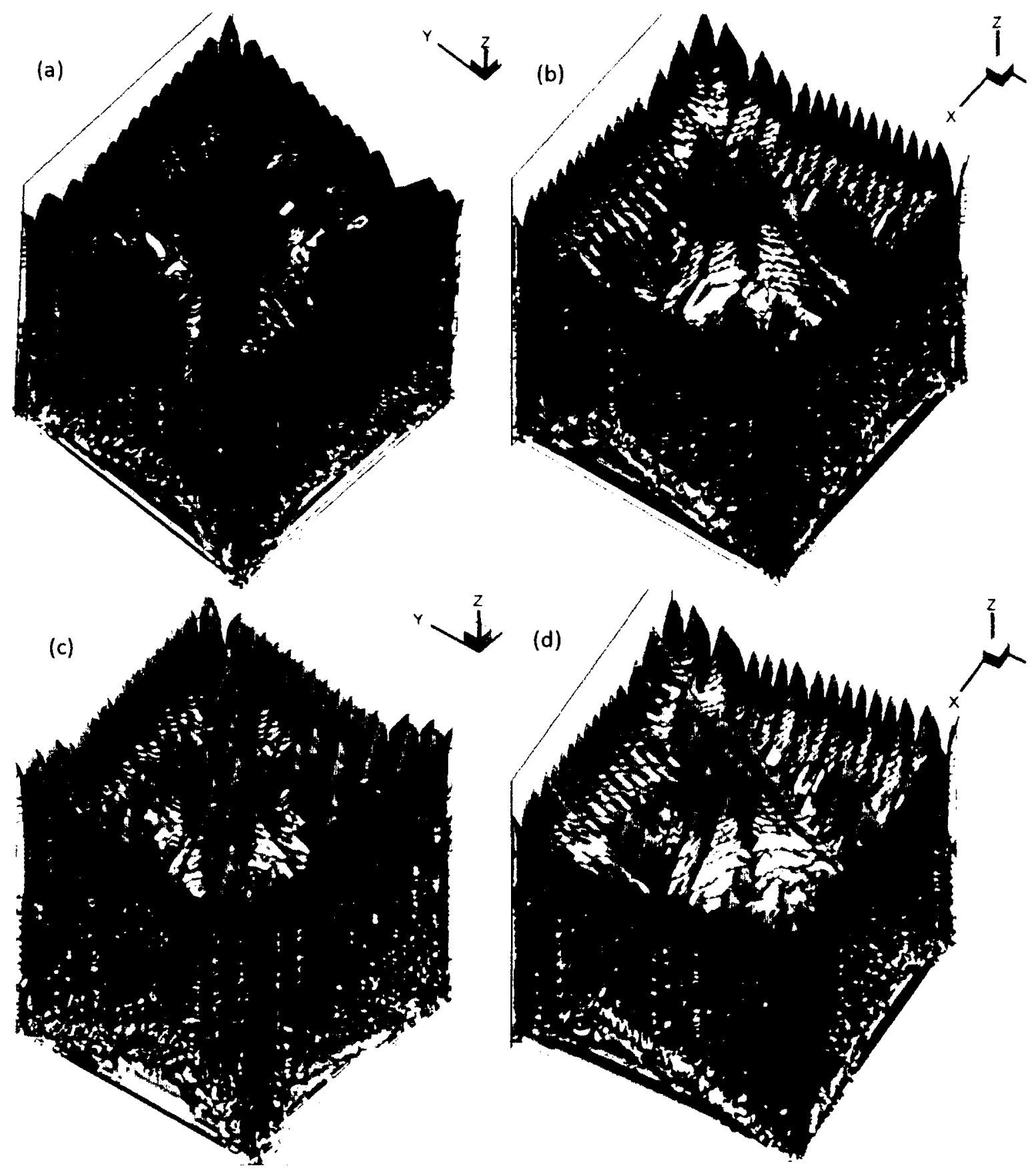

Figure 4.8: Microstructures of Sample_3 $(G=160 \mathrm{~K} / \mathrm{mm})$ for cooling rates: (a) $10 \mathrm{~K} / \mathrm{s}$, (b) $100 \mathrm{~K} / \mathrm{s}$, (c) $500 \mathrm{~K} / \mathrm{s}$, (d) $1000 \mathrm{~K} / \mathrm{s}$. 


\subsection{The Effect of Cooling Rate and Temperature Gradient on Microstructure Density}

The second study was performed to investigate the effect of cooling rate on the microstructure density. Microstructure density is determined as the number of dendrites in the control volume. Two simulation sets are used for the second study. The first set with the temperature gradient equal to $400 \mathrm{~K} / \mathrm{mm}$ has three subsets with different initial temperatures $\left(T_{U}=883 \mathrm{~K}, T_{L}=871 K\right),\left(T_{U}=893 \mathrm{~K}, T_{L}=881 \mathrm{~K}\right),\left(T_{U}=903 \mathrm{~K}, T_{L}=\right.$ $891 \mathrm{~K}$ ) and each subset has four test runs with different cooling rates $(\epsilon=1000,3000,6000,12000 \mathrm{~K} / \mathrm{s})$. Figure 4.9 shows the effect of cooling rate on the microstructure density obtained in the first set.

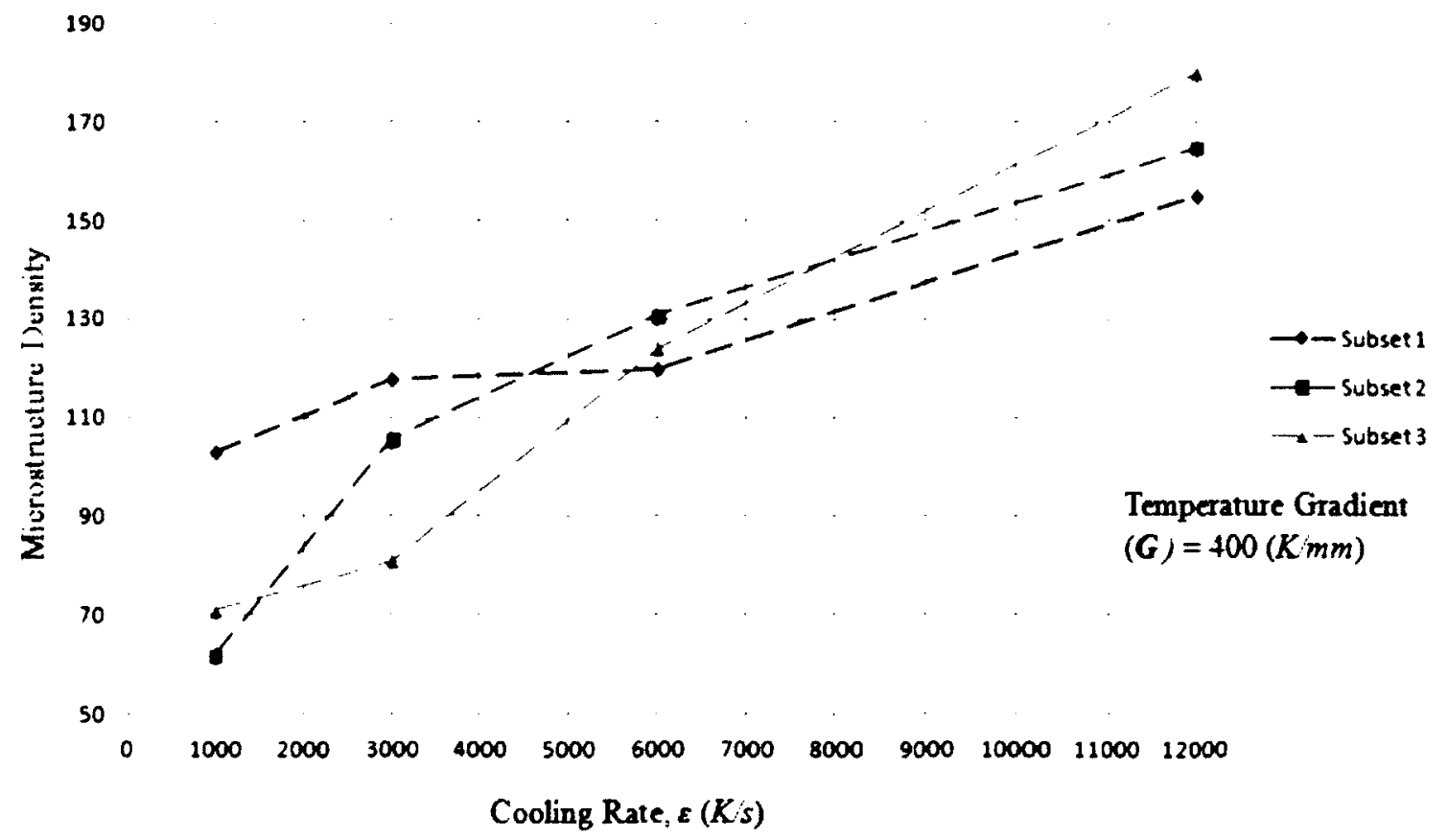

Figure 4.9: The effect of cooling rate on the microstructure for set number one. 
The results show that as the cooling rate increases the microstructure becomes more dense. For example, the resultant microstructures of subset 2 obtained using different cooling rates are shown in Figure 4.10. The microstructure produced at the lower cooling rate of $1000 \mathrm{~K} / \mathrm{s}$ case (Figure $4.10 \mathrm{a}$ ) has 62 dendritic grains. As the cooling rate increases, the structures become denser with smaller grains. The microstructures in Figure $4.10 \mathrm{~b}, \mathrm{c}$, and d obtained using higher cooling rates of 3000,6000 and $12000 \mathrm{~K} / \mathrm{s}$, respectively, have $106,131,165$ grains. 

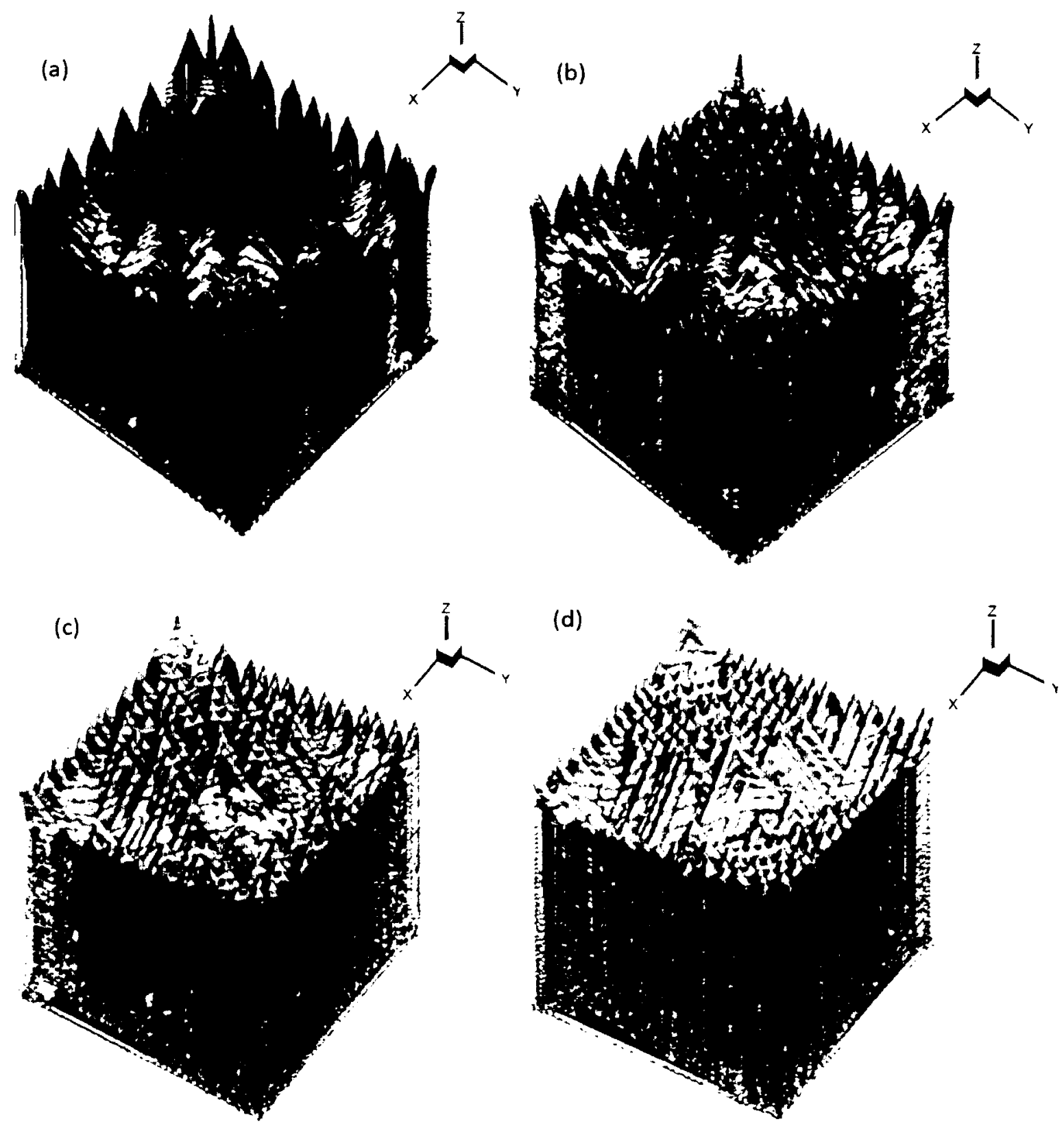

Figure 4.10: Microstructures of set l_run test2 for cooling rates: (a) $1000 \mathrm{~K} / \mathrm{s}$, (b) 3000 $\mathrm{K} / \mathrm{s}$, (c) $6000 \mathrm{~K} / \mathrm{s}$, (d) $12000 \mathrm{~K} / \mathrm{s}$.

The second set has four subsets with temperature gradient equal to $800 \mathrm{~K} / \mathrm{mm}$ in each of them and with various initial temperatures $\left(T_{U}=895 \mathrm{~K}, T_{L}=871 \mathrm{~K}\right),\left(T_{U}=905 \mathrm{~K}, T_{L}=\right.$ $881 \mathrm{~K}),\left(\mathrm{T}_{U}=915 \mathrm{~K}, \mathrm{~T}_{\mathrm{L}}=891 \mathrm{~K}\right)\left(\mathrm{T}_{\mathrm{U}}=925 \mathrm{~K}, \mathrm{~T}_{\mathrm{L}}=901 \mathrm{~K}\right)$. Each subset has four test 
runs with different cooling rates $(\epsilon=1000,3000,6000,12000 \mathrm{~K} / \mathrm{s})$. The effect of cooling rate on the microstructure density shows the same trend as the first set where increasing the cooling rate leads to increase in the microstructure density, see Figure 4.11 .

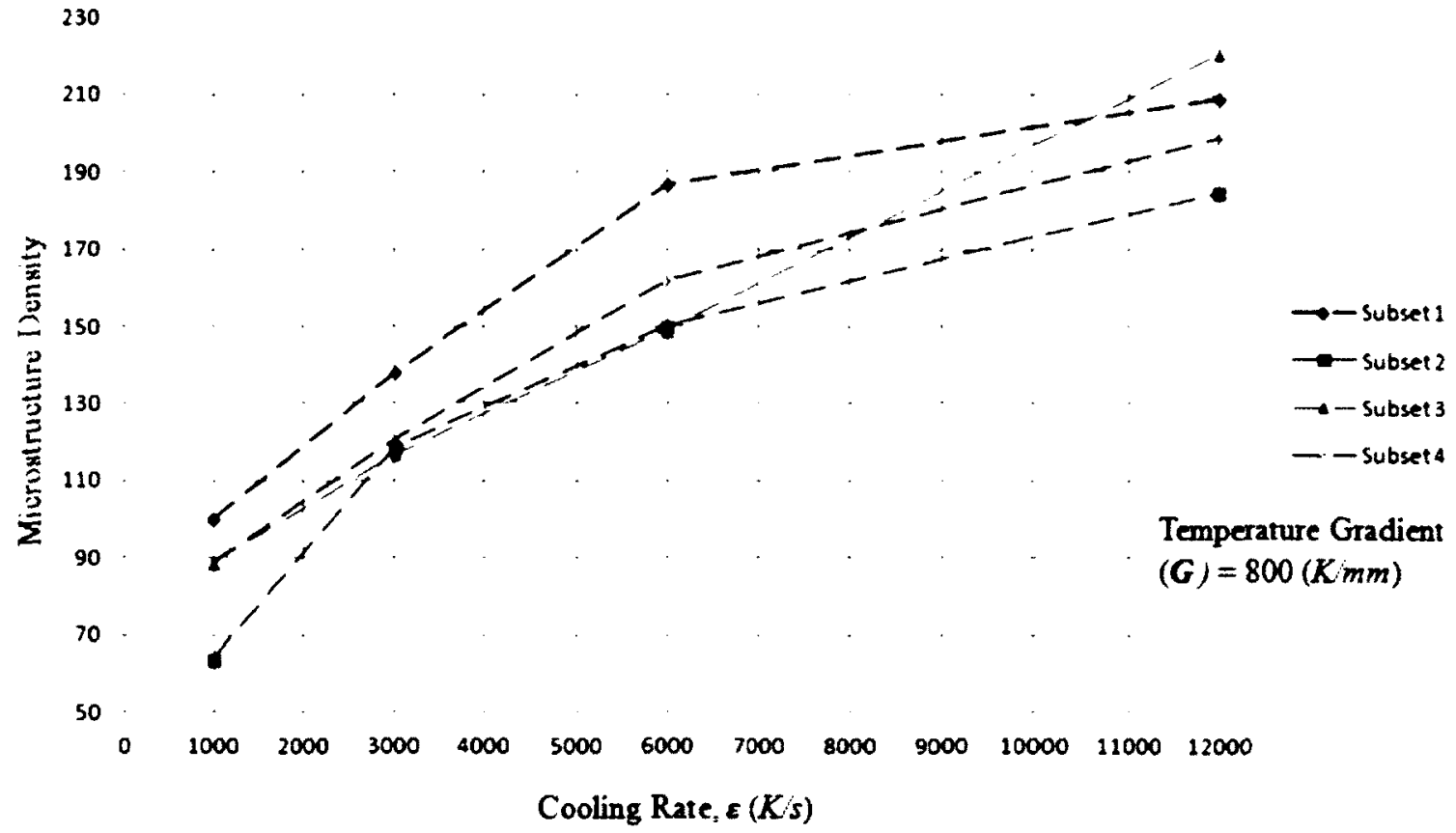

Figure 4.11: The effect of cooling rate on the microstructure for simulation set number two.

\subsection{The Effect of the Initial Solid/liquid Interface Roughness on the Microstructure}

The third study was conducted to investigate the effect of the initial solid/liquid interface roughness on the final microstructures. Three solid phase surfaces were used for this study: the first surface contains one nucleus whose volume is 22 cells in the middle of the control volume as shown in Figure 3.2. The second surface contains two thousand nuclei whose volumes vary between 10 and 22 cells as shown in Figure 4.12 . The third surface 
composes of two-thousand nuclei with sizes vary between 22 and 35 cells as shown in

Figure 4.13. In this case, the roughness of surface_3 is the highest.

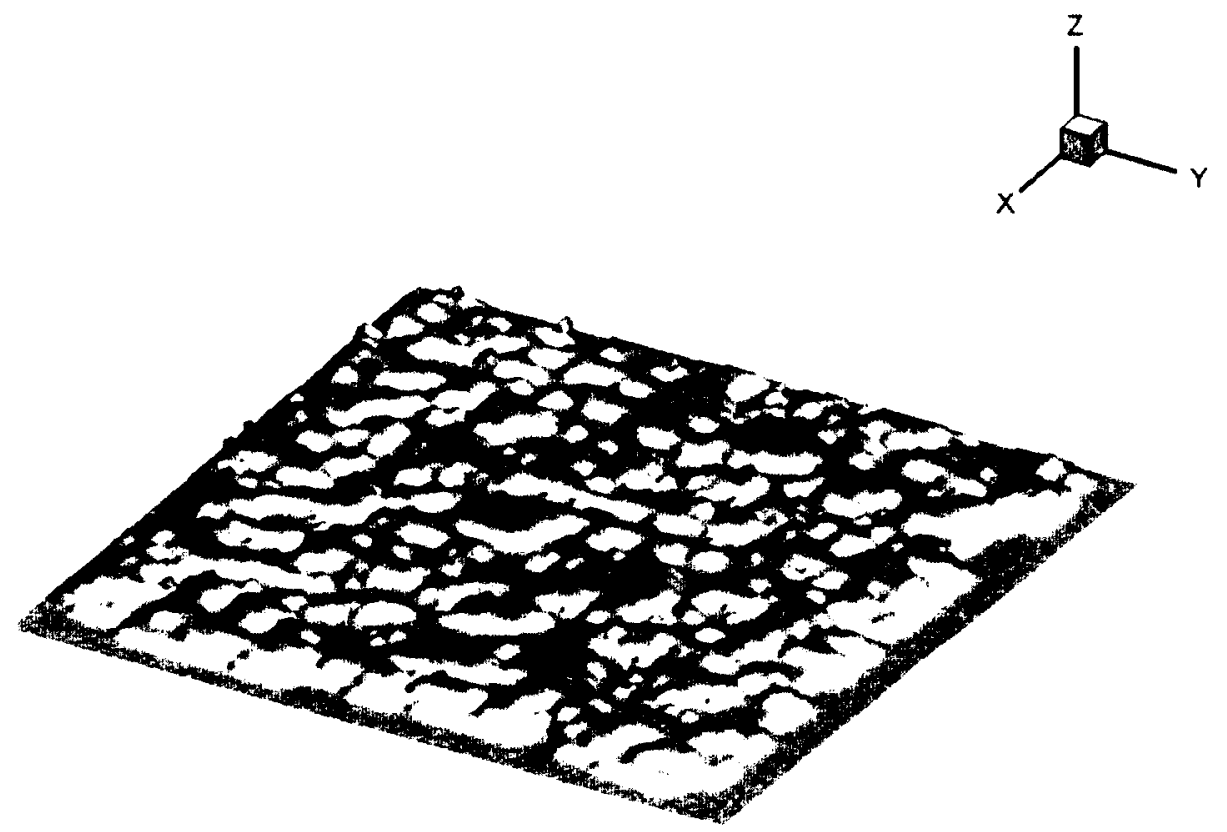

Figure 4.12: The initial solid/liquid interface corresponding to the second solid phase surface.

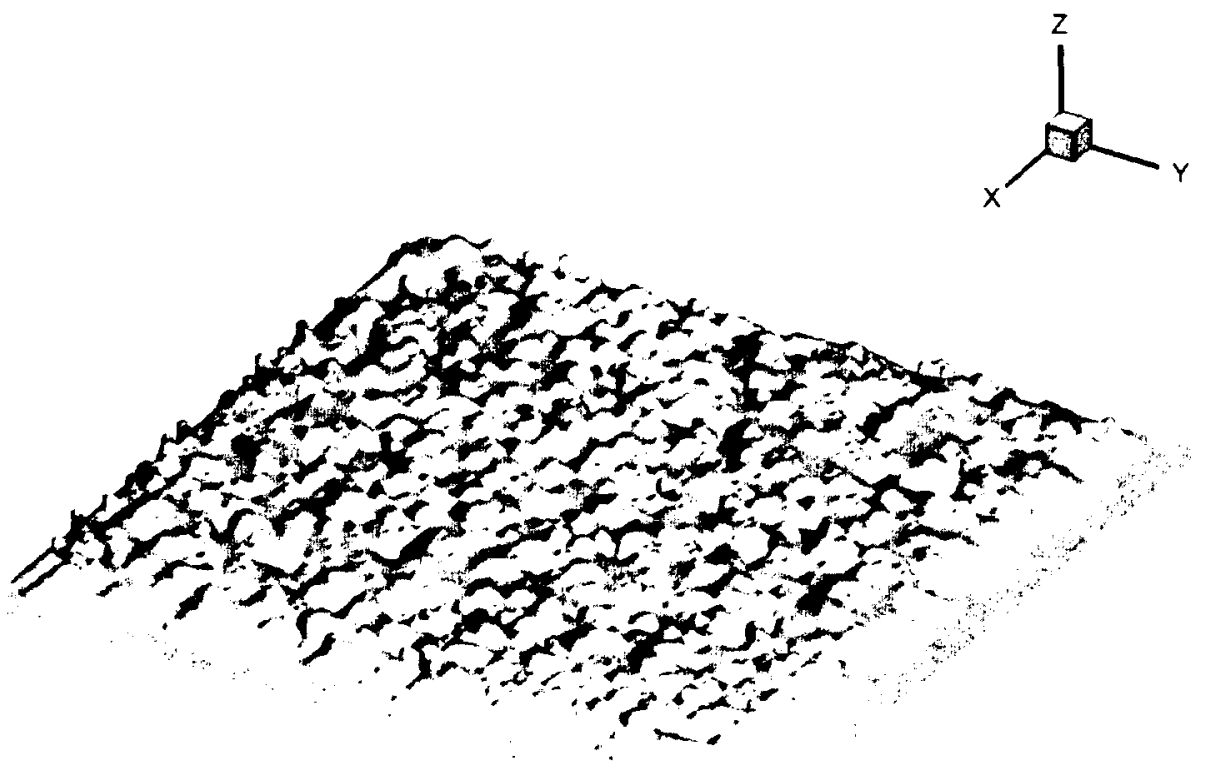

Figure 4.13: The initial solid/liquid interface corresponding to the third solid phase surface. 
The following parameters are used in the investigations for each surface:

- $\mathrm{T}_{\mathrm{U}}=875 \mathrm{~K}$.

- $\mathrm{T}_{\mathrm{L}}=863 \mathrm{~K}$

- $\mathrm{G}=80 \mathrm{~K} / \mathrm{mm}$.

- Cooling rates $(\epsilon): 10,100,500,1000 \mathrm{~K} / \mathrm{s}$.

The density of the resultant microstructures obtained under these conditions using three initial solid phase surfaces described above is shown in Figure 4.14. The microstructure's density obtained using surface_ 1 is lower than that produced with surfaces 2 and 3 for all cooling rates. As the initial solid surface roughness increases, the final microstructure becomes denser and surface_3 produces the highest microstructure density because it has the highest initial surface roughness.

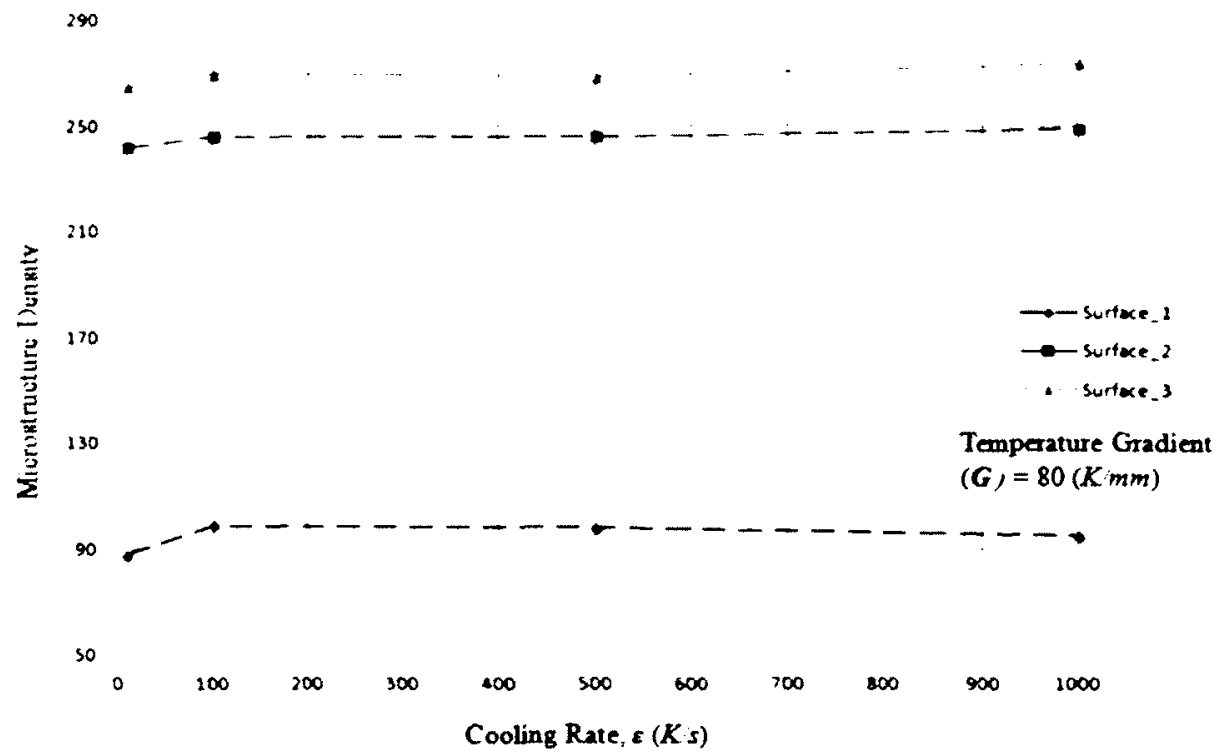

Figure 4.14: Microstructure density versus cooling rate for the three initial solid surfaces. 
The resultant microstructures obtained using first-, second-, and third solid phase surface shape in simulations with the cooling rate $1000 \mathrm{~K} / \mathrm{s}$ are shown in Figure $4.15,4.16$, and 4.17 respectively.

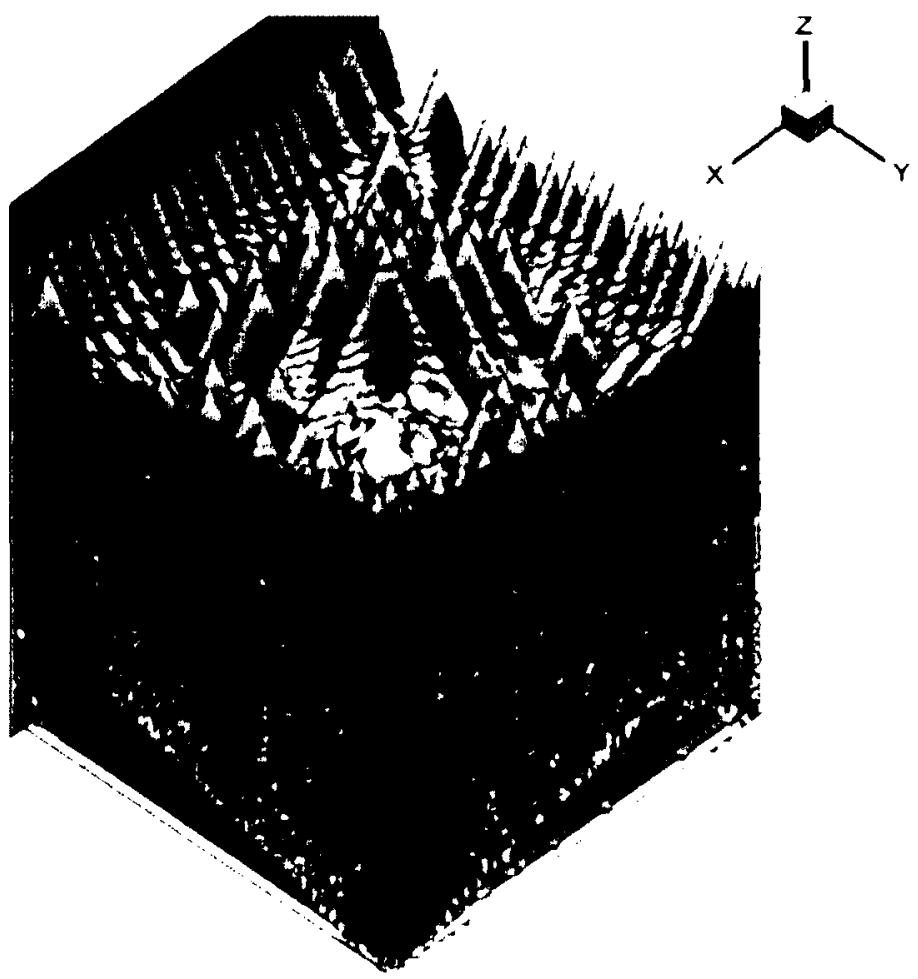

Figure 4.15: The resultant microstructure of surface one, (number of grains $=95$ ), cooling rate $=1000 \mathrm{~K} / \mathrm{s}$. 


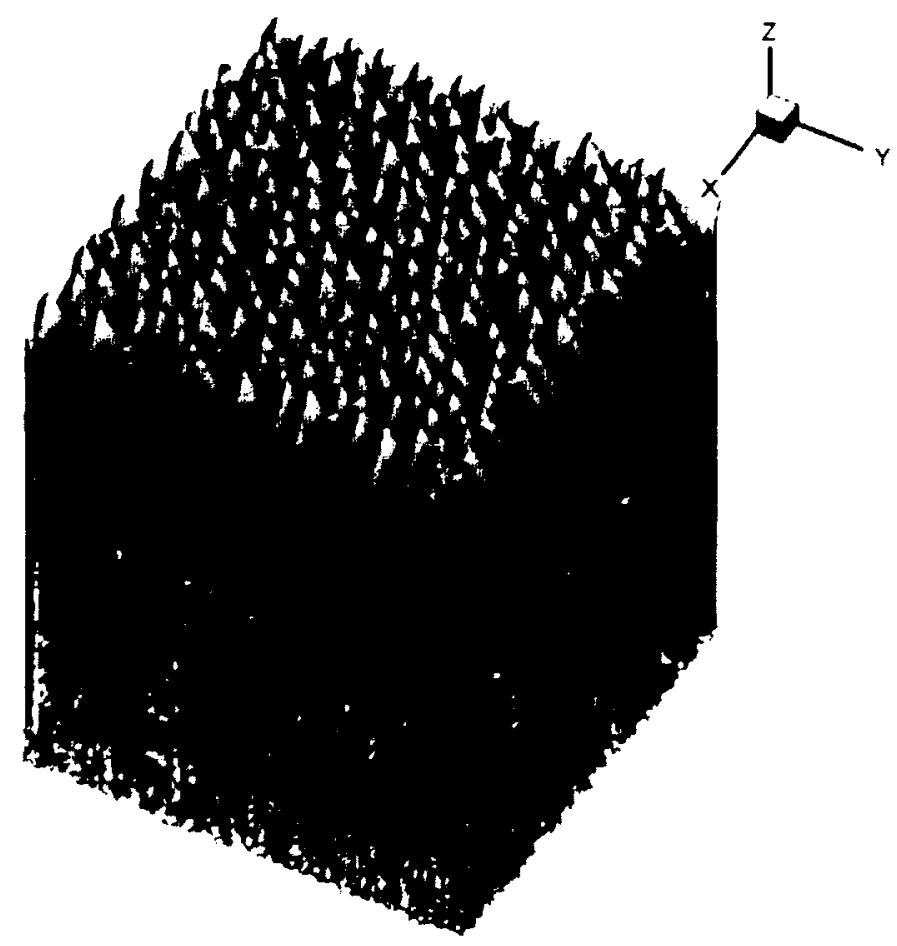

Figure 4.16: The resultant microstructure of surface two, (number of grains $=249$ ), cooling rate $=1000 \mathrm{~K} / \mathrm{s}$.

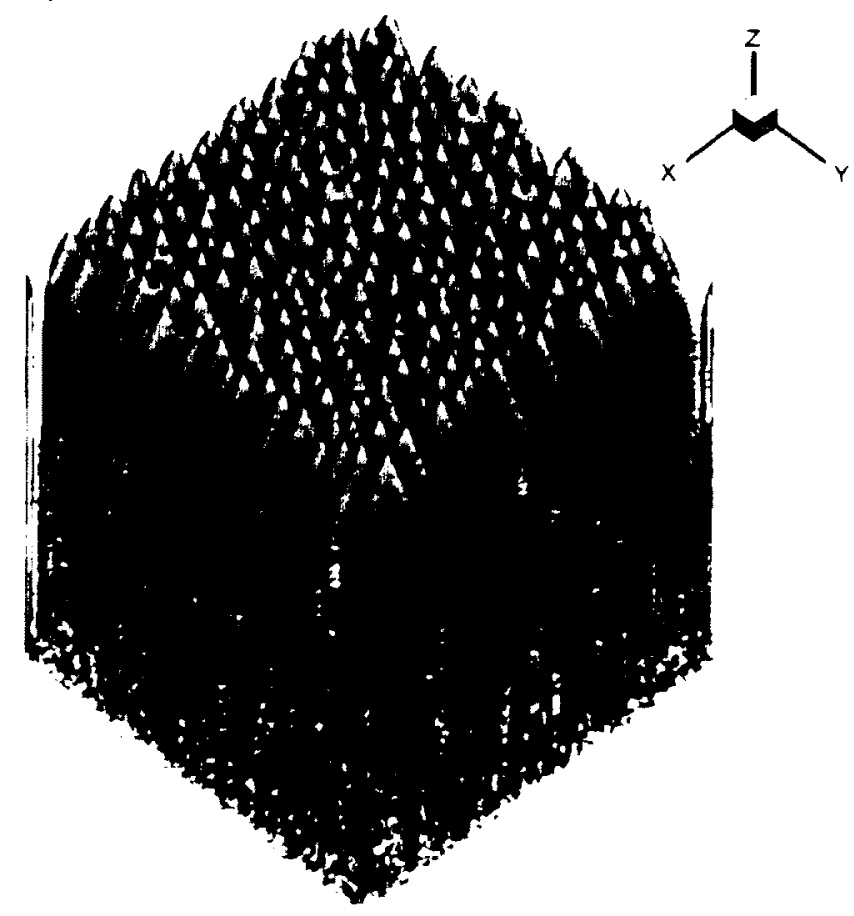

Figure 4.17: The resultant microstructure of surface three, (number of grains $=274$ ), cooling rate $=1000 \mathrm{~K} / \mathrm{s}$. 
Figure 4.15 shows the resultant microstructure of the first initial solid surface where one nucleus was imposed in the middle of control volume. In this case, the microstructure contains around 98 dendritic grains. On the other hand, the microstructure produced using rough initial solid surfaces (Figure 4.16 and 4.17 ) are columnar grains because many grains start to grow together at the beginning of solidification process. Therefore, each grain will grow at the expense of the branches of the adjacent grains.

Finally, an implicit solver was implemented by Goldaktec $(\mathcal{C}$ instead of explicit to solve the mass transfer equations. The implicit solver eliminates the needs to use small time step, which is determined by Fourier number, to solve the mass transport equations. As a result, the simulation time reduced significantly. Figure 4.18 shows results of three runs with the following parameters:

- Test_run $\mathrm{l}\left(\mathrm{T}_{\mathrm{U}}=880 \mathrm{~K}, \mathrm{~T}_{\mathrm{L}}=880 \mathrm{~K}, \mathrm{G}=0 \mathrm{~K} / \mathrm{mm}, \epsilon=0 \mathrm{~K} / \mathrm{s}\right)$.

- Test_run $2\left(\mathrm{~T}_{\mathrm{U}}=880.5 \mathrm{~K}, \mathrm{~T}_{\mathrm{L}}=880 \mathrm{~K}, \mathrm{G}=33 \mathrm{~K} / \mathrm{mm}, \epsilon=10 \mathrm{~K} / \mathrm{s}\right)$.

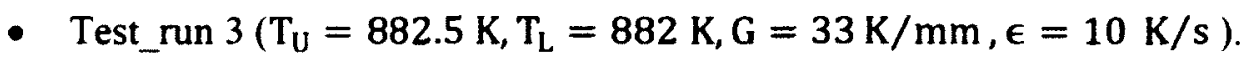

The simulation time of each run was equal to 200 minutes. This simulation time of implicit solver is 15 times faster than the explicit solver. 


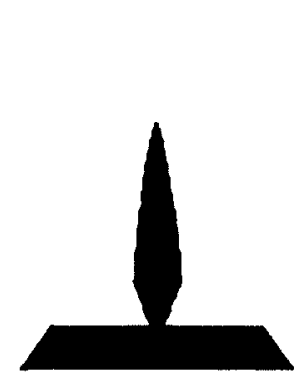

Test nun 1

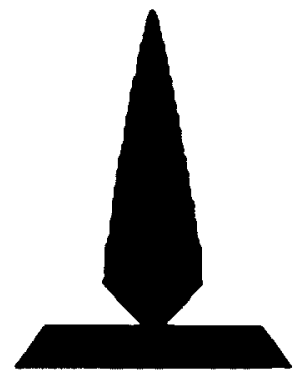

Test run 2

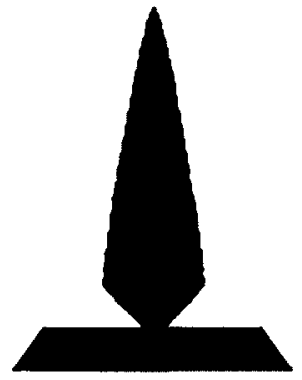

Test run 3

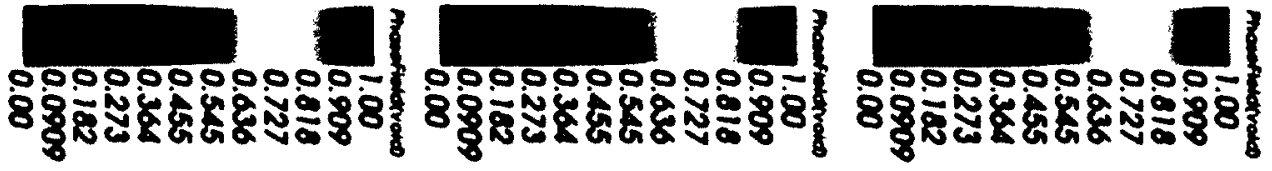

Figure 4.18: The resultant dendrite of using implicit solver. 


\section{Chapter 5}

\section{Conclusions}

The simulation results demonstrate that the dendritic structures are produced at low temperature gradients. Meanwhile, the microstructure starts to have a mixed dendritic and columnar structure as the cooling rate decreases and/or temperature gradient increases. At low value of cooling rate and high value of temperature gradient, the microstructures becomes fully columnar. Therefore, both cooling rate and temperature gradient have an effect on the microstructure morphology. Simulations also show that there is a transition region where the dendritic and columnar grains coexist. This simulation result is compatible with constitutional undercooling theory that is illustrated in Figure 2.15. It could be concluded that the model successfully predicts the changes in microstructure morphology in response to the cooling rate and temperature gradient.

Results demonstrate that in the simulations with the small values of cooling rate and temperature gradient (wherein temperature gradient was equal to 1.6 and $16 \mathrm{~K} / \mathrm{mm}$ and cooling rate was equal to $10,100,500$, and $1000 \mathrm{~K} / \mathrm{s}$ ) the microstructures composed of one dominant dendrite located in the middle of control volume was obtained. In case of small temperature gradient, the size of control volume is too small to show more than one dendrite grain, thus a larger control volume should be used to check the density of microstructure, which is computationally expensive. As the temperature gradient increases $(\mathrm{G}=160 \mathrm{~K} / \mathrm{mm})$, more dendrites appear and the microstructure becomes more dense. 
Our results demonstrate that when temperature gradient is sufficiently high the cooling rate produces strong effect on the density of the solidification structure. As cooling rate increases structure becomes more dense and also a transition from dendritic to columnar morphology happens. At small temperature gradient values the only one dendritic grain is produced in the simulation volume and no effect of cooling rate on the solidification density can be studied unless the size of computational volume is significantly increased.

The study of the effect of initial solid/liquid interface roughness on the microstructure at different cooling rates demonstrated that increase in the roughness of the initial solid/liquid interface leads to the increase in the density of microstructure. Furthermore, the microstructure of the rougher surfaces are composed of columnar grains rather then dendritic grains because of competitive growth. This result shows that it can be important to use the realistic model of melting process for the simulation of solidification patterns of welding before the simulation of solidification process is produced.

The obtained results show that it is possible to reproduce qualitatively correct relationship between solidification parameters and microstructure morphology by using cellular model. The model used in this thesis has some limitations due to restricted time step. So, if time step problem is resolved then more realistic simulations could be performed. This model can be used as a test bed to simulate real welding processes. The model was provided to Goldaktec $C$ in order to incorporate it within the VrSuite . By combining the model with finite element heat and mass flow analysis utilising the implicit method for the solution of heat flow and diffusion problems (CA-FE), real welding process for real welding structures can be simulated to predict the microstructures numerically. 


\section{List of References}

[1] M. Groover, Fundamentals of Modern Manufacturing: Materials, Processes, and Systems. Fourth ed. JOHN WILEY \& SONS, INC., pp. (696, 704), 2006.

[2] J. Larry, Welding Principles and Applications. Six ed. Delmar, Cengage Learning, pp. $(6,5,73) 2008$.

[3] E. Waike Moos, "Value added by Welding Technology," Welding and Cutting, Vol. 53, No. 9, pp. 190, 2001 .

[4] J. DuPont, "Fundamentals of Weld Solidification," Welding Fundamentals and Processes, ASM Handbook, Vol. 6A, pp. 96-113, 2001.

[5] S. David, S. Babu, and J. Vitek, "Welding: Solidification and Microstructure," JOM, Springer, Vol. 55, No. 6, pp. 14-20, 2003.

[6] R. Messler. Principle of Welding Processes Physics Chemistry and Metallurgy. WILEY-VCH, pp. (56, 132, 448, 443, 131, 173), 2004.

[7] S. Kou. Welding Metallurgy. Second ed. John Wiley \& Sons, Inc, pp. (165, 306, 171, 156, 159, 166, 172, 176, 200, 202), 2003.

[8] R. Davis, and N. Wheaton. Welding Brazing and Soldering Handbook, ASM International, Vol. 6. 1994.

[9] R. Blondeau. Metallurgy and Mechanics of Welding. John Wiley \& Sons, Inc., 2008.

[10] S. Kalpakjian, and S. Schmid. Manufacturing, Engineering and Technology. Six ed. Prentice Hall, 2005.

[11] R. Timings. Engineering Materials. Second ed. Vol. 1. Addison Wesley Longman Limited, pp. $(44,43), 1998$.

[12] J. Rutter, and B. Chalmer, Can. J. Physiol., Vol. 31, pp. 15, 1953.

[13] O. Grong. Metallurgical Modelling of Welding, 2nd ed., The Institute of Materials, pp. $273,1997$. 
[14] W. Savage, and R. Hrubec, Weld Journal., Vol. 51, pp. 260s, 1972.

[15] S. Kou, "Fluid Flow and Solidification in Welding: Three Decades of Fundamental Research at the University of Wisconsin," Welding Journal, Nov 2012.

[16] D. Raabe, F. Roters, F. Barlat, and L-Q. Chen. Continuum Scale Simulation of Engineering Materials: Fundamentals Microstructures Process Applications. First ed. WILEY-VCH, pp. 57, 2004.

[17] M. Rappaz, M. Bellet, and M. Deville. Numerical Modeling in Materials Science and Engineering. Springer, 1998.

[18] K. Janssens, D. Raabe, and E. Kozeschnik, Mark A. Miodownik, and Britta Nestler. Computational Materials Engineering: An Introduction to Microstnucture Evolution. First ed. Elsevier, 2007.

[19] N. Packard, "Theory and Applications of Cellular Automata," World Scientific, pp. $305,1986$.

[20] S. Brown, and N. Bruce, “A 3-Dimensional Celleular Automaton Model of 'FREE' Dendritic Growth," Scripta Metallurgica et Materialia, Elsevier. Vol. 32, No. 2, pp. 241 . $246,1995$.

[21] Ch-A. Gandin, and M. Rappaz, "A coupled Finite Element-Cellular Automaton Model for the Prediction of Dendritic Grain Structures in Solidification Processes," Acta metall, mater., Elsevier. Vol. 42, No. 7, pp. 2233-2246, 1994.

[22] J. Spittle, S. Brown, and T. Williams, "A Cellular Automation Model of the SteadyState "FREE" Growth of a non- Iosthermal Dendrite," Acta metal. Mater, Elsevier. Vol. 42, No. 8, pp. 2893-2898, 1994.

[23] A. Artemev and J. Goldak, "Cellular Simulation of the Dendrite Growth in Al-Si Alloys," Canadian Metallurgical Quarterly, Elsevier. Vol. 36, No. 1, pp. 57-64, 1997.

[24] R. Sasikumar, and E. Jacob, "Simulation of side Branch Evolution in Thermal Dendritic Grains," Scripta Materialia, Elsevier. Vol. 35, pp. 505-510, 1996.

[25] Y. Wei, X. Zhan, Z. Dong, and L. Yu, "Numerical Simulation of Columnar Dendritic Grain Growth during Weld Solidification Process," Technology of Welding, Vol. 12, pp. 46, 2007. 
[26] M. Martinez and A. Artemev, "Three Dimensional Computer Model of Dendrite Growth in Tertiary Al-Cu-Si Alloys," Master Thesis, Carleton University, 1999.

[27] T. Carozzani, H. Digonnet and Ch-A. Gandin, "3D CAFE modeling of grain structures: application to primary dendritic and secondary eutectic solidification," Modeling Simul. Mater. Sci, IOP Publishing, Vol. 20, 2012.

[28] Xianfei Zhang, Jiuzhou Zhao, Hongxiang Jiang, and Mingfang Zhu, "A threedimensional cellular automaton model for dendritic growth in multi-component alloys," Acta Materialia, Elsevier. Vol. 60, pp. 2249-2257, 2012.

[29] Shi Yu-feng, Xu Qing-yan, and Liu Bai-cheng, "Simulation and experimental validation of three-dimensional dendrite growth," Nonferrous Met., Vol. 22, pp. 2756$2761,2012$.

[30] S. Michelic, J. Thuswaldner, and C. Bernhard, "A modified cellular automaton method for poly dimensional modeling of dendritic growth and microsegregation in multicomponent alloys," Materials Science and Engineering, IOP Publishing, Vol. 33, 2012.

[31] Sen Luo, and Miao Yong Zhu, "A two-dimensional model for the quantitative simulation of the dendritic growth with cellular automaton method," Computational Materials Science, Elsevier. Vol. 71, pp. 10-18, 2012.

[32] M. F. Zhu, S. Y. Lee, and C. P. Hong, "Modified cellular automaton model for the prediction of dendrite growth with melt convection," Physical Review, Vol. 69, 2004.

[33] X. Zhan, Z. Dong, Y. Wei, and R. Ma, "Simulation of Grain Morphologies and Competitive Growth in Weld Pool of Ni-Cr Alloy," Journal of Crystal Growth, Vol. 311 , Elsevier, pp. 4778-4783, 2009.

[34] V. Pavlyk, "Modelling and Direct Numerical Simulation of Dendritic Structures under Solidification Conditions during Fusion Welding," Shaker Verlag GmbH, Germany, 2004.

[35] W. Kurz, and D. Fisher. Fundamentals of Solidification. Third ed. CRC Press, 1992. $11-22$.

[36] M. Glicksman. Principles of Solidification: An Introduction to Modern Casting and Crystal Growth Concepts. Springer, pp. 314, 2010. 
[37] A. Wheeler, N. Ahmad, W. Boettinger, R. Braun, G. McFadden, and B. Murray, "Recent Developments in Phase-Field Models of Solidification," Adv. Space Res, COSPAR, Vol. 16, No. 7, pp. 163-172, 1995.

[38] Zhang Lin, and Zhang Cai-bei, "Two-dimensional cellular automaton model for simulating structural evolution of binary alloys during solidification," Nonferrous Met., Vol. 16, pp. 1410-1416, 2006.

[39] Ch-A. Gandin, "Modeling of solidification: Grain structures and segregations in metallic Alloys," Comptes Rendus Physique, Elsevier. Vol. 11, pp. 216-225, 2010.

[40] D. Stefanescu. Science and Engineering of Casting Solidification. Second ed. Springer, 2009.

[41] D. Porter, K. Easterling. Phase Transformations in Metals and Alloys. Second ed. Chapman \& Hall, 1992. 